Universidade de São Paulo

Escola Superior de Agricultura "Luiz de Queiroz"

Avaliação de métodos para a quantificação de biomassa e carbono em florestas nativas e restauradas da Mata Atlântica

\title{
Eduardo Gusson
}

Tese apresentada para obtenção do título de Doutor em Recursos Florestais. Área de concentração: Conservação de Ecossistemas Florestais 
Eduardo Gusson

Engenheiro Florestal

\section{Avaliação de métodos para a quantificação de biomassa e carbono em florestas nativas e} restauradas da Mata Atlântica

versão revisada de acordo com a resolução CoPGr 6018 de 2011

Orientador:

Prof. Dr. PAULO YOSHIO KAGEYAMA

Tese apresentada para obtenção do título de Doutor em Recursos Florestais. Área de concentração: Conservação de Ecossistemas Florestais

\section{Piracicaba}




\section{Dados Internacionais de Catalogação na Publicação DIVISÃO DE BIBLIOTECA - DIBD/ESALQ/USP}

Gusson, Eduardo

Avaliação de métodos para a quantificação de biomassa e carbono em florestas nativas e restauradas da Mata Atlântica / Eduardo Gusson.- - versão revisada de acordo com a resolução CoPGr 6018 de 2011. - - Piracicaba, 2014.

112 p: il.

Tese (Doutorado) - - Escola Superior de Agricultura "Luiz de Queiroz", 2014.

1. Amostragem dupla 2. Índice de Vegetação por Diferença Normalizada - NDVI 3. Modelos preditivos 4 . Viés de predição I. Título

CDD 634.90981

G982a

"Permitida a cópia total ou parcial deste documento, desde que citada a fonte -O autor" 


\section{AGRADECIMENTOS}

Ao Professor Paulo Yoshio Kageyama, meu mestre das florestas, pelos ensinamentos, apoio e credibilidade.

Ao pesquisador Edgar de Souza Vismara, pelas discussões e expressivas contribuições para a concretização dos capítulos desta tese.

Aos Professores Carlos Roberto Sanquetta, Edson Vidal e Flávio Gandara, membros da banca examinadora desta tese, os quais trouxeram ótimas contribuições ao trabalho.

Aos meus filhos Lucas, Júlia e Lorena, pelos incentivos em minha continua busca por meu fortalecimento pessoal.

A minha esposa Fabiana, pelo amor, amizade e apoio ao longo destes últimos anos.

Aos meus pais, Aldo e Marlene, por me educarem na escola da vida. A meu irmão Marcelo, pela longa convivência e presença nos momentos necessários.

Aos amigos Paulo Guilherme Molin e Frederico Miranda, pela ajuda nos assuntos relacionados ao sensoriamento remoto.

A toda equipe de estagiárias do projeto carbono AES, as mais recentes, Susane Rasera, Carla Chiles, Renata Melo, Renata Gatti, Luiza Nougalli e Rebeca Lima, e aos profissionais colaboradores que atuaram no mesmo, Thiago Roncon e Daniela Pereira, pelo apoio na coleta e sistematização de dados.

Aos amigos, Girlei Costa da Cunha, Lauro Rodrigues, Jaime Sotomayor, Ana Paula Ferez, com os quais tive a oportunidade de discutir assuntos relacionados ao tema desta tese.

Aos amigos pesquisadores do laboratório, João Dagoberto e Renata Evangelista, pelo aprendizado conjunto em trabalhos relacionados à restauração florestal pelo PTECA.

A equipe de apoio do LARGEA, Andréia Moreno, Elza Martins e Talita Leme, pela colaboração logística.

A equipe de profissionais da AES Tietê, Paola Bocardo, Fabiana Menezes, Sônia Hermsdorff, Emerson Viveiros, Odemberg Veronez, José Luiz Simionato, Donizeti Barbosa, Sílvio Santos, pelo apoio nas atividades de pesquisa relacionadas ao projeto.

Aos professores João Batista e José Luiz Stape, do Departamento de Ciências Florestais da ESALQ, pelas contribuições ao projeto da AES Tietê e orientações sobre o monitoramento de carbono em florestas nativas.

A empresa AES Tietê e a Fundação de Estudos Agrários "Luiz de Queiroz", pela bolsatrabalho concedida ao longo desses anos de projeto.

Ao Departamento Aeroviário do Estado de São Paulo, pelo apoio logístico nas atividades de pesquisa realizadas no aeroporto de Registro-SP. 


\section{SUMÁRIO}

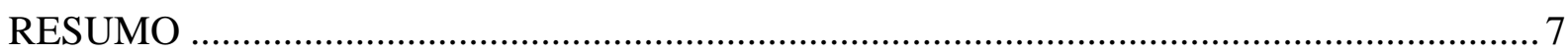

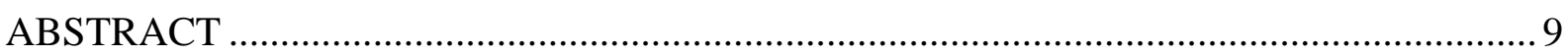

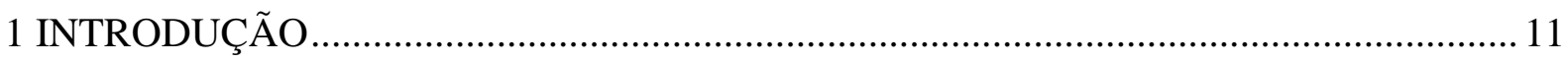

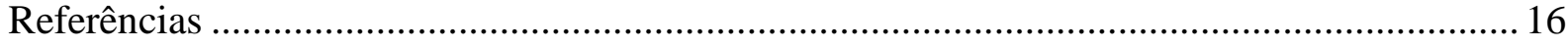

2 APLICAÇÃO DO ÍNDICE DE VEGETAÇÃO NDVI EM PROCESSOS DE AMOSTRAGEM PARA A QUANTIFICAÇÃO DE ESTOQUES DE BIOMASSSA E CARBONO DE FLORESTAS NATIVAS RESTAURADAS ........................................... 19

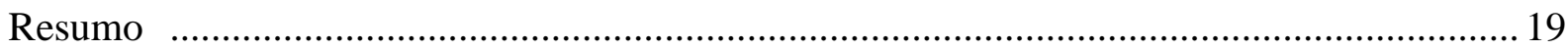

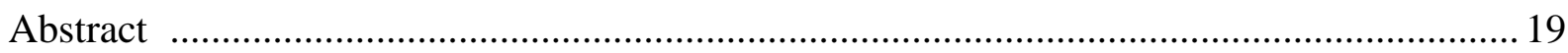

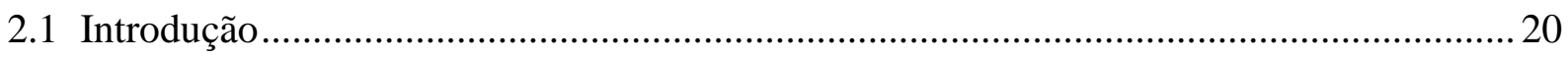

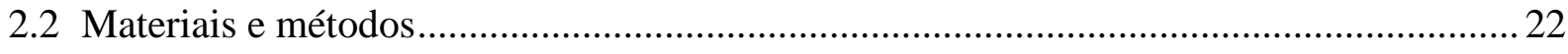

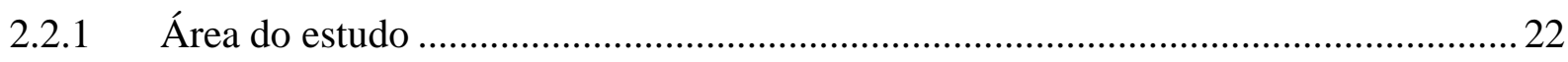

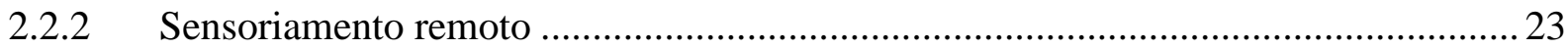

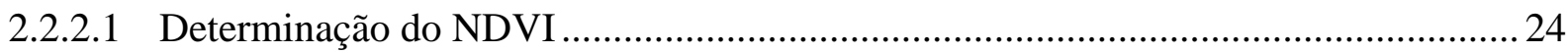

2.2.2.2 Aplicação do NDVI em nível de parcela ................................................................ 24

2.2.2.3 Aplicação do NDVI para a estratificação da área elegível do projeto ....................... 25

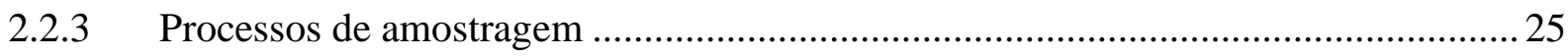

2.2.4 Inventário florestal: procedimentos de campo ........................................................ 27

2.2.5 Determinação do estoque de biomassa e carbono....................................................28

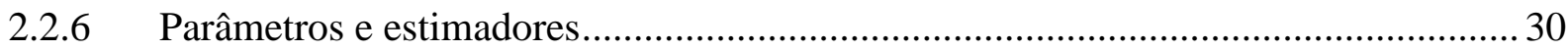

2.2.6.1 Estimador ordinário para amostragem aleatória simples e estratificada.................... 31

2.2.6.2 Estimador de regressão para a amostragem aleatória simples .................................. 33

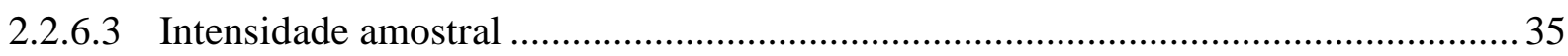

2.2.6.4 Qualidade do ajuste do modelo de regressão ......................................................... 35

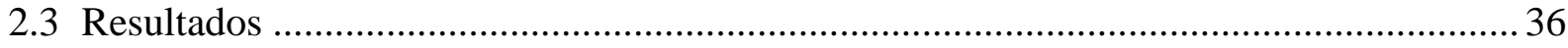

2.3.1 Análise de correlação do modelo: biomassa vs. NDVI …........................................ 37

2.3.2 Estimativas de biomassa pelos diferentes processos de amostragem ....................... 39

2.3.2.1 Processo de amostragem utilizando o estimador ordinário .......................................39

2.3.2.2 Processo de amostram utilizando o estimador de regressão .................................... 43

2.3.3 Estimativas de carbono equivalente para o projeto .............................................. 45

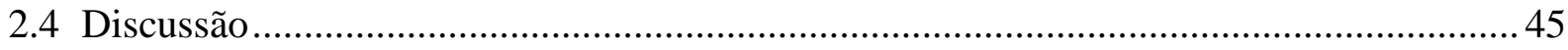

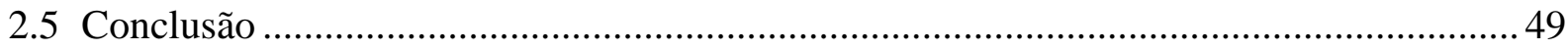


Referências

3 FATORES ASSOCIADOS ÀS INCERTEZAS NAS ESTIMATIVAS DE ESTOQUE DE BIOMASSA EM FLORESTA NATIVA DA MATA ATLÂNTICA ............53

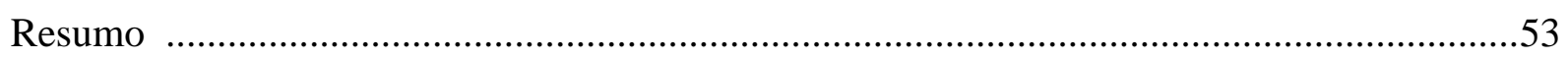

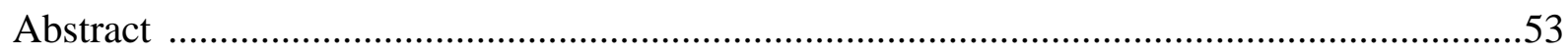

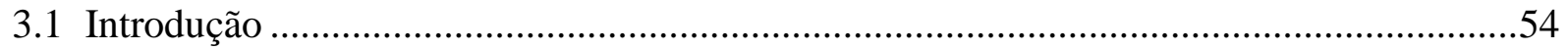

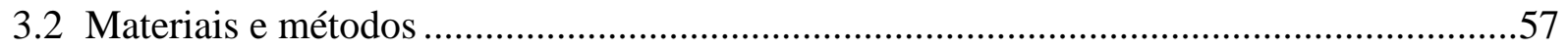

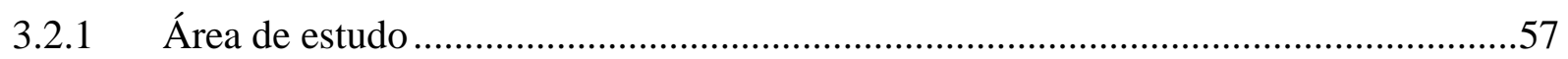

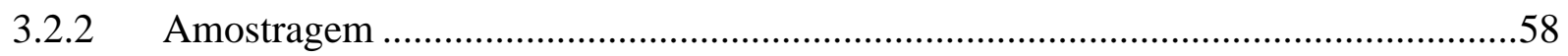

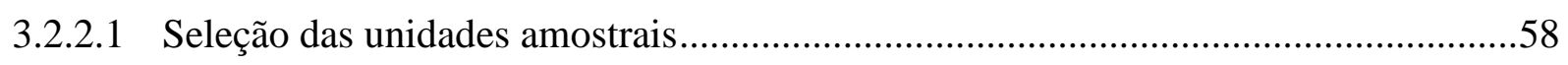

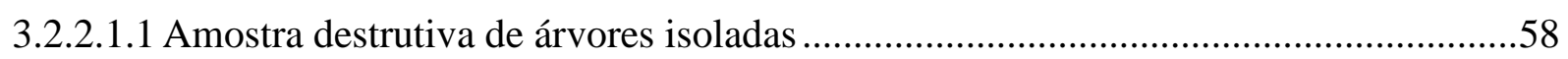

3.2.2.1.2 Amostra destrutiva em parcelas ...........................................................................60

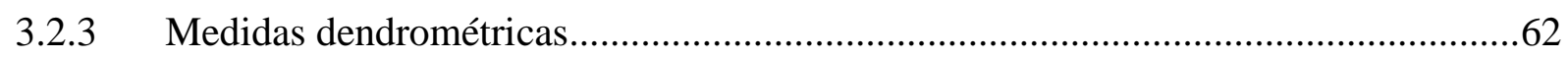

3.2.4 Resistência à penetração da madeira ........................................................................62

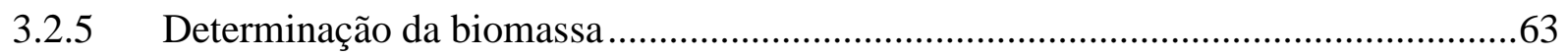

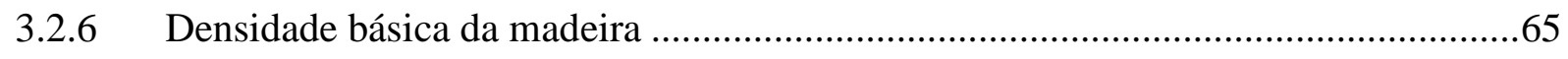

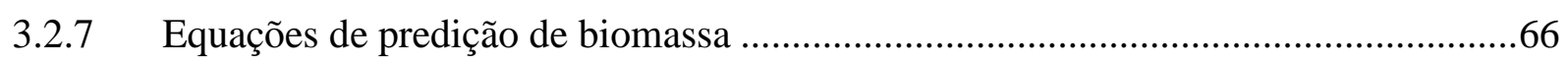

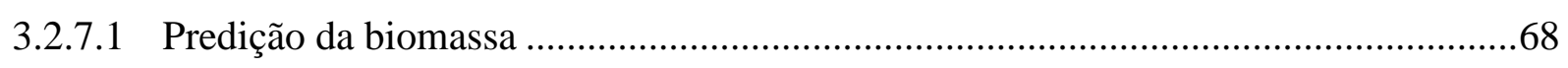

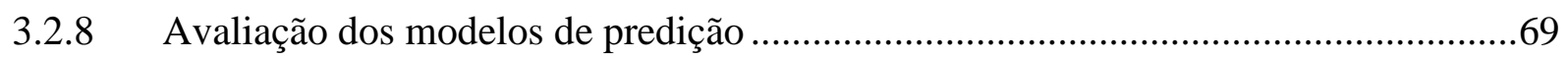

3.2.8.1 Qualidade de ajuste e aplicação dos modelos ............................................................69

3.2.8.2 Incertezas associadas ao uso de diferentes equações de predição..............................70

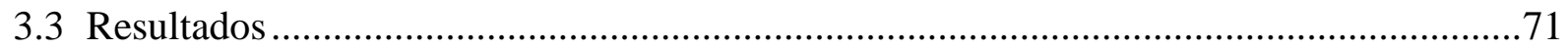

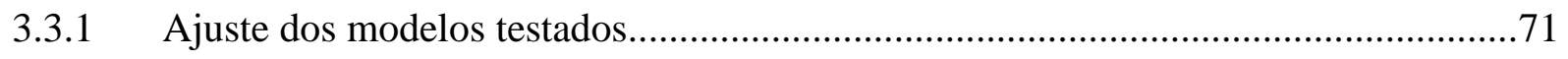

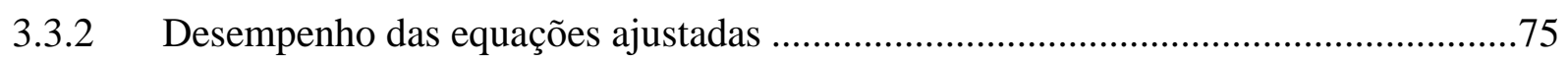

3.3.3 Desempenho das equações de predição disponíveis em literatura .............................80

3.3.4 Influência da fonte de informação de densidade da madeira na predição da

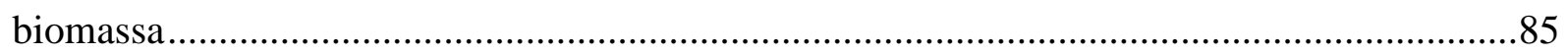

3.3.5 Estimativas de biomassa da floresta pelo uso das diferentes equações de

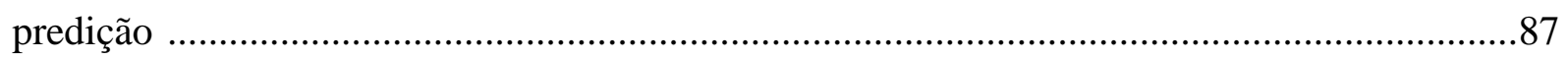

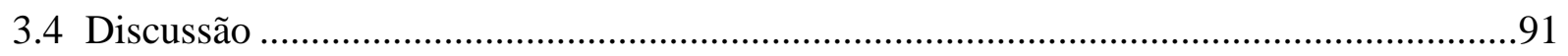

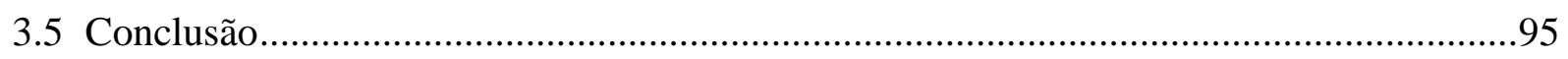

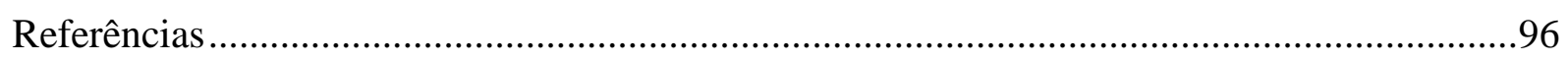

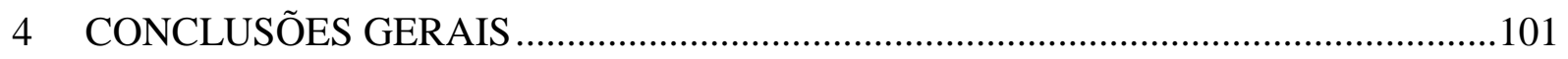

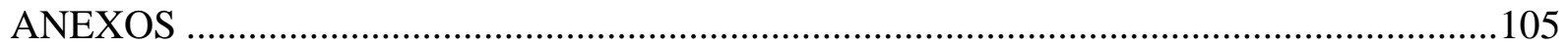




\section{RESUMO}

\section{Avaliação de métodos para a quantificação de biomassa e carbono em florestas nativas e restauradas da Mata Atlântica}

A quantificação de biomassa e carbono em florestas requer a aplicação de métodos adequados para se obter estimativas confiáveis de seus estoques. Neste sentido, o objetivo deste trabalho foi avaliar a aplicação de alguns métodos utilizados para a predição e estimação dessas variáveis em florestas nativas e restauradas da Mata Atlântica. Para isso, um primeiro capítulo aborda o uso do índice de vegetação NDVI como ferramenta auxiliar no inventário de estoques de biomassa em áreas de restauração florestal. Diferentes métodos de amostragem foram comparados em termos de precisão e conservadorismo das estimativas. Os resultados demonstraram que o NDVI apresentou adequada correlação com a biomassa estimada nas parcelas do inventário florestal instaladas em campo, sendo viável sua aplicação, seja para auxiliar na determinação de estratos, na aplicação da amostragem estratificada, seja como variável suplementar na utilização de um estimador de regressão relacionando-o à biomassa, no procedimento da amostragem dupla. Este último método, possibilitou minimizar as incertezas acerca das estimativas, valendo-se de uma intensidade amostral reduzida, fato que torna seu uso interessante, principalmente aos estudos em escala ampla, de modo a aumentar a confiabilidade das quantificações de estoques de carbono presentes na biomassa florestal, a custos de inventário reduzido. Um segundo capítulo discute a abordagem metodológica utilizada para inferir sobre a qualidade de modelos preditivos quando da seleção de modelos concorrentes para a aplicação em estudos de biomassa de florestas nativas. Para tanto, seis modelos considerando diferentes combinações de variáveis preditoras, incluindo diâmetro, altura total e alguma informação relativa à densidade da madeira, foram construídos a partir de dados de uma amostra de 80 árvores. As equações de predição de biomassa seca geradas por estes modelos foram avaliadas quanto à sua qualidade de ajuste e desempenho de

aplicação. Neste segundo caso, aplicando-as aos dados de outra amostra composta por 146 árvores presentes em nove parcelas destrutivas instaladas em diferentes estágios sucessionais da floresta, de modo a possibilitar a avaliação dos vieses preditivos. No intuito de se verificar as discrepâncias nas estimativas de biomassa devido à aplicação das diferentes equações de predição de biomassa, as equações desenvolvidas, junto a outras disponíveis na literatura, foram aplicados aos dados de um inventário florestal realizado na área estudada. O estudo confirma a natureza empírica destas equações, atentando para a necessidade de prévia avaliação de seu desempenho de predição antes de sua aplicação, em especial, das ajustadas com amostras de outras florestas, expondo alguns dos principais fatores associados às causas de incertezas nas quantificações dos estoques de biomassa nos estudos realizado em florestas nativas.

Palavras-chave: Amostragem dupla; Índice de Vegetação por Diferença Normalizada NDVI; Modelos de predição; Viés de predição; Sequestro de carbono 


\begin{abstract}
Evaluation methods for quantifying biomass and carbon in native and restored Atlantic Forests
\end{abstract}

The biomass and carbon quantification requires the application of appropriate methods to obtain reliable estimates of their stocks in natural and planted forests. The aim of this study was to evaluate different applicable methods to estimate biomass in both, natural and restored Atlantic Forests. The first chapter discusses the use of the vegetation index (NDVI) as an auxiliary tool in the inventory of biomass stocks in forest restoration areas. Different sampling methods were compared in terms of its accuracy and conservativeness. The results shown an adequate correlation between the vegetation index and the measured biomass, making the NDVI applicable either as supporting decision tool to define strata in the stratified sampling or as a predictor in the double sampling procedure. The last method allowed to the minimization of the uncertainties related to the biomass estimation combined to the reduction of sampling efforts. It makes the approach very interesting, especially in the context of large-scale surveys. The second chapter discusses the methodological approach used to evaluate the quality of predictive models applied to biomass studies in natural forests. For this, six models were fitted from 80 sample trees, using different combinations of predictor variables, such as, total height and information of wood density. The predictive equations generated by the models were evaluated according to their quality of fit and prediction performance. In order to evaluate its prediction performance, the equations were applied to the dataset of another 146 sample trees measured in nine destructive sample plots. The plots were located in different forest successional stages allowing the evaluation of model predictive bias among the stages. A third step of the analysis was the application of literature equations to a dataset of a forest inventory conducted in the study area, in order to verify the discrepancies in the estimates due to the use of these different models. The study confirms the empirical nature of the biomass equations and the need of previous evaluation in terms of prediction performance. This conclusion is even more relevant when we consider the equations that were obtained from other forests types, exposing some of the key factors associated to the causes of uncertainty in the biomass estimation applied to natural forests.

Keywords: Double sampling; Normalized Difference Vegetation Index - NDVI; Prediction models; Bias prediction; Carbon sequestration 


\section{INTRODUÇÃO}

A redução dos ecossistemas naturais, resultado de um histórico processo de devastação imposto pelas atividades humanas, tem causado perdas inestimáveis desses repositórios de diversidade biológica, culminando em eminentes transformações no equilíbrio terrestre. No intuito de organizar ações globais para o enfrentamento dos problemas ambientais, surge na Conferência das Nações Unidas sobre o Meio Ambiente e Desenvolvimento, a Rio-92, algumas convenções estabelecendo normas e princípios a serem adotados por seus países signatários. Neste sentido, as convenções do clima, de diversidade biológica e de desertificação merecem destaque devido à complementaridade dos temas tratados, sendo inerente a todas estas convenções a necessidade de se reconhecer a magnitude dos impactos das ações antrópicas. Assim, ao longo das últimas décadas, muitas pesquisas foram desenvolvidas buscando, por um lado, um melhor conhecimento das causas e efeitos dessas ações sobre o meio ambiente e, ao mesmo tempo, apontando estratégias para o enfrentamento dessas questões através de uma abordagem multidisciplinar.

Neste sentido, o Painel Intergovernamental de Mudanças Climáticas (Intergovernamental Panel on Climate Change - IPPC), tem se dedicado a compilar informações científicas sobre o assunto. Já a Convenção-Quadro das Nações Unidas sobre Mudanças Climáticas - CQNUMC (United Nations Framework Convention on Climate Change - UNFCCC) formada pelos países signatários desta convenção, em reuniões internacionais realizadas desde 1995, as Conferências das Partes (COP), tem discutido, entre outros temas, as propostas de ações para a mitigação dos efeitos causadores dessas mudanças climáticas. Neste contexto, apesar de serem os aspectos ambientais os elementos que deveriam receber maior peso nas decisões desta convenção, quase que unanimemente os critérios econômicos e políticos são os quais regem os acordos firmados.

Em seu último relatório, o IPCC apresentou estimativas de que os desflorestamentos e outras mudanças do uso do solo contribuíram com o lançamento de 180 [100; 260] Pg C, entre os anos de 1750 e 2011(IPCC, 2013), sendo esta considerada a segunda maior fonte de emissões dos Gases do Efeito Estufa (GEEs) de origem antrópica. Para as florestas tropicais, apenas na década do ano 2000, estas estimativas de emissões devido ao desflorestamento são na ordem de 1,14 Pg C por ano, de um estoque atual de aproximadamente $229 \mathrm{Pg} \mathrm{C}$ presente na biomassa dessas florestas (BACCINI et al., 2012). No entanto, estas estimativas são ainda cercadas de muitas incertezas, as quais são atribuídas à insuficiência de informações concretas referentes aos estoques de carbono presentes nas florestas (HOUGTHON; HALL; GOETZ, 
2009) e às taxas regionais de desmatamento. Neste sentido, Chave et al. (2005) expõem ser a falta de modelos padronizados para converter as medições das arbóreas em estimativas de biomassa acima do solo, um das principais fontes de incertezas dos estoques de carbono em florestas tropicais.

Devido a estas incertezas, pesquisas buscando quantificar os estoques desses elementos nos ecossistemas florestais passaram a ser alvo da comunidade científica no intuito de levantar informações para uso nos inventários de emissões, estocagens ou remoções dos GEEs. Assim, após algumas décadas sem trabalhos expressivos, estudos relacionados aos estoques de carbono, realizados em diferentes ecossistemas florestais, retomam como um importante eixo das investigações. Estes possuem o propósito de subsidiar decisões na esfera das políticas públicas, no que concernem as ações para o combate ao desmatamento e incentivos aos reflorestamentos, visando assegurar as metas internas de redução das emissões dos GEEs. Ao mesmo tempo, buscam disponibilizar elementos técnicos e metodológicos para serem aplicados em projetos florestais relacionados à remoção de carbono (atividades de projeto de Florestamento/Reflorestamento) ou Redução de Emissões por Desmatamento e Degradação Florestal (REDD), com o intuito de aumentar a confiabilidade das estimativas de créditos comercializados por estas atividades.

Nas estimativas de estoques de biomassa e carbono em floresta, o uso do sensoriamento remoto é crucial, possibilitando o monitoramento de amplas áreas em periodicidade constante (WILKIE; FINN, 1996), servindo como uma ferramenta para preencher as lacunas entre os estudos locais e intensivos, e aqueles, globais e amplos, respondendo assim às necessidades dos tomadores de decisão e gestores (CORLETT, 1995; KANGAS et al., 2000; FREITAS; MELLO; CRUZ, 2005).

O uso de dados orbitais constitui um método indireto e não destrutivo para estimativa de parâmetros biofísicos em florestas, sendo a aplicação de técnicas de interpolação geoestatística, uma forma de obtenção de informações de variáveis importantes da floresta (LEAL, 2013). Neste sentido, índices de vegetação têm sido utilizado para correlacionar indicadores biofísico da floresta, tal como a biomassa florestal, sendo o Índice de Vegetação por Diferença Normalizada (Normalized Difference Vegetation Index - NDVI) bastante aplicado para esta finalidade.

Entre as diversas aplicações do NDVI para uso nas estimativas de biomassa em florestas, tem-se o sua aplicação como critério para auxiliar a estratificação da população amostral, quando da realização do inventário florestal através da amostragem aleatória 
estratificada, ou como variável suplementar, na aplicação de um estimador de regressão quando da utilização do método de amostragem dupla.

Este segundo método é um procedimento muito útil em inventários florestais, podendo ser utilizado para a amostragem em múltiplas ocasiões, cuja amostra da segunda ocasião constitui uma subamostra da primeira (PÉLLICO NETTO; BRENA, 1997) ou buscando correlacionar duas variáveis mensuradas simultaneamente. Neste caso, usando uma variável obtida com baixo custo e menor complexidade de mensuração, mas com alta intensidade amostral, como variável suplementar na definição de um estimador de regressão, o qual é aplicado para inferir sobre outra variável obtida com alto custo e alta complexidade de mensuração, mas com menor intensidade amostral. Para Cochran (1977), a aplicação do estimador de regressão apresenta melhoras nas estimativas desta variável obtida com baixa intensidade, principalmente quando a variável auxiliar tem correlação significativa com a variável que se quer estimar e é conhecida em toda a área sem erros relacionados à sua amostragem.

Em ambas as situações, o intuito da aplicação da amostragem dupla é o de reduzir a intensidade amostral na coleta de dados da variável de maior complexidade, e consequentemente, os custos e tempo de execução do inventário. No caso do monitoramento de estoques de carbono em florestas, a variável obtida com baixa intensidade amostral é a biomassa, quantificada pelo inventário de campo, e a variável de alta intensidade, é o NDVI, determinado por procedimentos de análise de imagens orbitais e conhecido em toda a área do projeto.

Apesar da grande utilidade da combinação destas técnicas na aplicação da amostragem dupla, até então, a CQNUMC não considerava entre suas ferramentas metodológicas de atividades de projetos de Florestamento/Reflorestamento, realizados no âmbito do Mecanismo de Desenvolvimento Limpo, a possibilidade de sua aplicação. Recentemente, por uma demanda exposta pelo projeto "AES Tietê Afforestation/Reforestation Project in State of São Paulo, Brazil", esta abordagem metodológica passou a ser oficialmente parte integrante das ferramentas de aplicação de amostragem destes projetos, sendo retratada na ferramenta metodológica: "Estimation of carbon stocks and change in carbon stocks of trees and shrubs in A/R CDM project activities" (UNFCCC, 2013).

Neste sentido, um primeiro capítulo desenvolvido neste trabalho aborda a aplicabilidade do NDVI em processos de amostragem de inventários florestais voltados à estimação dos estoques de biomassa e carbono em florestas nativas. Entre estes, encontra-se a amostragem dupla, a qual correlaciona a biomassa ao NDVI, utilizando o valor deste índice 
como variável auxiliar na definição de um estimador de regressão. Classes de valores do índice NDVI também foram utilizadas como critério de estratificação da população. Estes processos de amostragem, além de outros tradicionalmente utilizados em inventário florestais, foram testados no intuito de avaliar sua eficiência, em termos de precisão e conservadorismo da estimativa, para aplicação nos monitoramentos de projetos florestais voltados ao mercado de carbono. Para isso, foi utilizado como um estudo de caso o projeto supramencionado da AES Tietê S/A, desenvolvido no interior do Estado de São Paulo.

No entanto, apesar do advento tecnológico envolvendo o uso das ferramentas de sensoriamento remoto e Sistemas de Informação Geográfico utilizadas nos estudos de estoque de carbono, deve-se ter clareza de que, a base de informações utilizadas para as extrapolações em escala, são as quantificações realizadas pelos métodos tradicionais de determinação e estimação de biomassa, realizados em campo. Sendo as árvores o elemento que mais contribui para a biomassa total das florestas, sua determinação, quase que exclusivamente, é focada neste componente.

A determinação da biomassa é obtida através de métodos diretos, no qual árvores são abatidas segundo um processo de amostragem estratificada. A partir do conjunto desses dados, técnicas de regressão são aplicadas para o desenvolvimento de modelos de predição, correlacionando a biomassa aos dados dimensionais das árvores, possibilitando sua aplicação nos inventários florestais voltados à estimação de estoques de carbono presentes na biomassa dessas florestas. Entre os dados dimensionais, o diâmetro e altura das árvores são os mais utilizados. Como a densidade da madeira é uma característica diretamente relacionada à biomassa das árvores, esta também é uma informação importante a ser considerada, no entanto, sua mensuração e determinação demandam de procedimentos laboriosos, motivo pelo qual comumente é desconsiderada como variável preditora dos modelos.

Uma série de critérios estatísticos é utilizada para avaliação do ajuste de modelos concorrentes, no intuito de se determinar o de melhor qualidade. No entanto, deve-se reconhecer que estes modelos de predição são empíricos e sítio-específico (VANCLAY, 1994; VISMARA; 2009; 2013). Assim, toda inferência relativa ao seu ajuste, por quaisquer que sejam os critérios adotados, são relativos ao próprio conjunto de dados utilizados em sua construção. Por este motivo, para que proporcionem estimativas biologicamente realistas, estes devem ser construídos de modo a incorporarem a máxima amplitude de condições biológicas possíveis (VANCLAY; 1994), possibilitando assim, estimativas confiáveis quando de sua aplicação futura na predição dos estoques de biomassa da floresta. 
Neste aspecto, faz-se necessário analisar a qualidade desses modelos, não apenas sob o ponto de vista de seu ajuste, mas também em função de seu desempenho de predição em situações em que a estrutura da floresta seja distinta à da amostra utilizada para seu ajuste, de modo a permitir sua adequada avaliação (VISMARA, 2013). Esta avaliação pode ser realizada verificando-se os vieses de predição da biomassa destas árvores pelo uso dos modelos concorrentes. Isto se torna ainda mais importante quando se utiliza modelos ajustados com dados de outras florestas, que não a utilizada para obtenção das amostras para a sua construção.

Apesar das equações alométricas de predição serem cruciais na estimativa de biomassa, raramente são diretamente testadas nos inventários, devido a difícil coleta de dados em campo para a determinação de biomassa de forma direta (CHAVE et al., 2005). Com isso, no uso de equações de predição, sejam estas construídas com dados da própria floresta, sejam equações disponíveis na literatura, se não realizadas a avaliação de seu desempenho preditivo, nunca serão conhecidos os erros que podem estar associados ao seu uso. Neste sentido, a aplicação de equações inadequadas para uma determinada situação, pode gerar quantificações de estoques de carbono bastante discrepantes da realidade, estando a seleção das equações de predição utilizadas para inferir sobre o estoque de biomassa entre os principais elementos da propagação dos erros dessas estimativas em escala (CHAVE et al., 2004).

Neste contexto, um segundo capítulo desenvolvido no presente trabalho visa avaliar distintas equações de predição de biomassa, em termos de qualidade ajuste e desempenho de aplicação, incluindo algumas desenvolvidas com dados da própria floresta estudada, assim como equações disponíveis na literatura, construídos a partir de dados de outras florestas. Este objetiva expor alguns fatores geradores de incertezas nas estimativas relacionadas à quantificação de biomassa em florestas nativas. Este estudo foi oportunamente realizado, aproveitando o licenciamento ambiental de um empreendimento aeroportuário, o qual contemplava a autorização para a supressão de parte de uma floresta secundária da Mata Atlântica, localizada no Município de Registro-SP. Assim foi possível a obtenção de amostras destrutivas em quantidade razoavelmente suficiente para poder testar estas questões. Com todo o exposto, as hipóteses testadas neste trabalho foram:

I. Em florestas nativas restauradas da Mata Atlântica, o índice de vegetação NDVI apresenta adequada correlação com a biomassa florestal, possibilitando seu uso como ferramenta auxiliar no inventário de estoques de biomassa em projetos florestais voltados ao mercado de carbono. 
II. A aplicação da amostragem dupla, utilizando o índice de vegetação NDVI como variável auxiliar na definição de um estimador de regressão, relacionando-o à biomassa florestal, é um processo de amostragem confiável para quantificar estoques de biomassa e carbono em florestas nativas com precisão, requerendo reduzida intensidade amostral.

III. A utilização da altura total e da densidade básica da madeira como variáveis preditoras dos modelos de biomassa aumentam a qualidade de ajuste dos mesmos, se comparado à utilização de modelos ajustados apenas com a variável preditora diâmetro do tronco.

IV. O estudo do desempenho de aplicação das equações de biomassa através da avaliação do viés de predição é um bom parâmetro para se reconhecer a grandeza das incertezas associadas ao uso de determinada equação na quantificação da biomassa das árvores de uma floresta.

V. Modelos de predição de biomassa são empíricos e sítio-específico.

VI. O índice de resistência do lenho à penetração, de fácil mensuração em campo através do aparelho Pilodyn, apresenta adequada correlação com a densidade básica da madeira e, deste modo, é útil para aplicação como uma das variáveis independentes do modelo de predição de biomassa de árvores da floresta tropical.

VII. As informações de densidade básica da madeira extraídas em literatura específica são adequadas para aplicação nas equações de predição de biomassa.

\section{Referências}

BACCINI, A; GOETZ, S. J.; WALKER, W. S.; LAPORTE, N. T. ; SUN, M. ; SULLA MENASHE, D.; HACKLER, J.; BECK, P. S. A.; DUBAYAH, R.; FRIEDL, M. A.; SAMANTA, S.; HOUGHTON, R.A. HOUGHTON, R. A. Estimated carbon dioxide emissions from tropical deforestation improved by carbon-density maps. NATURE CLIMATE CHANGE, New York, v. 2, n. 3, p 182-185, Mar. 2012.

CHAVE, J.; ANDALO, C.; BROWN, S.; CAIRNS, M.; CHAMBERS, J.C.; EAMUS, D.; FÖLSTER, H.; FROMARD, F.; HIGUCHI, N.; KIRA, T.;LESCURE, J.; NELSON, B.W.; OGAWA, H.; PUIG, H.; RIÉRA, B.; YAMAKURA, T. Tree allometry and improved estimation of carbon stocks and balance in tropical forests. Oecologia, Heidelberg, v. 145, n. 1, p. 87-99, Jun. 2005.

COCHRAN, W.G. Sampling Techniques. $3^{\text {nd }}$ ed. New York: John Wiley, 1977. 428 p.

CORLETT, R. T. Tropical secondary forests. Progress in Physical Geography, London, v. 19, p. 159-172, 1995. 
FREITAS, S. R.; MELLO, M. C. S.; CRUZ, C. B. M. Relationships between forest structure and vegetation indices in Atlantic Rainforest. Forest Ecology and Management, Wisconsin, v. 218, n. $1 / 3$, p. $353-362,2005$.

HOUGTHON; R.A.; HALL, F.; GOETZ, S.J. Importance of biomass in the global carbon cycle. Jornal of Geophysical Research, Washington, v.144, n. G00E03, 13 p, Set. 2009.

INTERGOVERNMENTAL PANEL ON CLIMATE CHANGE - IPCC. Climate Change 2013: The physical science basis. Stockholm, Sept. 2013. Report - Working group I contribution to the IPCC fifth assessment report (AR5).

KANGAS, J.; IOJA, R.; LESKINEN, P.; MEHTÄTALO. Improving the quality of landscape ecological forest planning by utilizing advanced decision-support tools. Forest Ecology and Management, Wisconsin, v. 132, n. 2/3, p. 157-171, 2000.

LEAL, F.A. Técnicas de sensoriamento remote e geoestatística aplicadas em um povoamento de Eucalyptus urophylla S. T. Blake para estimativa de volume. Dissertação (Mestrado em Ciências Florestais). 2013. 96 p. Departamento de Engenharia Floresta, Universidade de Brasília, 2013.

PÉLLICO NETTO, S.; BRENA, D.A. Inventário Florestal. Curitiba, 1997. 316 p.

UNITED NATIONS FRAMEWORK CONVENTION ON CLIMATE CHANGE UNFCCC. A/R Methodological tool: Estimation of carbon stocks and change in carbon stocks of trees and shrubs in A/R CDM project activities. Report. CDM-EB75-A26, Version 04.0, Oct. 2013, 32p.

VANCLAY, J. K. Modelling forest growth and yield: applications to mixed tropical Forests. Wallingford: CAB International, 1994. 212 p.

VISMARA, E.S. Mensuração da biomassa e seleção de modelos para a construção de equação de biomassa. 2009. 102 p. Dissertação (Mestrado em Recursos Florestais) - "Escola Superior de Agricultura 'Luiz de Queiroz”,Universidade de São Paulo, Piracicaba, 2009.

Avaliação da construção e aplicação de modelos florestais de efeitos fixos e efeitos mistos sob o ponto de vista preditivo. 2013. 106p. Tese (Doutorado em Recursos Florestais) - "Escola Superior de Agricultura 'Luiz de Queiroz", Universidade de São Paulo, Piracicaba, 2013.

WILKIE, D. S.; FINN, J. T. Remote sensing imagery for natural resources monitoring: A guide for first-time users. New York: Columbia University Press, 1996. 295 p. 


\title{
2 APLICAÇÃo do ÍNDICE DE VEGETAÇÃO NDVI EM PROCESSOS DE AMOSTRAGEM PARA A QUANTIFICAÇÃO DE ESTOQUES DE BIOMASSSA E CARBONO DE FLORESTAS NATIVAS RESTAURADAS
}

\section{Resumo}

Este estudo visa avaliar a aplicabilidade do índice de vegetação NDVI para auxiliar nos inventário de estoques de biomassa em florestas nativas. Para isso, utilizaram-se informações reais obtidas pelo monitoramento do projeto de Restauração Florestal e Créditos de Carbono da AES Tietê S/A, como um estudo de caso. Diferentes processos de amostragem utilizados em inventário florestal foram comparados em termos de precisão e conservadorismo das estimativas de biomassa e carbono. Os resultados demonstram que o índice de vegetação NDVI apresentou adequada correlação com a biomassa medida nas parcelas de inventário florestal instaladas em campo. Desta forma, este índice apresenta-se como importante ferramenta tanto para auxiliar na determinação de estratos, na aplicação da amostragem estratificada simples, ou como variável auxiliar na aplicação da amostragem dupla, pelo uso de estimador de regressão relacionando-o à biomassa. Este último processo de amostragem foi capaz de minimizar as incertezas acerca das estimativas, valendo-se de uma intensidade amostral reduzida, fato que torna seu uso interessante para a aplicação em inventários de biomassa e carbono de florestas nativas, principalmente nos quais abrangem amplos limites territoriais, onde a logística de instalação de parcelas de monitoramento em grandes quantidades encontram barreiras da ordem operacional e de custo.

Palavras-chave: Biomassa florestal; Índice de Vegetação por Diferença Normalizada - NDVI; Amostragem dupla; Estimador de regressão; Restauração florestal

\begin{abstract}
This study aims to evaluate the applicability of the vegetation index NDVI to assist in inventory of biomass stocks in natural forests. For this, we used the information obtained in the study of case project, entitled "Forest Restoration and Carbon Credits AES Tietê S/A". Different sampling procedures commonly used in forest inventories were applied, looking to compare them in terms of accuracy and conservativeness of the estimates of biomass and carbon. The vegetation index NDVI show good correlation with the measured biomass in the field inventory plots. As result, this index can be applied as support decision tool to define the strata in the stratified random sampling as well as a predictor variable of the regression estimator in the double sampling procedure. This latter procedure was able to minimize the uncertainty of estimates, using a reduced sampling effort. It makes the approach very interesting in the context of biomass and carbon surveys applied to natural and restored Atlantic forests. It is because those studies are often applied in large areas, where the field works are time consuming and very expensive.
\end{abstract}

Keywords: Forest biomass; Normalized Difference Vegetation Index - NDVI; Double sampling; Regression estimator; Forest restoration 


\subsection{Introdução}

Atividades de projetos florestais voltados ao mercado de carbono demandam de um processo de monitoramento para acompanhar as variações espaço-temporal dos estoques deste elemento nos reservatórios verificáveis dentro seus limites. Para isso, procedimentos de inventário florestal são realizados periodicamente, a partir dos quais, estima-se a quantidade de créditos gerados em determinado período a serem comercializados.

Nestes projetos, unidades amostrais são instaladas em campo segundo um procedimento de amostragem pré-definido, sendo empregado comumente, os mais tradicionais utilizados em inventários florestais. Nestas são coletados dados das variáveis que compõem os modelos matemáticos de predição de biomassa ou carbono. Os valores médios obtidos nestas unidades amostrais são então extrapolados para a área total do projeto, considerando um nível de incerteza aceitável com relação à estimativa da média. Com isso, o número mínimo de unidades amostrais instaladas e mensuradas em campo passa a ser definida em função da variabilidade existente entre os valores médios individuais das unidades amostrais.

Esses procedimentos de mensuração das florestas dependem, muitas vezes, de extensivos e dispendiosos trabalho de campo, os quais, por vez, abrangem uma área restrita de toda a população (FREITAS; MELLO; CRUZ, 2005). Neste sentido, Corlett (1995) e Kangas et al. (2000) sugerem o uso do sensoriamento remoto como ferramenta para preencher a lacuna existente entre os estudos intensivos de pequena escala (local) e os de ampla escala (global), de modo a prover informações úteis para os tomadores de decisão.

O uso do sensoriamento remoto como ferramenta de análise permite estudos de monitoramento em uma ampla área em períodos de tempo constantes (WILKIE; FINN, 1996). A convergência entre as técnicas de sensoriamento remoto e indicadores biofísicos pode ser valiosa para estudos de diagnóstico, monitoramento e quantificação de biomassa, especialmente em habitats ameaçados, como a Mata Atlântica (FREITAS; MELLO; CRUZ, 2005). Assim, as técnicas de sensoriamento remoto têm sido amplamente utilizadas em estudos e aplicações na área florestal, merecendo destaque os projetos que visam a quantificação de biomassa florestal (LEAL, 2013).

Índices de vegetação obtidos através de sensores remotos podem ser utilizados como indicadores de biomassa (GAMON et al., 1995). Estes índices são formados a partir de combinações de vários valores espectrais que são matematicamente recombinados, de forma a obter-se um único valor que indica a quantidade ou o vigor vegetativo dentro um pixel 
(CAMPBELL, 1996). Em florestas tropicais, algumas pesquisas associam os índices de vegetação com a diversidade de espécies arbóreas e a biomassa florestal (BOYD, 1999; FOODY et al., 2001; FOODY et al., 2003; MATOS; KIRCHNER, 2007).

Os índices de vegetação são diversos, sendo o Índice de Vegetação por Diferença Normalizada - NDVI (Normalized Difference Vegetation Index), o qual utiliza a relação entre bandas do vermelho e infravermelho próximo, um dos mais populares (ROUSE et al., 1974). O NDVI pode ser correlacionado com as tradicionais medições realizadas nas florestas visando produzir melhorias na inferência das estimativas de parâmetros biofísicos. Existem diversos trabalhos científicos que buscam descrever o NDVI como um bom indicador da biomassa em todos os tipos de florestas distribuídas pelo mundo (TAN et al., 2007; ZHENG et al., 2007; MASELLI et al., 2009) e, especialmente, nas florestas tropicais atlânticas (SADER et al., 1989; WATZLAWICK et al., 2009; AMARAL et al., 2010).

A aplicação do NDVI para uso na estimativa da biomassa pode ocorrer de duas formas: i) utilizando este índice como critério para a estratificação da população, quando da realização do inventário florestal através da amostragem aleatória simples estratificada, ou ii) como variável auxiliar na aplicação do estimador de regressão para se estimar a biomassa, pelo processo da amostragem dupla.

O primeiro caso é um sistema comumente utilizado em procedimentos de inventário florestal, onde florestas definidas com alguma característica de similaridade para a expressão da média da variável em análise são agrupadas em estratos. Esta estratificação pode ser realizada, a priori, se reconhecida previamente a existência desses estratos, ou posteriormente, se os estratos são reconhecidos apenas após os levantamentos de campo. Na teoria, as unidades amostrais definidas dentro de um mesmo estrato são mais homogêneas e, por isso, resultam em melhorias na precisão das estimativas. Assim, as inferências estatísticas são realizadas primeiramente ao nível de estrato, para posteriores inferências em nível de população, ponderando-se os resultados dos estratos em função de seu tamanho. Esta condição tende a reduzir a variância e, consequentemente, a intensidade amostral requerida para atingir a precisão desejável para as estimativas do total da população.

Já o segundo caso, é um sistema de amostragem que se utiliza de duas variáveis correlacionadas, onde uma variável obtida com baixo custo e menor complexidade de mensuração é amostrada com grande intensidade na área do projeto, enquanto que a outra, de alto custo e alta complexidade de mensuração, é amostrada com baixa intensidade. A variável obtida com grande intensidade é então usada como auxiliar para melhorar a precisão da estimativa da variável obtida com baixa intensidade (COCHRAN, 1977). Para isso, faz-se o 
uso de um estimador de regressão obtido pelo ajuste da relação entre estas variáveis. O estimador de regressão é muito eficaz quando a variável auxiliar tem correlação significativa com a variável que se quer estimar e é conhecida em toda a área sem erro amostral. No caso em questão, a variável mensurada com baixo custo é o valor do índice NDVI, tomado pixel a pixel de toda a área útil do projeto, ou seja, através do censo populacional. Já a variável de alto custo é o carbono mensurado nas unidades amostrais instaladas em campo através de método de inventário florestal tradicional.

Este capítulo aborda a aplicabilidade do NDVI para auxiliar nos inventário de estoques de carbono em florestas nativas restauradas através do plantio misto de espécies arbóreas, utilizando informações reais obtidas pelo monitoramento do projeto de Restauração Florestal e Créditos de Carbono da AES Tietê S/A, como um estudo de caso. O objetivo é comparar a eficiência dos diferentes processos de amostragem utilizados nestas modalidades de projeto, em termos de precisão e conservadorismo da estimativa de biomassa e carbono e, desta forma, demonstrar a confiabilidade da utilização do índice NDVI para a estimativa da biomassa do projeto, seja como critério de estratificação, seja como variável auxiliar do estimador de regressão.

\subsection{Material e métodos}

\subsection{1 Área do estudo}

O estudo abrange toda área elegível, segundo os critérios pré-definidos pelo Mecanismo de Desenvolvimento Limpo (MDL) da Convenção-Quadro das Nações Unidas sobre Mudanças Climáticas - CQNUMC (United Nations Framework Convention on Climate Change - UNFCCC), já reflorestada no âmbito do "Projeto MDL de Reflorestamento no Estado de São Paulo da AES Tietê"'. Estas dizem respeito aos reflorestamentos presentes às margens de oito reservatórios hidroelétricos existentes ao longo da Bacia do Rio Tietê, no centro e oeste do Estado de São Paulo, e mais um localizado na Bacia do Rio Grande, na divisa com o estado de Minas Gerais, os quais juntos apresentam um perímetro de 4,34 mil quilômetros de extensão.

Os reflorestamentos presentes nas áreas elegíveis do projeto perfazem 2.001,2 hectares, de um total de 2.714,5 hectares implantados pela AES Tietê entre os anos de 2001 a 2010. A Tabela 2.1 traz informações referentes à quantidade de áreas elegíveis reflorestadas inclusas na amostragem da população. 
Os reflorestamentos do projeto, cujo objetivo está voltado à restauração florestal de áreas de preservação permanente (APP), localizam-se as margens dos reservatórios hidroelétricos sob domínio da empresa AES Tietê, em faixa definida pela Cota Máxima Operativa Normal e a Cota Máxima dos reservatórios. Para o processo de restauração florestal destas áreas tem se adotado o plantio de mudas de espécies nativas, o qual considera em sua definição, os modelos com alta diversidade de espécies e premissas da sucessão secundária da floresta tropical.

Tabela 2.1 - Quantidade de áreas elegíveis implantadas entre os anos de 2000 e 2010 nos diferentes reservatórios hidroelétricos da AES Tietê

\begin{tabular}{c|ccccc}
\hline Reservatório Hidroelétrico* & $\mathbf{2 0 0 1 - 2 0 0 2}$ & $\mathbf{2 0 0 3 - 2 0 0 5}$ & $\mathbf{2 0 0 6 - 2 0 0 8}$ & $\mathbf{2 0 0 9 - 2 0 1 1}$ & Total \\
\hline AGV & 169,62 & 23,48 & 0,00 & 172,19 & 365,29 \\
BAB+CAC+LIM+MOG+EUC & 74,74 & 35,31 & 0,00 & 0,00 & 110,05 \\
BAR & 79,15 & 34,41 & 0,00 & 0,00 & 113,55 \\
IBI & 64,67 & 140,76 & 69,82 & 0,00 & 275,24 \\
PRO & 374,49 & 180,63 & 0,00 & 581,97 & $1.137,10$ \\
Total & $\mathbf{7 6 2 , 6 7}$ & $\mathbf{4 1 4 , 5 9}$ & $\mathbf{6 9 , 8 2}$ & $\mathbf{7 5 4 , 1 6}$ & $\mathbf{2 . 0 0 1 , 2 4}$ \\
\hline
\end{tabular}

* AGV - Água Vermelha; BAB - Barra Bonita; BAR - Bariri; CAC - Caconde; EUC - Euclides da Cunha; IBI - Ibitinga; LIM - Limoreiro; MOG: Mogi-mirim; PRO - Promissão.

\subsubsection{Sensoriamento remoto}

Para o mapeamento das áreas elegíveis do projeto, assim como a extração dos índices de vegetação NDVI (Índice de Vegetação por Diferença Normalizada) aplicados neste estudo, foram utilizados mosaicos de imagens ortoretificadas do sensor Rapideye. Estes cobriam toda a área de abrangência do projeto, cujas cenas foram obtidas em meados de julho de 2011 . O processamento e análises das imagens foram realizados no programa ArcGIS, versão 9.3 (ESRI).

Os limites dos polígonos de plantio das áreas discretas elegíveis inclusas neste estudo foram aferidos com base nos levantamentos topográficos planialtimétricos. O conjunto dessas áreas discretas representa a população amostral. Cada um desses polígonos recebeu um identificador, sendo possível reconhecer, além das informações geoespaciais, outros atributos tais como a idade do reflorestamento. 


\subsubsection{Determinação do NDVI}

A obtenção do valor do índice de vegetação NDVI foi realizada através da ferramenta ArcMAP. O procedimento para o cálculo matemático na obtenção do valor do índice NDVI foi realizado utilizando a ferramenta "raster calculator", presente na aba "spatial analyst" do programa. Nessa opção, selecionaram-se as bandas três e cinco da imagem em uso, sendo elas a vermelho e infravermelho próximo, respectivamente, nas quais baseiam-se a extração do NDVI. Uma vez finalizado este procedimento, gerou-se um valor para o NDVI, pixel a pixel, para toda área elegível do projeto. O cálculo do valor de NDVI neste procedimento é realizado conforme descrito:

$$
N D V I=\frac{N I R-R}{N I R+R}
$$

onde: NDVI é o Índice de Vegetação por Diferença Normalizada; NIR é a refletância da banda do infravermelho próximo, e; $R$ é a refletância da banda do vermelho.

O NDVI baseia-se na alta absorção da clorofila que é verificada na região espectral do vermelho e na alta refletância explicada pela estrutura interna das folhas, na região do infravermelho próximo (NIR), podendo saturar em coberturas vegetais densas com valores de índice de área foliar elevados (Leal, 2013). O valor de NDVI varia entre -1 e 1. Geralmente em vegetações saudáveis, o índice apresenta valores em torno de 0,2 e 0,8 (ROUSE et al.,1973). Pixels com valores de NDVI inferiores a 0,2 neste trabalho são expressos normalmente por solos desnudos os quais tendem a gerar pequenos valores positivos de NDVI (por exemplo 0,1 a 0,2).

\subsubsection{Aplicação do NDVI em nível de parcela}

Para desenvolver o estudo da correlação entre estoque de carbono do inventário florestal e o valor de NDVI, os valores de NDVI dos pixels contidos dentro dos polígonos das parcelas de inventário foram computados utilizando a ferramenta "zonal statistics", também contida na aba "spatial analyst". Esse procedimento gera um arquivo tabelado contendo diversas estatísticas descritiva dos valores atribuídos aos pixels encontrados dentro de cada parcela permanente. Dentre essas estatísticas encontra-se o número de pixels (quantidade de pixels contidos dentro do polígono), bem como a média, somatória e desvio padrão dos 
valores de NDVI dos pixels da parcela. Esta média foi utilizada como variável preditora para gerar a correlação entre o NDVI e os valores de estoque de carbono obtidos através das parcelas de inventário em campo. Salienta-se que foram computados, na estimativa da média do valor de NDVI da parcela, apenas os pixels com mais de 50\% de sua área contida dentro da parcela.

\subsubsection{Aplicação do NDVI para a estratificação da área elegível do projeto}

Os procedimentos para a obtenção do valor do índice NDVI da área elegível do projeto (população amostral), neste caso, foram os mesmos adotados para a determinação do NDVI em nível de parcela. Para a estratificação da área da população em função do NDVI, criaram-se três classes distintas as quais consideraram os intervalos do valor do NDVI apresentados no Tabela 2.2. Para a estratificação da área do projeto em função das classes de NDVI, duas abordagem distintas foram utilizadas: uma em nível hierárquico de área discreta (polígono de plantio), valendo-se da média dos valores de NDVI apresentados por cada pixel, e; outra, considerando individualmente cada pixel presente na área do projeto como sendo a unidade de avaliação. Neste segundo caso, uma área discreta pode apresentar manchas com pixels apresentando valores contidos em diferentes estratos pré-definidos.

Tabela 2.2 - Divisão das classes de NDVI

\begin{tabular}{ccc}
\hline Classe & Valor do NDVI & Condição da cobertura vegetal \\
\hline 1 & $<0,25$ & rala \\
2 & $0,25-0,50$ & moderada \\
3 & $>0,50$ & densa \\
\hline
\end{tabular}

\subsubsection{Processos de amostragem}

Visando reconhecer a variabilidade existente na população, ou seja, os reflorestamentos presentes em toda área de abrangência do projeto e, ao mesmo tempo, buscando a maior representatividade desses reflorestamentos na amostragem, parcelas (unidades amostrais) de inventário florestal foram instaladas baseadas no procedimento da amostragem aleatório simples. Buscando melhorar a precisão das estimativas, estratificações da população foram realizadas considerando diferentes critérios de agrupamento das áreas de 
reflorestamento do projeto, entre estes: a região dos reservatório hidroelétrico, a idade do plantio e as classes de intervalo do valor de NDVI. Por fim, um último procedimento aplicado a inventários florestais foi utilizado - a amostragem dupla.

Assim, os sistemas (processsos) de amostragem comparados neste estudo, foram os seguintes:

I. amostragem aleatória simples;

II. amostragem estratificada por reservatório hidroelétrico (região);

III. amostragem estratificada por idade de plantio;

IV. amostragem estratificada por classes de NDVI, considerando o valor médio deste índice para cada área discreta (talhão de plantio) do projeto;

V. amostragem estratificada por classes de NDVI independente;

VI. amostragem dupla, considerando o uso do valor do NDVI como variável auxiliar na determinação do estimador de regressão para a estimativa da biomassa.

Para a amostragem aleatória simples (Sistema I) e amostragem simples estratificada, por idade e reservatório hidroelétrico (Sistemas II e III), as áreas discretas elegíveis do projeto encontram-se totalizadas na Tabela 2.1. Para o a amostragem estratificada por classes de NDVI, a Tabela 2.3 apresenta a totalização de áreas dentro de cada uma dessas classes, para as duas abordagens de estratificação considerando este índice (Sistemas IV e V).

Salienta-se que a estratificação da amostragem foi realizada posteriormente à execução dos inventários de campo, apenas no momento da análise dos dados.

Tabela 2.3 - Totalização das áreas elegíveis do projeto (ha) em estratos definidos em função das classes de NDVI

\begin{tabular}{ccccc}
\hline $\begin{array}{c}\text { Método de } \\
\text { separação das } \\
\text { áreas em estratos }\end{array}$ & $\begin{array}{c}\text { Classe 1 } \\
\text { (NDVI: } \mathbf{< ~ 0 , 2 5 )}\end{array}$ & $\begin{array}{c}\text { Classe 2 } \\
\text { (NDVI: 0,25 - 0,50) }\end{array}$ & $\begin{array}{c}\text { Classe 3 } \\
\text { (NDVI: > 0,50) }\end{array}$ & Total \\
\hline Sistemas IV & 604,66 & $1.024,83$ & 371,75 & \\
Sistemas V & 634,64 & 928,48 & 438,11 & $2.001,24$ \\
\hline
\end{tabular}




\subsubsection{Inventário florestal: procedimentos de campo}

As parcelas instaladas apresentam formas retangulares e área constante de $400 \mathrm{~m}^{2}$. Em virtude dos diferentes espaçamentos de plantio existentes nestes reflorestamentos, adotou-se parcelas com dimensões variáveis de largura e comprimento, sendo estas definidas em função do espaçamento da entrelinha, considerando sempre, para a definição da largura das parcelas, a distância equivalente a quatro vezes o espaçamento médio entre as linhas de plantio. Desta forma, o comprimento da parcela passa a ser a distância para atingir a área fixa de $400 \mathrm{~m}^{2}$. Nos quatro vértices da parcela foram locadas estacas de canos de PVC. Junto à primeira árvore mensurada na parcela instalou-se uma placa de alumínio contendo o código de identificação da parcela. Um total de 111 parcelas amostrais foi instalado em campo para este estudo.

Das árvores presentes no interior da parcela, mensurou-se o diâmetro do tronco a 0,30 $\mathrm{m}$ de altura do solo (Diâmetro do Caule a $0,30 \mathrm{~m}-c 30$ ) e a altura total $(h t)$ do indivíduo. Indivíduos bifurcados abaixo de $0,30 \mathrm{~m}$ de altura tiveram todos os troncos mensurados. Apenas foram mensurados os troncos que apresentaram diâmetro igual ou maior a 5,0 cm. A medida do diâmetro foi tomada com o uso de suta dendrométrica, sendo a anotação do valor em centímetros e com precisão em milímetros. Adotou-se a mensuração do diâmetro do caule à altura de 0,30 m por dois motivos: primeiramente, devido ao fato de que, em plantios de espécies nativas, há uma forte tendência das espécies apresentarem maior número de bifurcações do tronco à altura inferiores ao DAP (Diâmetro à Altura do Peito medido a 1,30 m do solo), de modo que, a mensuração mais próxima da base do caule, adotada no estudo, evita a necessidade de mensuração de muitos troncos, até mesmo a inclusão equivocada de galhos grossos presentes nesta altura; em segundo, a equação de predição de biomassa seca utilizada no estudo foi ajustada tendo como uma de suas variáveis, a inclusão desta medida a 0,30 do solo e não o DAP.

A altura total da árvore foi medida com o uso de um clinômetro eletrônico Vertex IV, da marca Haglöf. Tal medida foi anotada em metros com precisão em centímetros. Indivíduos regenerantes presentes dentro da parcela, cujo diâmetro encontrava-se na classe de inclusão pré-definida, também foram mensurados.

Em campo, os indivíduos tiveram sua identificação botânica reconhecida, aferida com a relação das espécies plantadas na área. No caso de não ser possível essa definição em campo, ou havendo dúvidas quanto a sua nomenclatura, um ramo foi coletado para a 
formação de exsicata para posterior identificação no herbário ESA (ESA - Herbário da Escola Superior de Agricultura Luiz de Queiroz).

A posição geográfica dos quatro vértices que delimitam a parcela foi obtida com uso de aparelho receptor de GPS, no sistema geodésico de projeção WGS84 (Word Geodetic System - 1984), em UTM (Universal Transversal de Mercator). O receptor GPS utilizado foi o PRO-XT da marca Trimble, com antena L1, o qual possibilita precisão inferior a 0,5 metros no código C/A pós-processamento. Para garantir a precisão dos pontos georeferenciados, 60 recepções por pontos ( 1 ponto a cada 5 segundo) foram realizadas.

A coleta dos dados do inventário florestal foram realizadas entre dezembro de $2011 \mathrm{e}$ março de 2012. Para a mensuração das observações de interesse nas parcelas, utilizou-se planilha pré-estruturada contendo campos para anotação dessas observações em aparelho coletor de dados digital.

\subsubsection{Determinação do estoque de biomassa e carbono}

Neste estudo considerou-se apenas o reservatório de carbono presente na biomassa seca total das árvores, ou seja, da porção aérea e subterrânea das árvores. Incluem-se na biomassa acima do solo os seguintes compartimentos das árvores: tronco; galhos, grossos e finos, e folha, e na biomassa abaixo do solo a porção das raízes grossas e finas, até o limite de $2,0 \mathrm{~cm}$ de diâmetro.

Para isso, utilizou-se um único modelo estatístico, o qual gerou uma equação de predição de biomassa seca das árvores que considera a soma de todos os compartimentos da árvore. Esta equação foi ajustada com base nos dados originais coletados no estudo realizado por Ferez (2010). Os dados amostrais utilizados no ajuste do modelo provêm de um reflorestamento incluso na região do estudo, o qual apresenta características similares às do projeto. Foram utilizadas 20 espécies arbóreas nativas, representantes dos diferentes grupos ecológicos utilizados em projetos de restauração florestal na região. De cada espécie foram abatidos quatro indivíduos, sendo estes selecionados por apresentarem valores medianos da área seccional de cada quartil da amostragem da população da espécie no reflorestamento. Assim, a amostra total contou com 80 árvores.

Por esta equação as estimativas de biomassa são feitas por árvore. A biomassa da parcela é então determinada pelo somatório das estimativas de todas as árvores presentes na parcela. A Tabela 2.4 resume as informações referentes à determinação do modelo de predição de biomassa utilizado no estudo. 
Tabela 2.4 - Informações referentes ao ajuste do modelo de regressão utilizado no estudo para a predição da biomassa seca total das árvores

Modelo matemático de predição de biomassa seca ajustado:

$$
\ln (B)=\beta_{0}+\beta_{1} \ln (c 30)+\beta_{2} \ln (h t)+\beta_{3} \ln (d b)+\varepsilon
$$

Teste de correlação produto-momento de Pearson referente às variáveis preditoras utilizadas com relação ao logaritmo da biomassa seca:

\begin{tabular}{|c|c|c|c|c|c|}
\hline Preditores & Valor-t & Valor-p & Estimativas & \multicolumn{2}{|c|}{ IC 95\%* } \\
\hline $\log (\mathrm{c} 30)$ & 210 & $<2,2 \mathrm{e}^{-16}$ & 0,9216074 & 0,8801055 & 0,949132 \\
\hline $\log (h t)$ & 138 & $<2,2 \mathrm{e}^{-16}$ & 0,8421316 & 0,7637277 & 0,8960516 \\
\hline $\log (d b)$ & & & ignificativo & & \\
\hline
\end{tabular}

Teste $t$ para os parâmetros do modelo:

$\begin{array}{ccccc}\text { Parâmetros } & \text { Estimativas } & \text { Desvio Padrão } & \text { Valor-t } & \text { Valor-p } \\ \beta_{0} & 7,54527 & 0,65332 & 11,549 & <2 \mathrm{e}^{-16} \\ \beta_{1} & 0,97825 & 0,06225 & 15,716 & <2 \mathrm{e}^{-16} \\ \beta_{2} & 0,53264 & 0,16186 & 3,291 & 0,00152 \\ \beta_{3} & 1,06742 & 0,14390 & 7,418 & 1,42 \mathrm{e}^{-10}\end{array}$

Avaliação da qualidade do ajuste do modelo de regressão:
EPR
Graus de Liberdade
$\mathbf{R}^{2}$
0,3854
76
0,9316
$\mathbf{R}^{2}$ ajustado
0,9289

Teste de hipótese sobre a homocedasticidade dos resíduos:

$\begin{array}{ccc}\text { valor-BP } & \text { Graus de Liberdade } & \text { valor-p } \\ 51.965 & 3 & 0,158\end{array}$

Teste de hipótese sobre a normalidade dos resíduos:

valor-W

valor-p

0,9367

0,06475

\begin{abstract}
* B é a biomassa seca da árvore inteira (kg / ha); c30 é a área da secção transversal do tronco a 0,30 de altura do solo $\left(\mathrm{m}^{2}\right) ; h t$ é a altura total da árvore; $d b$ é a densidade básica da madeira da espécie $\left(\mathrm{g} / \mathrm{cm}^{3}\right) ; \beta_{0}, \beta_{1}, \beta_{2}, \beta_{3}$ são os coeficientes a serem estimados; $\varepsilon$ é o componente aleatório do modelo; IC $95 \%$ é o Intervalo de confiança com $95 \%$ de probabilidade para a estimativa do coeficiente de correlação de Pearson; EPR é o erro padrão residual da regressão linear; valor BP é o valor do teste Breusch-Pagan para homocedasticidade dos resíduos na aceitação da pressuposição do modelo, e; valor-W é o valor do teste Shapiro-Wilk para homogeneidade dos resíduos

Nota-se que o teste de correlação produto-momento de Pearson aplicado com a finalidade de detectar a correlação entre as variáveis preditoras (área da secção transversal, altura total e densidade básica da madeira) e a variável resposta (biomassa seca), apresentou valor-p abaixo de 0,01 para todos os preditores. Assim, rejeitou-se a hipótese nula, sendo
\end{abstract}


possível concluir que a correlação é diferente de zero. As estimativas de correlação para $c 30$ e $h t$ foram adequadas, mostrando um bom potencial para ajustar o modelo de regressão. Mesmo não significativa, a densidade básica da madeira foi incluída no modelo, visto que este indicador é importante para evitar predições enviesadas no desempenho do modelo, conforme discutido por Vismara (2013).

O teste t, aplicado para testar se os parâmetros do modelo de regressão são iguais (hipótese nula) ou diferente de zero (hipótese alternativa), também apresentou baixo valor-p para todos parâmetros do modelo, sendo, assim, possível a conclusão de que estes são diferentes de zero. $\mathrm{O}$ coeficiente de determinação $\left(\mathrm{R}^{2}\right)$ apresentou valor de 0,93 mostrando que o modelo apresentou bom ajuste aos dados e comprovando a existência de uma boa relação linear entre as variáveis estudadas. Na verificação dos pressupostos de normalidade dos resíduos, realizada através da aplicação do teste Shapiro-Wilk, e de homocedasticidade, avaliada a partir do teste de Breusch-Pagan, os valores-p para ambos os testes confirmam o aceite destas pressuposições para o modelo utilizado. Com todo o exposto, pode-se considerar o modelo adequado para a aplicação no presente estudo.

Para a conversão da biomassa em carbono total, adotou-se como sendo o teor de carbono na biomassa florestal igual a 0,47 (IPCC, 2011). Posteriormente para a conversão de carbono total em carbono equivalente $\left(\mathrm{CO}_{2}\right.$ eq. $)$, multiplicou-se o valor do carbono estimado por 3,66667, que representa a razão entre o peso molecular do $\mathrm{CO}_{2}$ e do carbono (44/12), resultando assim no valor de créditos comercializáveis no mercado, em $\mathrm{tCO}_{2 \text {-eq. }}$.

\subsubsection{Parâmetros e estimadores}

A partir de um delineamento amostral baseado em unidades de amostras tomadas aleatoriamente de uma população-alvo, tem-se duas opções para estimar seus parâmetros. Estas opções podem ser vistas como dois diferentes modelos estatísticos que descrevem o comportamento de alguma variável da referida população.

O primeiro é um modelo mais simples, onde os parâmetros populacionais são explicados pelas estimativas de suas médias $(\widehat{Y})$ e pelas medidas de dispersão das estimativas (variância ou desvio padrão) considerando a distribuição normal (ou Gaussiana). O segundo modelo também assume a distribuição normal das estimativas, porém usa uma informação auxiliar para estimar os parâmetros populacionais citados acima. Para melhor compreensão sobre os métodos que incorporam informações auxiliares, pesquisas podem ser feitas em Cochran (1977) e Kiregyera (1984). 
Neste estudo testou-se a aplicação e eficiência do uso do modelo que utiliza o estimador de regressão linear para as estimativas de biomassa, em comparação aos modelos convencionais que utilizam estimadores ordinários, considerando um tamanho amostral fixo definido por 111 parcelas amostrais. As estimativas dos parâmetros considerando as diferentes abordagens de amostragem utilizada neste estudo são apresentadas a seguir.

\subsubsection{Estimador ordinário para amostragem aleatória simples e estratificada}

Os estimadores abaixo descritos foram utilizados para os Sistemas de I a V descritos no item 2.2.2. Cabe observar que quando se adota a amostragem simples aleatória, a população é composta apenas por um único estrato, ou seja, não há estratificação da amostragem. Assim, os valores estimados para o estrato são, na verdade, as estimativas do parâmetro da população amostral.

O estimador da média da amostragem aleatória estratificada para cada estrato é:

$$
\bar{y}=\frac{\sum_{i=1}^{n} y_{i}}{n}
$$

onde: $\bar{y}$ é a estimativa da média do estrato, no caso o valor da biomassa (t.ha ${ }^{-1}$ ); $y$ é o valor obtido para a variável biomassa em cada unidade amostral; $i$ é o índice que identifica as parcelas de amostragem e $n$ é o tamanho da amostra no estrato.

O estimador da variância da média estimada para cada estrato é:

$$
V \widehat{A R}\{\bar{y}\}=\frac{\frac{\sum_{i=1}^{n}\left(y_{i}-\bar{y}\right)}{n-1}}{n}\left(1-\frac{n}{N}\right)
$$

onde $V \widehat{A R}\{\bar{y}\}$ é a variância da média estimada para o estrato; : $\bar{y}$ é a estimativa da média do estrato determinada na eq. (2.2); $y$ é o valor obtido para a variável em cada unidade amostral; $i$ é o índice que identifica as parcelas de amostragem, e; $n$ é o tamanho da amostra no estrato e $N$ é o tamanho do estrato.

O desvio padrão da média para cada estrato é dado por: 


$$
s \overline{d\{\bar{y}}\}=\sqrt{V \overline{A R\{\bar{y}}\}}
$$

onde $\widehat{s d\{\bar{y}}\}$ é o desvio padrão da média do estrato, e $\sqrt{V \widehat{A R\{\bar{y}}\}}$ é a variância da média estimada na eq. (2.3).

Já o intervalo de confiança da média estimada para o estrato é calculado por:

$$
I C_{90 \%}=\bar{y} \pm s \overline{d\{\bar{y}} \cdot t_{(1-\alpha, n-1)}
$$

onde IC é o intervalo de confiança; $\mathrm{t}_{(1-\alpha ; \mathrm{n}-1)}$ é o quantil da distribuição $t$ student com probabilidade $\alpha$, definida para este estudo em $90 \%$, e com $n$ - 1 graus de liberdade (g.l. $=n-1$ ), sendo $n$ o tamanho da amostra.

O total de cada estrato é obtido por:

$$
T_{h}=N_{h} \bar{y}_{h}
$$

onde: $T$ é o valor total da estimativa para cada estrato; $N$ é a área do estrato (ha); $\bar{y}$ é a estimativa da média do estrato, e; $h$ é o índice que identifica o estrato.

Para a amostragem aleatória simples, $T$ então representa o valor total da variável em análise para a toda a população. No caso da amostragem aleatória estratificada tem-se a necessidade de dar continuidade aos cálculos para a totalização em nível de população, agregando os valores das estimativas obtidas para cada estrato.

Assim, na amostragem aleatória estratificada, a média estimada da população $\left(\overline{y_{s t}}\right)$ é computada pela agregação das estimativas de cada estrato, conforme a seguir:

$$
\overline{y_{s t}}=\frac{\sum_{h=1}^{s} T_{h}}{N}
$$

onde: $\overline{y_{s t}}$ é a média estimada pelo estimador ordinário da amostragem aleatória estratificada, $s$ é o número de estratos; $h$ é o índice que identifica o estrato, e; $N$ é a área total do projeto (ha).

Já o desvio padrão estimado da população é dado por: 


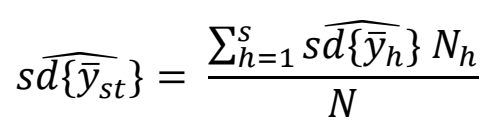

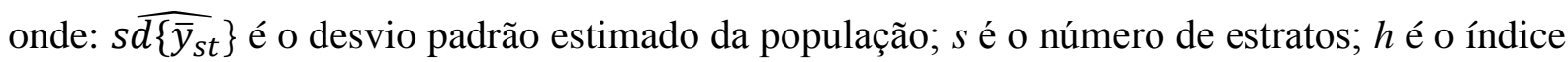
que identifica o estrato; $\left.s{\widehat{d}\left\{\bar{y}_{h}\right.}_{h}\right\}$ é o desvio padrão da média no estrato $h$; $h$ é o índice que identifica o estrato; $\mathrm{N}$ é a área total do projeto, e; $N_{h}$ é a área do estrato.

O intervalo de confiança da média estimada da população é calculado por:

$$
I C_{90 \%}=\overline{y_{s t}} \pm s{\bar{d}\left\{\bar{y}_{s t}\right\}} \cdot t_{(1-\alpha, n-1)}
$$

onde: IC é o intervalo de confiança; $\mathrm{t}_{(1-\alpha, n-1)}$ é o quantil da distribuição $t$ student com probabilidade $\alpha$, definida para este estudo em $90 \%$, e com $n-1$ graus de liberdade (g.l. $=n-1$ ), sendo $n$ o tamanho da amostra.

\subsubsection{Estimador de regressão para a amostragem aleatória simples}

Para as estimativas dos parâmetros de uma amostragem aleatória simples utilizando o estimador de regressão, tem-se as seguintes pressuposições. Supondo uma amostra aleatória, onde as variáveis $y_{i}$ e $x_{i}$ são valores obtidos para cada unidade na amostra, e a média da população $\bar{X}$ associada à $x_{i}$ é conhecida, a estimativa de regressão linear de $\bar{Y}$ (a média da população de $y_{i}$ ) é:

$$
\widehat{y_{\text {reg }}}=\beta_{0}+\beta_{1}(\bar{x})
$$

Expressando apenas em função de $b$, tem-se:

$$
\widehat{y_{\text {reg }}}=\bar{y}+\beta_{1}(\bar{X}-\bar{x})
$$

onde: $\bar{y}$ e $\bar{x}$ são as médias das amostras das variáveis $\mathrm{Y}$ e $\mathrm{X}$, no caso, a biomassa (t.ha ${ }^{-1}$ ) e NDVI, respectivamente; o índice subscrito reg indica a regressão linear, e $\beta_{1}$ é uma estimativa da variação em Y quando para X é atribuído um valor e $\beta_{0}$ é o intercepto, ambos estimados pelo método dos quadrados mínimos. 
O modelo de regressão descreve a dispersão condicional da variável principal (Y), dada uma variação da variável auxiliar (X) na população. Como observação, deve-se notar que $\bar{y}$ é a estimativa da média do método tradicional, o qual é calibrado de acordo com a variação observada da variável auxiliar representada pelo segundo termo da equação 1 $\left[\beta_{1}(\bar{X}-\bar{x})\right]$.

A única característica indesejável do estimador de regressão é o seu viés. De acordo com Shiver e Borders (1996), o viés da regressão pode ser calculado por:

$$
\text { Viés }=\frac{1}{n}
$$

onde: $n$ é o número de unidades amostrais.

No entanto, de acordo com a eq. (2.9), o estimador de regressão é assintoticamente imparcial quando $n$ é grande.

Seguindo a descrição das estimativas associadas aos estimadores de regressão, tem-se a variância desse estimador, a qual é calculada por:

$$
V A \widehat{R\left\{Y_{\text {reg }}\right\}}=\frac{s_{X . Y}^{2}}{n}\left(1-\frac{n}{N}\right)
$$

onde: $s_{X . Y}^{2}\left(=\frac{\sum_{i=1}^{n}(y i-\bar{y})^{2}-b^{2} \sum_{i=1}^{n}(x i-\bar{x})^{2}}{n-2}\right)$ é o quadrada do resíduo; $y i$ é uma observação da biomassa total $\left(\mathrm{t} \mathrm{ha}^{-1}\right)$ estimada na parcela $i$; $x i$ é o valor do índice NDVI observado na parcela $i$; $n$ é o tamanho da amostra, e; $N$ é o tamanho da população.

Cabe observar que, para a estimativa da variância, o estimador de regressão utiliza a variância condicional de cada nível de X. A variância total é a soma das variâncias de cada nível e com uma boa relação entre X e Y, sendo comumente menor do que a variância global do estimador ordinário.

O desvio padrão da média é dado por:

$$
\left.s \widehat{d\left\{\widehat{Y_{\text {reg }}}\right.}\right\}=\sqrt{\left.\operatorname{VA\widehat {R\{ Y_{\text {reg}}}}\right\}}
$$

A fórmula para calcular o intervalo de confiança para a média calculada, para esta abordagem, é a mesma aplicada no procedimento do estimador ordinário, descrita na eq. (2.9), utilizando, porém, os estimadores da média e desvio padrão populacional obtido na eq. (2.10) e eq.(2.13), respectivamente, como se segue: 


$$
I C_{90 \%}=\widehat{y_{\text {reg }}} \pm s \widehat{d\left\{\widehat{Y_{\text {reg }}}\right\} \cdot t_{(1-\alpha, n-1)}}
$$

\subsubsection{Intensidade amostral}

A intensidade de amostragem é uma função da variabilidade do parâmetro em análise, do erro máximo da amostragem admitido para as estimativas e da probabilidade de confiança fixada para as mesmas (PÉLLICO NETTO; BRENA, 1997). Neste sentido, o Comitê Executivo do Mecanismo de Desenvolvimento Limpo, tem requerido que a incerteza acerca das estimativas da média seja inferior a 10\%, em nível de confiança de $90 \%$ de probabilidade (UNFCCC, 2010), sendo esta recomendação adotada no presente estudo.

O tamanho da amostra, ou seja, o número de parcelas necessárias para a precisão requerida da estimativa da média para um dado erro desejado, é dado por:

$$
n^{*}=\frac{t^{2} S^{2} N}{N E_{d}^{2}+t^{2} S^{2}}
$$

onde: $n^{*}$ é o número de parcelas amostrais requeridas; $t$ é o valor do quantil da distribuição $\mathrm{t}$ com probabilidade 1- $\alpha$, sendo $\alpha$ definido para este estudo em $90 \%$, e $n-1$ graus de liberdade, onde $n$ é o tamanho da amostra subtraído uma unidade para cada estrato adicional existente ; $E_{d}$ é o erro desejado para a estimativa da média, definido em $10 \%$; e $N$ é o tamanho da população; e $S$ é o desvio padrão da estimativa da média, o qual varia em função do sistema de amostragem, sendo $s \widehat{d\{\bar{y}}\}$ para a amostragem aleatória, ou ainda, para um determinado estrato da amostragem estratificada (e neste caso $N$ é o tamanho do estrato), $s{\widehat{d}\left\{\bar{y}_{s t}\right\}}_{\text {para a }}$ amostragem estratificada e $s \widehat{d\left\{Y_{\text {reg }}\right\}}$ para a amostragem dupla.

Este procedimento para a determinação do número de parcelas amostrais requeridas no processo de inventário está em conformidade com a ferramenta metodológica "Cálculo do número de parcelas de amostragem para medições dentro de uma atividade do projeto de Florestamento/Reflorestamento de MDL", proposta pelo Comitê Executivo do MDL (UNFCCC, 2010).

\subsubsection{Qualidade do ajuste do modelo de regressão}


Uma das questões fundamentais na aplicação da amostragem dupla com estimador de regressão é a qualidade do ajuste do modelo de regressão. Assim, para se verificar a qualidade do estimador de regressão é necessário realizar um estudo da correlação entre as variáveis, bem como verificar o atendimento das pressuposições do modelo linear ajustado.

A fim de detectar a correlação entre a variável preditora (NDVI) e a variável resposta (biomassa) foi utilizado o teste de correlação produto-momento de Pearson. Este procedimento testa a hipótese nula de que a correlação entre as variáveis é zero contra a hipótese alternativa de que essa correlação é maior do que zero. Utilizou-se intervalo de confiança de $95 \%$ para a estimativa do coeficiente de correlação de Pearson.

O modelo de regressão linear foi ajustado, conforme a expressão abaixo:

$$
B=\beta_{0}+\beta_{1} \cdot n d v i+\varepsilon
$$

onde: $B$ é a biomassa da parcela (kg/ha); o $n d v i$ é o valor médio do NDVI da parcela; $\beta_{0}$ e $\beta_{1}$ são os coeficientes a serem estimados; e $\varepsilon$ é o erro aleatório do modelo.

Para se testar os parâmetros do modelo de regressão aplicou-se o teste- $t$ aos parâmetros no intuito de verificar se estes são iguais a zero, para a qual assume-se a hipótese nula, ou diferente de zero, para a hipótese alternativa. Adicionalmente, um gráfico de dispersão do valor de NDVI em função da biomassa, com o respectivo modelo de regressão ajustado, foi utilizado de modo a possibilitar a verificação visual da linha de tendência da regressão com relação aos dados. Por fim, é apresentado o coeficiente de determinação $\left(\mathrm{R}^{2}\right)$ para a avaliação da qualidade do ajuste do modelo de regressão.

Dentre as pressuposições assumidas para o modelo de regressão tem-se a normalidade dos resíduos e homocedasticidade da variância. O gráfico quantil-quantil é um bom instrumento para verificar a pressuposição de normalidade dos resíduos sendo aqui utilizado. Este gráfico confronta os quantis da distribuição normal padronizada contra os quantis da distribuição de resíduos do modelo. Já para verificar a pressuposição de homocedasticidade, um teste bastante utilizado é o teste de Breusch-Pagan.

\subsection{Resultados}




\subsubsection{Análise de correlação do modelo: biomassa vs. NDVI}

Primeiramente são apresentados os resultados da análise de correlação entre as variáveis em estudo, ou seja, entre a biomassa e o índice NDVI, a fim de se reconhecer a qualidade do ajuste do modelo e sua possibilidade de aplicação.

A Tabela 2.5 mostra os resultados do teste de hipótese sobre a correlação entre a variável preditora NDVI e a variável resposta biomassa, através do teste de correlação produto-momento de Pearson. De acordo com o valor- $p$ calculado, o qual foi inferior a 0,01, a hipótese nula é rejeitada, concluindo-se assim que a correlação é diferente de zero entre as variáveis em análise. A estimativa de correlação foi de 0,62515 , fato que demonstra potencial para a construção do modelo de regressão.

Tabela 2.5 - Resultados do teste de hipótese sobre a correlação entre NDVI e biomassa

\begin{tabular}{lccccc}
\hline valor $\boldsymbol{t}$ & Graus de Liberdade & valor- $\boldsymbol{p}$ & Estimativa & \multicolumn{2}{c}{ IC 95\%* } \\
\hline 8,3622 & 109 & $2,236 \mathrm{e}^{-13}$ & 0,62515 & 0,49662 & 0,72684 \\
\hline * Intervalo de confiança de 95\% para a estimativa do coeficiente de correlação de Pearson &
\end{tabular}

A Tabela 2.6 traz a estimativa e desvio padrão do parâmetro do modelo, assim como as estatísticas do teste $t$. O teste $t$ para os parâmetros do modelo de regressão, aplicados para testar se este assume a hipótese nula, no caso de serem iguais a zero, ou a hipótese alternativa, no caso de serem diferentes de zero, apresentou valor- $p$ extremamente baixo para $\beta_{1}$ e acima de 0,05 para $\beta_{0}$. O fato do intercepto não ser diferente de zero estatisticamente o mesmo faz sentido do ponto de vista das variáveis estudadas, já que, com NDVI próximo de zero a biomassa presente na área também é próxima de zero. Do ponto de vista da estimação da biomassa este detalhe não apresenta nenhuma inconveniência, já que, o estimador pode ser expresso apenas em função de $\beta_{1}$. (eq. 2.11).

Tabela 2.6 - Teste t para os parâmetros do modelo de regressão linear

\begin{tabular}{ccccc}
\hline & Estimativa & Desvio Padrão & valor-t & valor-p \\
\hline$\left(\widehat{\boldsymbol{\beta}_{\mathbf{1}}}\right)$ & $186.678,0$ & 9962 & 18,95 & $2,00 \mathrm{E}-16$ \\
$\left(\widehat{\boldsymbol{\beta}_{\mathbf{0}}}\right)$ & 5596 & 8515 & 0.657 & 0.512 \\
\hline
\end{tabular}

O valor do coeficiente de determinação do modelo ajustado, em torno de 0,7656, demonstra que o modelo se ajustou aos dados, mostrando uma adequada relação linear entre as variáveis estudadas (Tabela 2.7). 
Tabela 2.7 - Estatísticas relacionadas à avaliação da qualidade do ajustamento do modelo de regressão

\begin{tabular}{cccc}
\hline EPR* & $\begin{array}{c}\text { Graus de } \\
\text { liberdade }\end{array}$ & $\mathbf{R}^{\mathbf{2}}$ & $\begin{array}{c}\mathbf{R}^{\mathbf{2}} \\
\text { ajustado }\end{array}$ \\
\hline 43960 & 110 & 0,7656 & 0,7635 \\
\hline *EPR - erro padrão residual da regressão & \multicolumn{3}{l}{}
\end{tabular}

Por fim, ainda é necessário verificar os pressupostos de homocedasticidade e normalidade dos resíduos para aceitar o modelo ajustado. Na aplicação do teste de BreuschPagan para verificar a pressuposição homocedasticidade dos resíduos, uma vez verificado um alto valor-p ( $\geqq 0,05$ ), observa-se que a hipótese nula, a qual assume a homocedasticidade, não pode ser rejeitada (Tabela 2.8). Em outras palavras, de acordo com o teste, não há evidências de rejeição da hipótese de homocedasticidade da variância.

Tabela 2.8 - Resultados do teste de hipótese sobre a pressuposição de homocedasticidade do modelo linear adotado

\begin{tabular}{cc}
\hline $\begin{array}{c}\text { valor-BP } \\
\text { (Breusch-Pagan })\end{array}$ & valor-p \\
\hline 2,5791 & 0,1083 \\
\hline
\end{tabular}

O gráfico quantil-quantil é um bom instrumento para verificar a pressuposição de normalidade dos resíduos, sendo aplicado neste estudo. A Figura 2.1 mostra o gráfico quantilquantil da distribuição normal para a análise da relação entre a biomassa e NDVI. Este gráfico confronta os quantis da distribuição normal padronizada contra os quantis da distribuição de resíduos do modelo. Pode-se notar alguma assimetria na direita causada por algumas observações. No entanto, a maior parte das observações está em distribuição normal, demonstrando que o pressuposto de normalidade pode ser aceito.

Contudo, de acordo com as análises de correlação e regressão apresentada, pode-se considerar que o modelo demonstrou adequada correlação linear entre as variáveis e atendimento a seus pressupostos, sendo assim, a utilização da variável auxiliar NDVI como estimador de regressão na inferência sobre os estoques de biomassa no presente estudo. 


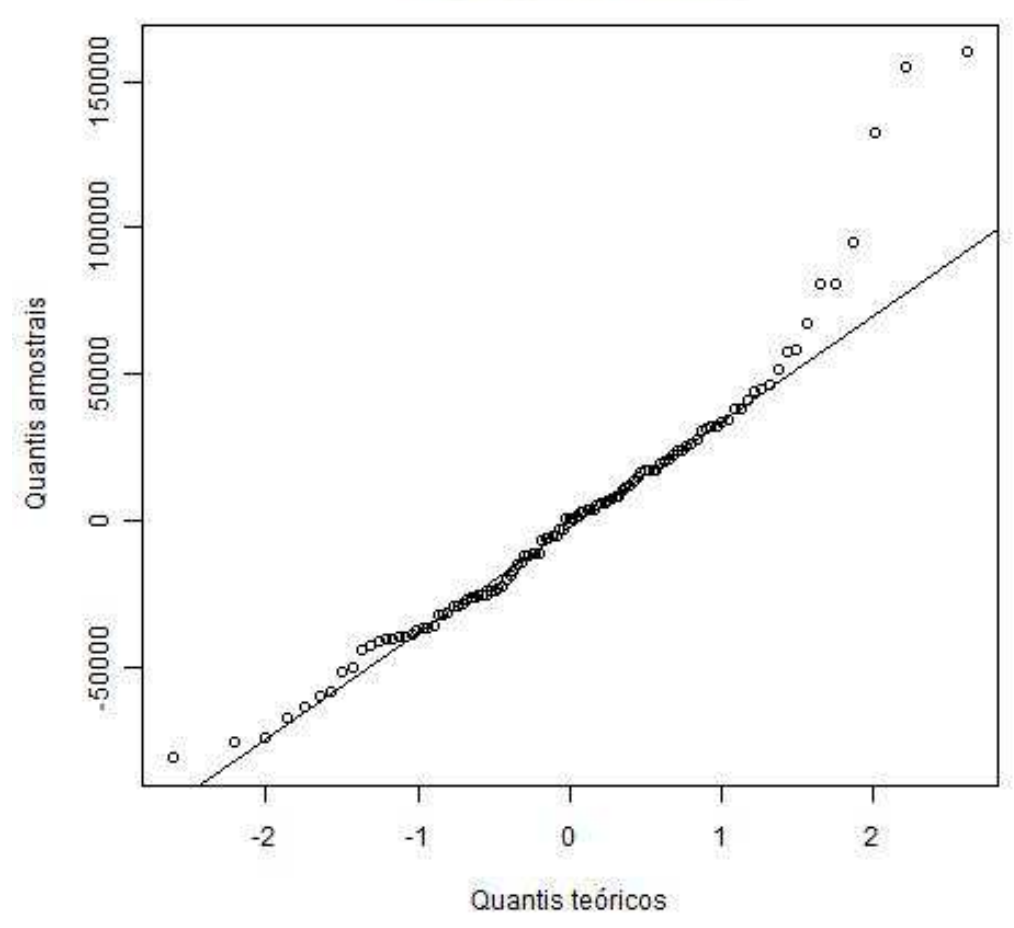

Figura 2.1 - Gráfico quantil-quantil da distribuição normal para os resíduos do modelo

\subsubsection{Estimativas de biomassa pelos diferentes processos de amostragem}

\subsubsection{Processo de amostragem utilizando o estimador ordinário}

A Tabela 2.9 apresenta o resumo da análise resultante da aplicação do estimador ordinário através dos processos de amostragem aleatória simples e aleatória estratificada, considerando, para esta última, diferentes abordagens para a estratificação das áreas de reflorestamento abrangidas pelo estudo. Incluem-se nesta tabela os diferentes estratos criados para as análises que consideram a estratificação por determinada característica do plantio, o número de parcelas inclusas na amostragem, a média de biomassa no estrato e a média ponderada pela área do estrato, e seus respectivos intervalo de confiança, a incerteza das estimativas dada em porcentagem e, por fim, o número de parcelas requeridas para atingir a suficiência amostral. 
Tabela 2.9 - Resultados das estatísticas acerca das estimativas da média de biomassa seca $\left(\right.$ t.ha $\left.{ }^{-1}\right)$ para os diferentes processos de amostragem utilizados no inventário de estoques do projeto

\begin{tabular}{|c|c|c|c|c|c|c|c|c|}
\hline \multirow[b]{2}{*}{ Estratos } & \multirow[b]{2}{*}{$\begin{array}{c}\text { Área } \\
\text { (ha) }\end{array}$} & \multirow[b]{2}{*}{$\begin{array}{l}\text { Número } \\
\text { de } \\
\text { parcelas } \\
\text { utilizadas } \\
(n) \\
\end{array}$} & \multicolumn{4}{|c|}{ Biomassa seca $\left(\right.$ t.ha $\left.{ }^{-1}\right)$} & \multirow[b]{2}{*}{$\begin{array}{c}\text { Erro } \\
\text { amostral } \\
(\%) \\
\end{array}$} & \multirow[b]{2}{*}{$n^{*}$} \\
\hline & & & $\begin{array}{c}\text { Média } \\
(\bar{y})\end{array}$ & $\operatorname{IC}_{90 \%}(\bar{y})$ & $\begin{array}{c}\text { Média } \\
\text { ponderada } \\
\text { pela área } \\
\text { do estrato } \\
\left(\overline{y_{s t}}\right) \\
\end{array}$ & $\mathbf{I C}_{\mathbf{9 0} \%}\left(\overline{y_{s t}}\right)$ & & \\
\hline \multicolumn{9}{|c|}{ Sistema I - Amostragem Aleatória Simples } \\
\hline Pop. & 2001,2 & 111 & 70,03 & {$[61,36 ; 78.70]$} & .. & .. & 12,38 & 157 \\
\hline \multicolumn{9}{|c|}{ Sistema II - Amostragem Estratificada por reservatório hidroelétrico } \\
\hline $\mathrm{AGV}$ & 365,3 & 16 & 79,32 & {$[51,58 ; 107,05]$} & 14,48 & {$[9,42 ; 19,54]$} & 34,97 & \\
\hline BAB & 110,0 & 22 & 92,16 & {$[73,17 ; 111,15]$} & 5,07 & {$[4,02 ; 6,11]$} & 20,61 & \\
\hline BAR & 113,6 & 26 & 95,38 & {$[76,45 ; 114,32]$} & 5,41 & {$[4,34 ; 6,49]$} & 19,85 & \\
\hline IBI & 275,2 & 18 & 47,64 & {$[37,18 ; 58,11]$} & 6,55 & {$[5,11 ; 7,99]$} & 21,97 & \\
\hline PRO & 1137,1 & 29 & 39,29 & {$[24,54 ; 54,04]$} & 22,32 & {$[13,94 ; 30,71]$} & 37,54 & \\
\hline Pop. & 2001,2 & 111 & .. & .. & 53,84 & {$[44,15 ; 63,52]$} & 17,99 & 210 \\
\hline
\end{tabular}

Sistema III - Amostragem Estratificada por ano de plantio

$\begin{array}{ccccccccc}2001-02 & 762,7 & 46 & 104,29 & {[90,55 ; 118,04]} & 39,75 & {[34,51 ; 4,98]} & 13,18 \\ 2004-05 & 414,6 & 33 & 72,48 & {[60,82 ; 84,15]} & 15,02 & {[12,60 ; 17,43]} & 16,09 & \\ 2007 & 69,8 & 6 & 30,82 & {[22,85 ; 38,80]} & 1,08 & {[0,80 ; 1,35]} & 25,88 & \\ 2009-10 & 754,2 & 26 & 15,35 & {[11,50 ; 19,21]} & 5,79 & {[4,33 ; 7,24]} & 25,08 & \\ \text { Pop. } & \mathbf{2 . 0 0 1 , 2} & \mathbf{1 1 1} & \mathbf{. .} & \mathbf{. .} & \mathbf{6 1 , 6 2} & {[\mathbf{5 5 , 7 6 ; ~ 6 7 , 4 9}]} & \mathbf{9 , 5 2} & \mathbf{8 2}\end{array}$

Sistema IV - Amostragem Estratificada por NDVI médio da área discreta

$\begin{array}{ccccccccc}<0,25 & 604,7 & 28 & 20,26 & {[14,61 ; 25,91]} & 6,12 & {[4,42 ; 7,83]} & 27,89 & \\ 0,25-0,50 & 1.024,8 & 51 & 72,26 & {[61,46 ; 83,07]} & 37,01 & {[31,47 ; 42,54]} & 14,95 & \\ >0,5 & 371,7 & 32 & 113,40 & {[97,28 ; 129,52]} & 21,06 & {[18,07 ; 24,06]} & 14,22 & \\ \text { Pop. } & \mathbf{2 . 0 0 1 , 2} & \mathbf{1 1 1} & \mathbf{. .} & \mathbf{. .} & \mathbf{6 4 , 1 9} & {[\mathbf{5 7 , 7 6 ; 7 0 , 6 2}]} & \mathbf{1 0 , 0 2} & \mathbf{9 9}\end{array}$

Sistema V - Amostragem Estratificada por NDVI independente

$\begin{array}{ccccccccc}<0,25 & 634,6 & 28 & 20,26 & {[14,61 ; 25,91]} & 6,43 & {[4,63 ; 8,22]} & 27,89 & \\ 0,25-0,50 & 928,5 & 51 & 72,26 & {[61,46 ; 83,07]} & 33,53 & {[28,51 ; 38,54]} & 14,95 & \\ >0,5 & 438,1 & 32 & 113,40 & {[97,28 ; 129,52]} & 24,83 & {[21,30 ; 28,36]} & 14,22 & \\ \text { Pop. } & \mathbf{2 . 0 0 1 , 2} & \mathbf{1 1 1} & \mathbf{. .} & \mathbf{. .} & \mathbf{6 4 , 7 8} & \mathbf{5 8 , 4 9 ; 7 1 , 0 7 ]} & \mathbf{9 , 7 1} & \mathbf{9 6}\end{array}$

*IC $90 \%$ representa o Intervalo de Confiança à $90 \%$ de probabilidade; $n *$ é o número de parcelas amostrais requeridas; Pop. indica os valores estimados para a população com base na média ponderada pela área do estrato

A biomassa média estimada pelo Sistema I, o qual considera a amostragem simples aleatória foi de 70,03 t.ha ${ }^{-1}$, com intervalo de confiança de 61,36 a 78,70 t.ha ${ }^{-1}$ para a média estimada. O erro amostral associado a esta estimativa foi $12,38 \%$ e o número de parcelas 
necessárias para um erro de $10 \%\left(n^{*}\right)$, em nível de $90 \%$ de probabilidade, foi de 157 unidades amostrais, ou seja, estima-se que deveriam ser utilizadas na amostragem da população mais 46 parcelas para se atingir a suficiência amostral para a estimada da média com o erro admissível considerado de $10 \%$.

A média de biomassa estimada pelo Sistema II, no qual aplicou-se amostragem simples estratificada, tendo como critério de estratificação a região do reservatório hidroelétrico, foi de 53,84 t.ha ${ }^{-1}$ com estimativa dentro do intervalo de confiança de 44,15 a 63,52 t.ha $^{-1}$, sendo o erro amostral associado à estimativa da média de 17,99\%, com valor de $n^{*}$ igual a 210 parcelas. Observa-se serem altas as incertezas acerca da estimativa da média individuais dos estratos, sempre maiores que 20\%. O cálculo da intensidade amostral requerida, com base nos dados das atuais 111 parcelas de inventário utilizadas no estudo, apontam para a necessidade de, ao menos, mais 98 parcelas para atingir a suficiência amostral, ou seja, uma quantidade $89 \%$ maior em relação ao número de parcelas utilizadas no estudo.

O Sistema III, o qual considera a amostragem estratificada por classes de idade de plantio, apresentou média de 61,62 t.ha ${ }^{-1}$ com intervalo de confiança da estimativa da média de 55,76 a 67,49 t.ha ${ }^{-1}$, com erro amostral relativo de 9,52\%, valor este inferior ao máximo requerido para o estudo que é de $10 \%$. Tal fato contribui para que no cálculo do número de parcelas necessárias com base neste sistema de amostragem, que foi de 82 parcelas, fosse inferior ao número de parcelas aplicado ao estudo.

Neste sistema é interessante notar haver certa coerência no acúmulo de biomassa em função da idade do plantio, sendo maiores as biomassas, quanto mais antigos são os plantios. Os plantios de 2001 e 2002, cuja medição das áreas ocorreu aproximadamente 10 anos após o plantio, apresentaram biomassa média estimada em 104,29 t.ha ${ }^{-1}[90,55 ; 118,04]$. Os plantio de 2004 e 2005, com idade média entre 7 e 8 anos, apresentou média de biomassa de 72,48 t.ha $^{-1}[60,82 ; 84,15]$. Já os plantios de 2007, com 5 anos de idade, apresentaram média de 30,82 t.ha $^{-1}[22,85 ; 38,80]$, e os plantios de 2009 e 2010, com 2 a 3 anos de idade, a média de biomassa estimada foi de 15,35 t.ha $^{-1}[11,50 ; 19,21]$. A Figura 2.2 apresenta um gráfico ilustrando esta tendência. 


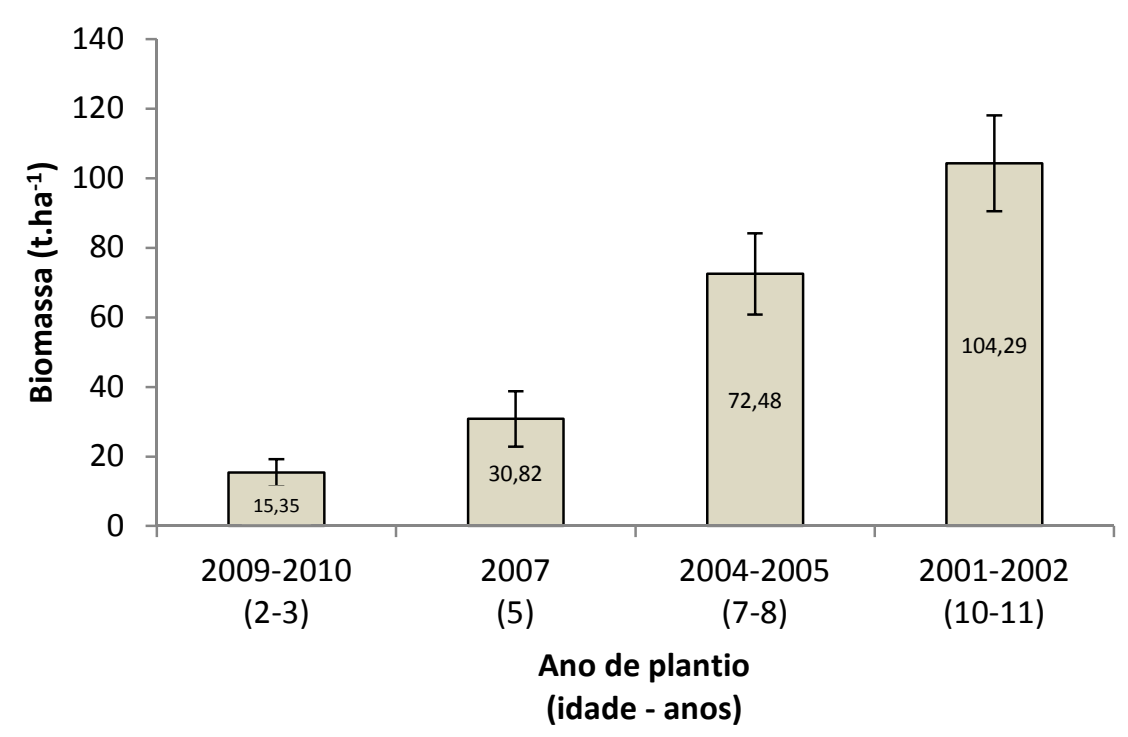

Figura 2.2 - Biomassa média $\left(\right.$ t.ha $\left.^{-1}\right)$ por ano de plantio dos reflorestamentos (barras indicam o intervalo de confiança da média)

Os erros amostrais associados às estimativas das médias nos estratos foram menores nos plantios mais antigos, com 13,18\% e 16\% respectivamente, para as classes 2001-02 e 2004-05, e maiores nas classes de 2007 e 2009-10, cuja incerteza girou em torno de $25 \%$. Porém, considerando a média da população obtida por este processo de amostragem, as incertezas associadas a esta estimativa foi a que apresenta-se menor entre todos os sistemas testados.

O Sistema IV, o qual considera três estratos definidos pela média de NDVI de cada área discreta do projeto em estudo, apresentou estimativa da média de biomassa de 64,19 t.ha ${ }^{-}$ 1, com intervalo de confiabilidade entre 57,76 e 70,62 t.ha ${ }^{-1}$, resultando em incerteza de $10,02 \%$ e $n *$ igual a 99 parcelas. Já o Sistema V, apresentou estimativa da média de biomassa de 64,78 t.ha $^{-1}$ e intervalo de confiança desta estimativa de 58,49 a 71,07 t.ha ${ }^{-1}$, com 9,71\% de incerteza, gerando valor $n *$ igual a 96 parcelas.

É importante notar que as estimativas das médias por estratos obtidas nos Sistemas IV e V são idênticas (Tabela 2.9). A diferença está na totalização das áreas dos estratos definidos pelos diferentes métodos de estratificação utilizando o NDVI, os quais geram médias, ponderadas pela área dos estratos, distintas. Outra observação é com relação aos valores médios de biomassa nas classes de NDVI, os quais são diretamente proporcionais aos valores do NDVI, ou seja, à medida que cresce o valor do intervalo de classe deste índice, aumenta o valor da biomassa média estimada, demonstrando possível correlação entre estas variáveis, fato confirmado nas análises de correlação entre estas variáveis realizadas neste estudo (Figura 2.3). Para o estrato considerando a classe de NDVI $<0,25$, a biomassa média 
estimada foi de 20,26 t.ha ${ }^{-1}$ [I.C.: 14,61; 25,91], para a classe de valores de NDVI entre 0,250,5, a média foi de 72,26 t.ha ${ }^{-1}$ [I.C.: 61,$\left.46 ; 83,07\right]$, e para a classe de NDVI > 0,5, a média foi de 113,40 t.ha $^{-1}$ [I.C.: 97,28; 129,52].

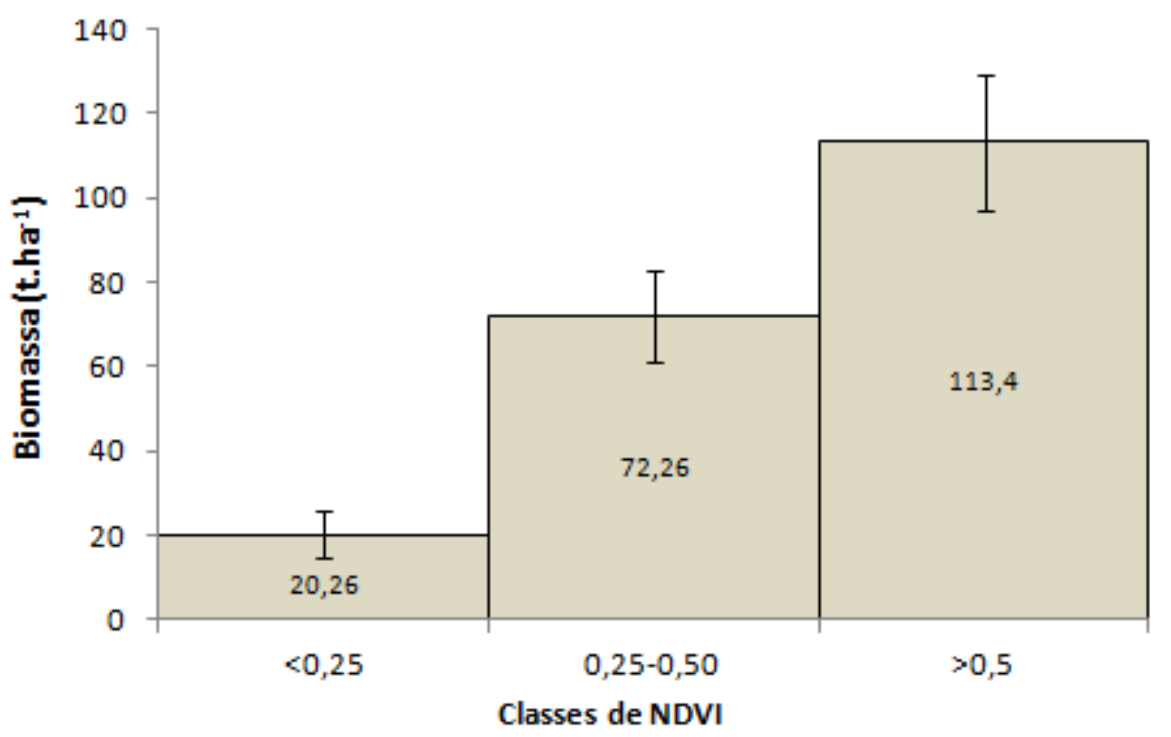

Figura 2.3 - Biomassa média $\left(\mathrm{t} \mathrm{ha}^{-1}\right.$ ) por classes de NDVI (barras expressam o intervalo de confiança da média)

\subsubsection{Processo de amostram utilizando o estimador de regressão}

As Tabelas 2.10 e 2.11 resumem a análise resultante da aplicação do estimador de regressão para o delineamento da amostragem dupla.

Tabela 2.10 - Valores das estatísticas utilizadas para obtenção das estimativas da média de biomassa (t.ha ${ }^{-1}$ ) e da biomassa total (toneladas) da população estudada pelo estimador de regressão

\begin{tabular}{cccccc}
\hline $\begin{array}{c}\text { Número de } \\
\text { parcelas } \\
(\mathbf{n})\end{array}$ & $\begin{array}{c}\text { Média de NDVI nas } \\
\text { parcelas } \\
(\overline{\boldsymbol{x}})\end{array}$ & $\begin{array}{c}\text { Média da } \\
\text { biomassa da } \\
\text { amostra } \\
(\overline{\boldsymbol{y}})\end{array}$ & $\begin{array}{c}\text { NDVI médio } \\
\text { da população } \\
(\overline{\boldsymbol{X}})\end{array}$ & $\begin{array}{c}\text { Estimativa } \\
\text { do } \\
\text { parâmetro } \\
\boldsymbol{\beta}_{\mathbf{1}}\end{array}$ & $\begin{array}{c}\text { Desvio } \\
\text { padrão } \\
\text { de } \boldsymbol{\beta}_{\mathbf{1}}\end{array}$ \\
\hline 111 & 0,368362 & 70,03 & 0,333329 & $186.678,0$ & $(9,962)$ \\
\hline
\end{tabular}

Tabela 2.11 - Valores da estimativa da média de biomassa (t.ha ${ }^{-1}$ ) da população usando o estimador de regressão

\begin{tabular}{ccccc}
\hline $\begin{array}{c}\text { Estimativa da } \\
\text { média da biomassa } \\
\left(\mathbf{t . h a}^{-1}\right)\end{array}$ & $\begin{array}{c}\text { Desvio padrão da } \\
\text { estimativa } \\
\left(\mathbf{t . h a}^{-1}\right)\end{array}$ & $\begin{array}{c}\text { Intervalo de } \\
\text { confiança }(\mathbf{9 0 \%}) \\
\text { da média } \\
\left(\mathbf{( t . h a}^{-1}\right)\end{array}$ & $\begin{array}{c}\text { Erro } \\
\text { amostral } \\
(\%)\end{array}$ & $\begin{array}{c}\text { Tamanho de } \\
\text { amostra } \\
\text { requerida } \\
\left(\mathbf{n}^{*}\right)\end{array}$ \\
\hline 62,23 & $\left(\sqrt{\left.V A \widehat{R\left\{\widehat{y_{\text {reg }}}\right\}}\right)}\right.$ & {$[55,89 ; 68,56]$} & 10,17 & 110 \\
\hline
\end{tabular}


O NDVI médio da população $(\bar{X})$ foi igual a 0,333329 . Cabe ressaltar que esta é a média de NDVI sem erro amostral, já que foi obtida através do censo populacional, com base em 800.496 observações. O NDVI médio $(\overline{\boldsymbol{x}})$ das 111 parcelas utilizadas na amostragem da biomassa da população foi de 0,3683617 , sendo o intervalo de confiança desta média, a 90\% de probabilidade, de 0,3306975 a 0,4060259. Nota-se que este intervalo incorpora a média real de NDVI da população; desta forma pode se considerar que a amostragem do NDVI das parcelas foi eficiente também em estimar este parâmetro populacional. A média de biomassa estimada através do estimador de regressão foi de 62,23 t.ha ${ }^{-1}$, com intervalo de confiança entre 55,89 e 68,56 t.ha ${ }^{-1}$. A incerteza associadas a esta estimativa foi de 10,18\%. Neste processo de amostragem, o cálculo do tamanho de amostra requerido mostra-se nulo, já que a incerteza em relação à estimativa da biomassa de $10,17 \%$ é praticamente igual ao erro desejado de $10 \%$.

A dispersão em torno da média da amostra de biomassa, quando utilizado o estimador ordinário na amostragem aleatória simples (Sistema I), foi maior do que a dispersão em torno da média condicional do estimador de regressão (Sistema V). A Figura 2.4 mostra o ganho que se tem utilizando a variável auxiliar para explicar a dispersão condicional da estimativa da média no levantamento da biomassa.

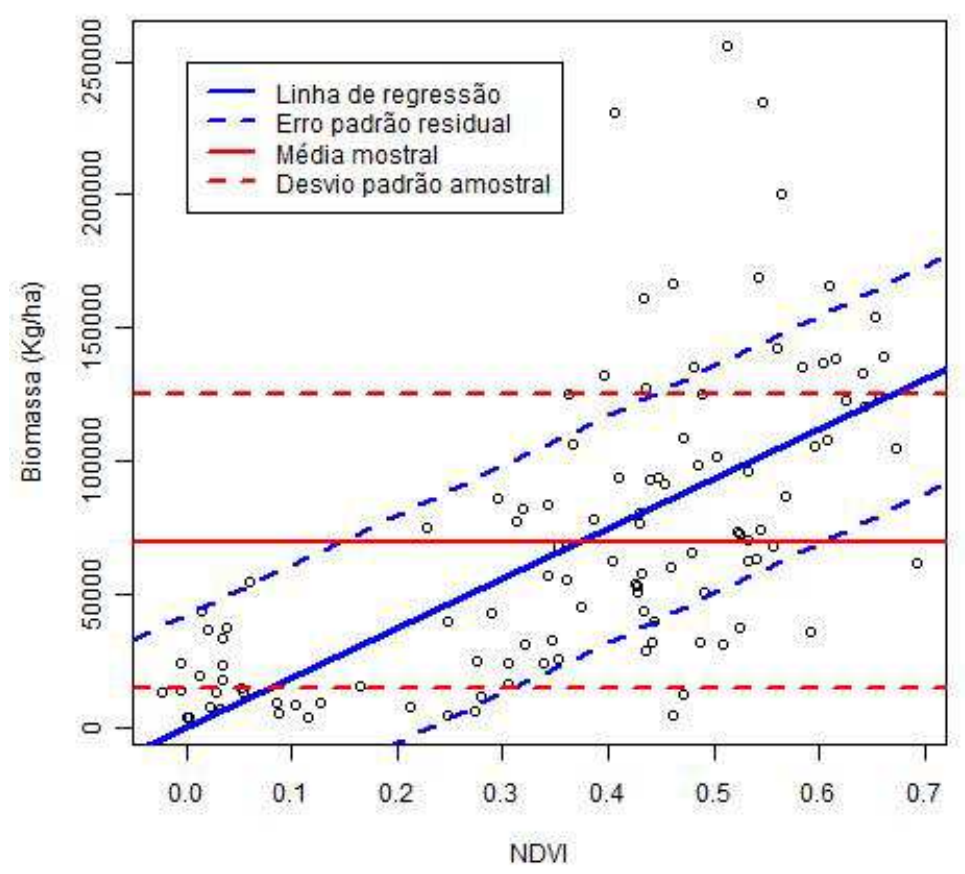

Figura 2.4 - Dispersão acerca das estimativas da média do modelo utilizando o estimador ordinário em comparação ao modelo com o estimador de regressão, demonstrando a linha de tendência de ambos os modelos 


\subsubsection{Estimativas de carbono equivalente para o projeto}

As estimativas das médias de biomassa por hectare determinadas através dos diferentes processos de amostragem, apesar de apresentarem diferenças as quais podem ser consideradas pequenas, quando utilizadas na extrapolação para a área total do projeto para se obter as estimativas totais de carbono equivalente do projeto - unidade de comercialização de créditos no mercado do MDL - estas diferenças tornam-se grandes em termos de valores absolutos (Tabela 2.12). Estes variam de $241.523 \mathrm{tCO}_{2 \text {-eq }}$, para a amostragem simples aleatória (Sistema I), a 185,663 $\mathrm{tCO}_{2 \text {-eq }}$ para a amostragem estratificada por reservatório (Sistema II), com valores intermediários a estes valores para os demais métodos (Sistemas III,

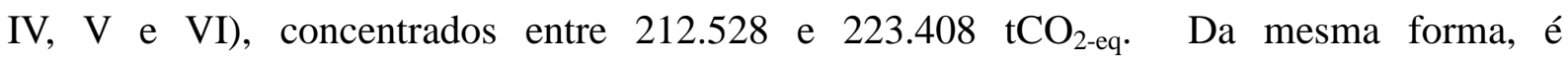
proporcionalmente amplo o intervalo de confiança acerca destas estimativas dos totais para o projeto, sendo esta amplitude menor, obviamente, quanto menor as incertezas associadas à estimativa.

Tabela 2.12 - Estimativas da média de carbono equivalente $\left(\mathrm{t}_{\mathrm{eq}}\right)$ para a área total do projeto e respectivos valores do desvio padrão e intervalo de confiança associados

\begin{tabular}{clccc}
\hline & & $\mathbf{C O}_{\text {2-eq }}$ total do \\
projeto & & \\
Sistemas & \multicolumn{1}{c}{ Tipo de amostragem } & $(\mathbf{t})$ & IC $_{\mathbf{9 0} \%}$ \\
\hline I & Simples aleatória & 241.523 & {$[211.618 ; 271.429]$} \\
II & Estratificada (reservatório) & 185.663 & {$[152.265 ; 219.061]$} \\
III & Estratificada (idade de plantio) & 212.528 & {$[192.293 ; 232.763]$} \\
IV & Estratificada (NDVI - área discreta) & 221.391 & {$[199.213 ; 243.569]$} \\
V & Estratificada (NDVI - independente) & 223.408 & {$[201.706 ; 245.111]$} \\
VI & Amostragem dupla & 214.602 & {$[192,763.236 .442]$} \\
\hline
\end{tabular}

\subsection{Discussão}

Em relação ao conservadorismo da estimativa da média da biomassa por unidade de área, quando esta foi obtida através do estimador de regressão $\left(\widehat{y_{\text {reg }}}\right)$, a estimação foi mais conservadora do que quando utilizada a média simples da amostra $(\bar{y})$, com valor de biomassa média de 64,4 t.ha $^{-1}$ para a primeira, contrapondo ao valor de 70,03 t.ha ${ }^{-1}$ para a segunda situação. Por outro lado, foi menos conservador do que quando a estimativa foi obtida pelo estimador ordinário aplicado ao delineamento da amostragem aleatória estratificada por 
reservatório, a qual apresentou média de 53,84 t.ha ${ }^{-1}$. Porém, neste caso, as incertezas associadas a esta estimativa, que foi de $17,99 \%$, não assegura a precisão desejada para o inventário.

Comparando as estimativas da média de biomassa do estimador de regressão às estimativas realizadas pelos métodos III e IV, os quais também utilizam o NDVI, mas como critério para a estratificação da população, observa-se que os valores são muito próximos, já que para estes métodos de inventário obtiveram-se médias de 64,19 e 64,78 t.ha ${ }^{-1}$, respectivamente. $\mathrm{O}$ valor mais próximo à média da biomassa obtida pelo estimador de regressão foi apresentado pelo Sistema III, o qual utiliza classes de idade de plantio na estratificação da amostragem. Este método apresentou média de 61,62 t.ha ${ }^{-1}$.

Para os métodos utilizando o estimador ordinário, a intensidade amostral aplicada ao estudo expressou-se suficiente para os Sistemas III, IV e V, e insuficiente para os Sistemas I e II. Esta insuficiência relaciona-se às incertezas associadas às estimativas das médias da biomassa, a qual apresentou-se insatisfatória às premissas pré-definidas para o estudo, que foi de erros máximos em torno de $10 \%$.

Os Sistemas de amostragem III, IV, V e VI apresentaram suficiência de intensidade amostral, conforme demonstrado no cálculo de $n^{*}$, cujos valores apresentaram-se inferiores ao número de parcelas utilizadas no estudo para estes métodos. A menor incerteza associada à estimativa da média foi apresentada pelo Sistema III, com 9,52\%.

Para os métodos utilizando o NDVI (Sistemas IV, V e VI), as incertezas associadas às estimativas da média também foram satisfatórias e com certa similaridade entre os valores, variando de $9,71 \%$ a $10,18 \%$, sendo este último valor relacionado ao método do estimador de regressão (Sistema VI).

Relativo à precisão do uso do estimador de regressão para o estudo da quantificação de biomassa em projetos de carbono, este foi mais preciso em estimar a média do que o estimador ordinário. A precisão foi verificada pela amplitude do intervalo de confiança e o respectivo nível de incerteza. Neste sentido, Matloff (1981) também comparou a estimativa da média incondicional da variável Y com a estimativa linear da média da variável Y, demonstrando que esta estimativa melhora substancialmente a estimativa sobre um estimador ordinário. Jewell e Queensberry (1986) utilizaram um método de regressão iterativo em amostra estratificada e demonstrou que o estimador linear apresenta uma grande superioridade, em termos de eficiência, na estimativa da média.

Em projetos de Florestamento/Reflorestamento é comum definir a idade do plantio como critério para a estratificação das amostras da população. Contudo, em se tratando de 
projetos de reflorestamentos para a restauração florestal, diferentes fatores podem influenciar seu desenvolvimento e, consequentemente, a variabilidade das estimativas de biomassa e carbono dentro do estrato definidos por este critério.

A variabilidade entre reflorestamentos de mesma idade podem ser decorrentes dos seguintes fatores: das propriedades físico-químicas do solo, influenciando a qualidade do sítio e desenvolvimento do plantio; da aplicação de tratos silviculturais de implantação e manejo dos reflorestamentos em intensidade distinta; da densidade de plantas definida pelo espaçamento de plantio adotado; das condições climáticas e pluviométricas, as quais podem variar se o projeto abranger amplas extensões regionais, da dinâmica dos ciclos biogeoquímicos intrínsecas de cada localidade; e, ainda, da composição das espécies utilizadas no modelo e suas inter-relações na dinâmica da sucessão ecológica da área em restauração, ditando a trajetória do comportamento das variáveis biofísicas em estudo.

No entanto, esta variabilidade não foi expressiva neste estudo a ponto de causar interferências substanciais ao método de amostragem estratificada por idade (Sistema III), que pudesse influenciar de modo significativo a precisão das estimativas e intensidade amostral requerida. Isto porque os reflorestamentos avaliados neste estudo de caso apresentam uma certa homogeneidade devido a padronização dos modelos e procedimentos operacionais de implantação e manutenção desses sistemas pela empresa responsável.

No entanto, reconhece-se a existência de diferentes métodos e modelos passíveis de aplicação para desencadear o processo de restauração, sendo os reflorestamentos com espécies nativas em alta diversidade e tecnologia apenas um dos métodos possíveis. Deste modo, existindo diferentes métodos e modelos aplicados em determinado projeto, muito provavelmente estas áreas apresentaram condições distintas de crescimento e acúmulo de biomassa. Assim, as áreas discretas equiâneas projeto poderão apresentar tanto sistemas florestais de alta complexidade estrutural e florística, com alto acúmulo de biomassa e carbono, até mesmo área onde o estoque é praticamente nulo, devido ao insucesso pleno das intervenções para a restauração florestal. Nestes casos, a utilização do NDVI vem a ser uma alternativa para contornar esse problema de heterogeneidade das condições das áreas de um projeto.

O uso do NDVI aplicado para auxiliar a estratificação da amostragem demonstrou-se eficiente neste estudo. Pode-se notar que ocorreu um crescimento proporcional das estimativas de biomassa quanto maior a classe do intervalo do NDVI do estrato. No entanto, ressalta-se que foram observadas ocorrências de algumas parcelas com valores discrepantes da média, tanto para mais, quanto para menos, com relação à média do estrato. Esta 
ocorrência pode estar associada: à densidade das copas das árvores nativas presentes no plantio, se densa ou rala, alterando a relação do valor deste índice com a biomassa; e à influência da vegetação herbácea na composição do valor do NDVI das parcelas, no caso dos plantios novos, aumentando o valor do índice para áreas com baixo estoque de biomassa lenhosa das árvores.

Contudo, a correlação entre as variáveis biomassa e NDVI foi comprovada. Tem-se assim, boas possibilidades para a aplicação do estimador de regressão envolvendo estas variáveis. Neste sentido, Sader et al. (1989) observaram que quando as condições do terreno não são altamente variáveis, o NDVI computado apresentou-se como um bom preditor da biomassa total.

Em relação ao viés intrínseco do estimador de regressão, este foi considerado como irrelevante para o presente estudo, já que o tamanho da amostra utilizada foi grande (111 unidades amostrais). Com tal tamanho amostral este viés expressou-se menor do que $1 \%$ (viés $=1 / 111$ ).

No sistema do estimador de regressão, se para uma variável a precisão da média está condicionada a incertezas nas estimativas devido à baixa intensidade amostral, para a outra, esta incerteza é teoricamente nula, já que o valor médio da população, no caso o NDVI, é obtido através de censo populacional.

Neste sentido, reconhecem-se possíveis fontes de erros nos procedimentos relacionados à obtenção dos valores de NDVI, tais como: o georeferenciamento das imagens, das parcelas e das áreas discretas do projeto; a época do ano do mapeamento pelo sensor remoto; os efeitos da interferência atmosférica; e os possíveis erros induzidos pelo homem na manipulação de dados. Assegura-se que todas estas fontes de erros foram minimizadas em seu máximo, através da utilização de método adequados de retificação de imagens de satélite RapidEye de alta resolução, obtenção de dados georreferenciados em campo com o uso de GPS operando em escala submétrica, e execução dos procedimentos automáticos para extração de dados dos valores do índice NDVI.

Com isso, é possível afirmar que a metodologia utilizada, aplicando o NDVI como variável auxiliar do estimador de regressão para a estimativa do estoque de biomassa e carbono, quando as fontes de erros na obtenção deste índice são minimizadas, demostrou-se útil e pode ser aplicada em estudos de quantificação de carbono em projetos desta modalidade. 


\subsection{Conclusão}

O índice de vegetação NDVI demonstrou correlação positiva com a biomassa presente nos reflorestamentos de espécie nativa da área do estudo. Desta forma, este índice pode ser utilizado tanto para auxiliar na determinação de estratos, na aplicação da amostragem estratificada, assim como variável auxiliar do estimador de regressão em estudos relacionados à estimativa de biomassa e carbono de florestas, principalmente os vinculados à modalidade de atividade de projeto de florestamento/reflorestamento voltados ao mercado de carbono desenvolvido na Mata Atlântica. Assim, o uso do NDVI passa a ser uma ferramenta de relevante aplicabilidade nos estudos de biomassa deste tipo de projeto, especialmente nos quais não se tem um controle padronizado de alguns fatores, como por exemplo, da idade de plantio, das práticas silviculturais e dos métodos de intervenção para a restauração.

Neste sentido, o modelo utilizando o estimador de regressão, relacionando a biomassa e o NDVI, através da amostragem dupla, demonstrou-se confiável para a aplicação. Este processo de amostragem foi capaz de minimizar as incertezas acerca das estimativas, valendose de uma intensidade amostral reduzida se comparado ao processo de amostragem simples aleatória. Assim, esta metodologia torna-se útil para aplicação especialmente em estudos que abrangem amplos limites territoriais, onde a logística de implantação de parcelas de monitoramento em grandes quantidades encontra barreiras da ordem operacional e de custo.

\section{Referências}

AMARAL, L.P.; FERREIRA, R.A.; WATZLAWICK, L.F; GENÚ, A.M. Análise da distribuição espacial de biomassa e carbono arbóreo acima do solo em Floresta Ombrófila Mista. Revista Ambiência (Edição Especial), Guarapuava, v.6, p. 103-114, 2010.

BOYD, D. S. The relationship between the biomass of Cameroonian tropical forests and radiation reflected in middle infrared wavelengths (3.0-5.0 $\mathrm{mu} \mathrm{m})$. International Journal of Remote Sensing, London, v. 20, n. 5, p. 1017-1023, 1999.

CAMPBELL, J. B. Introduction to remote sensing. New York: The Guilford Press, 1996. $622 \mathrm{p}$.

COCHRAN, W.G. Sampling Techniques. $3^{\text {nd }}$ ed. New York: John Wiley \& Sons, 1977. 428p.

CORLETT, R. T. Tropical secondary forests. Progress in Physical Geography, London, v. 19, p. 159-172, 1995. 
FEREZ, A. P. C. Efeito de práticas silviculturais sobre as taxas iniciais de sequestro de carbono em plantios de restauração da Mata Atlântica. 2010. 108 p. Dissertação

(Mestrado em Ciência) - Escola Superior de Agricultura "Luiz de Queiroz" - Universidade de São Paulo, Piracicaba, 2010.

FOODY, G. M.; BOYD, D. S.; CUTLER, M. E. J. Predictive relations of tropical forest biomass from Landsat TM data and their transferability between regions. Remote Sensing of Environment, New York, v. 85, p. 463-474, 2003.

FOODY, G. M.; CUTLER, M. E.; MCMORROW, J.; PELZ, D.; TANGKI, H.; BOYD, D. S.; DOUGLAS, I. Mapping the biomass of Bornean tropical rain forest from remote sensed data. Global Ecology \& Biogeography, Oxford, v. 10, p. 379-387, 2001.

FREITAS, S. R.; MELLO, M. C.S.; CRUZ, C.B.M. Relationships between forest structure and vegetation indices in Atlantic Rainforest. Forest Ecology and Management, Wisconsin, v. 218, n. 1/3, p. 353-362, 2005.

GAMON, J.A.; FIELD, C.B.;GOULDEN, M.L.; GRIFFIN, K.L.; HARTLEY, A.E.; JOEL, G.; PEÑUELAS, J.; VALENTINI, R. Relationships Between NDVI, Canopy Structure, and Photosynthesis in Three Californian Vegetation Types. Ecological Applications, Washington, DC, v. 5, n. 1, p. 28-41, 1995.

JEWELL, N.P. Queensberry, C.P. Regression Analysis Based on Stratified Sample.

Biometrika, v. 73, n. 3, p. 605-661, 1986.

KANGAS, J.; IOJA, R.; LESKINEN, P.; MEHTÄTALO. Improving the quality of landscape ecological forest planning by utilising advanced decision-support tools. Forest Ecology and Management, Wisconsin, v. 132, n. 2/3, p. 157-171, 2000.

LEAL, F.A. Técnicas de sensoriamento remoto e geoestatística aplicadas em um povoamento de Eucalyptus urophylla S. T. Blake para estimativa de volume. Dissertação (Mestrado em Ciências Florestais). 2013. 96p. Departamento de Engenharia Floresta, Universidade de Brasília, 2013.

MASELLI, F.; CHIESI, M.; FIBBI, L.; MORIONDO, M.; BINDI, M. Estimating net forest carbon fluxes by the integration of ground and remote sensing data. Italian Journal of Remote Sensing, Firenze, v. 41, n. 2, p. 97-108, 2009.

MATLOFF, N.S. Use of regression functions for improved estimation of means.

Biometrika, Oxford, v. 68, n.3, p. 685-689, 1981.

MATOS, F.D.A.; KIRCHNER, F. F. Estimativa de biomassa da floresta ombrófila densa de terra firme na Amazônia Central com o satélite IKONOS II. Floresta, Curitiba, v. 38, n. 1, p. 157-171, 2008.

MELLO, J.M. de. Geoestatística aplicada ao inventário florestal. 2004. 110 p. Tese (Doutorado em Recursos Florestais) - Escola Superior de Agricultura "Luiz de Queiroz", Universidade de São Paulo, Piracicaba, 2004.

KIREGYERA, B. Regression-type estimators using two auxiliary variables and the model of double sampling from finite populations. Metrika, Oxford, v. 31, n. 1, p. 215-226, 1984. 
ROUSE, J.W.; HAAS, R.H.; SCHELL J. A.; DEERING, D.W. Monitoring vegetation systems in the great plains with ERTS. In: EARTH RESOURCES TECHNOLOGY SATELLITE - 1 SYMPOSIUM, 3., Washington, 1973. Proceedings... Washington, D.C.: NASA. Goddart Space Flight Center, v.1, p.309-317, 1973.

ROUSE, J.W.; HAAS, R.H.; DEERING, D.W.; SCHELL, J.A.; HARLAN, J.C. Monitoring the vernal advancement and retrogradation (green wave effect) of natural vegetation; NASA/GSFC Type III Final Report, Greenbelt, MD, 1974, 371 p.

SADER, S.A.; WAIDE, R.B.; LAWRENCE, W.T.; JOYCE, A.T. Tropical forest biomass and successional age class relationships to a vegetation index derived from Landsat TM data. Remote Sensing of Environment, New York, v. 28, n. 0, p. 143-198, 1989.

SHIVER, B.D.; BORDERS, B.E. Sampling techniques for forest resource inventory. New York: John Wiley, 1996, 356p.

TAN, K.; PIAO, S.; PENG, C.; FANG, J. Satellite-based estimation of biomass carbon stocks for northeast China's forests between 1982 and 1999. Forest Ecology and Management, Wisconsin, v. 240, n. 1/3, p. 114-121, 2007.

UNITED NATIONS FRAMEWORK CONVENTION ON CLIMATE CHANGE UNFCCC. Aforestation/reforestation Methodological tool: Calculation of the number of sample plots for measurements within A/R CDM project activities. Report. CDM-EB 58, Annex 15 Version 02.1.0, Nov. 2010, 7p.

Guidelines on application of specified versions of A/R CDM methodologies in verification of registered A/R CDM project activities. Report. CDM-EB 63, Annex 26, Version 01.0, Sept. 2011, 3p.

Aforestation/reforestation methodological tool: Demonstrating appropriateness of volume equations for estimation of aboveground tree biomass in A/R CDM project activities. Report. CDM-EB 46, Annex 19, Version 01.0.1, Mai. 2012. 9p.

. Aforestation/reforestation Methodological tool: Estimation of carbon stocks and change in carbon stocks of trees and shrubs in A/R CDM project activities. Report. CDM-EB 75 - Annex 26, Version 04.0, Oct. 2013, 32p.

VISMARA, E. S. Avaliação da construção e aplicação de modelos florestais de efeitos fixos e efeitos mistos sob o ponto de vista preditivo. 2013. 106p. Tese (Doutorado em Recursos Florestais) - Escola Superior de Agricultura "Luiz de Queiroz”, Universidade de São Paulo, Piracicaba, 2013.

WATZLAWICK, L. F.; KIRCHNER, F. F.; SANQUETTA, C. R. Estimativa de biomassa e carbono em floresta com araucária utilizando imagens do satélite Ikonos II. Ciência Florestal, Santa Maria, v. 19, n. 1-2, p. 169-181, Mar-Jun 2009.

WILKIE, D.S.; FINN, J.T. Remote sensing imagery for natural resources monitoring: A guide for first-time users. New York: Columbia University Press, 1996. 295p.

ZHENG, G.; CHEN, J.M; TIAN, Q.J.; JU W.M.; XIA, X.Q. Combining remote sensing imagery and forest age inventory for biomass mapping. Journal of Environmental Management, London, v. 85, n. 3, p. 616-623, Nov. 2007. 


\title{
3 FATORES ASSOCIADOS ÀS INCERTEZAS NAS ESTIMATIVAS DE ESTOQUE DE BIOMASSA EM FLORESTA NATIVA DA MATA ATLÂNTICA
}

\section{Resumo}

Este estudo analisa alguns fatores relacionados aos erros de predição e de estimação de estoque de biomassa em floresta nativa da Mata Atlântica, localizada no município de Registro-SP. Para isso, inicialmente avaliou-se o ajuste de equações de predição de biomassa a partir de dados de uma amostra estratificada contendo 80 árvores de 10 espécies distintas, considerando diferentes combinações de preditores, incluindo diâmetro, altura total e informação relativa à densidade da madeira. Juntamente com outras equações disponíveis em literatura, verificou-se o desempenho de aplicação desses, utilizando-as na predição da biomassa de um conjunto de 146 árvores presentes em nove parcelas destrutivas instaladas em diferentes estágios sucessionais da floresta. Posteriormente estas foram aplicadas aos dados de inventário florestal previamente realizado na área do estudo com o objetivo de se verificar as discrepâncias nas estimativas e incertezas associadas às quantificações de biomassa devido ao uso das diferentes equações de predição. O estudo confirma a natureza empírica dessas equações, expondo alguns fatores relacionados à sua construção e ajuste que podem gerar vieses preditivos, atentando também para a necessidade de previa avaliação do desempenho de predição das equações antes de sua aplicação e, em especial, das ajustadas com amostras de outras florestas. Por fim, o estudo demonstra as discrepâncias nas estimativas de estoques de biomassa em florestas nativas devido ao uso de diferentes modelos de predição.

Palavras-chave: Modelos de predição; Biomassa florestal; Viés de predição

\begin{abstract}
This study analyzes some factors related to predictions errors and estimation of biomass stocks in natural forests of the Atlantic Forest, in the municipality of Registro-SP. Initially, we assessed the biomass prediction models fitted from a stratified samples composed of 80 trees and 10 different species and considering different combinations of variables as predictors, such as, DBH, total height and information of wood density. With the fitted models and other models extracted from literature, we verified its prediction performance in 146 sample trees of nine destructive plots measured in different forest successional stages. Later, these models were applied to a forest inventory dataset, previously conducted in the study area, in order to verify the discrepancies in estimates and the associated uncertainties due to the use of different prediction models in different scenarios. The study confirms the empirical nature of these models, clarifying some factors related to the fitting procedures and later selection, that can generates predictive bias. It was noted the need to evaluate the model according to its performance, before its application, especially in those cases where the models come from different forest types. Finally, the study demonstrates the discrepancies in the estimates of biomass and carbon stocks in natural forests due to the use of different models.
\end{abstract}

Keywords: Prediction models; Forest biomass; Bias prediction 


\subsection{Introdução}

Florestas constituem um dos principais reservatórios de carbono orgânico na biosfera terrestre. Apenas na faixa da região tropical, estima-se existirem cerca de $229 \mathrm{Pg} \mathrm{C}$ atualmente estocados na biomassa aérea de seus ecossistemas, com perdas na ordem de 1,14 Pg C por ano, entre 2000 e 2010 devido a processos de desflorestamento (BACCINI et al., 2012). Esta é a segunda maior fonte de emissões antropogênicas de gases de efeito estufa (GEEs) em nível global, representando de 20\% a 25\% das emissões anuais (MOUTINHO; SCHWARTZMAN, 2005). Já para Van Der Werf et al. (2009) os desflorestamentos representam de 6 a 17\% das emissões globais de GEEs.

Incertezas relativas às estimativas de emissões de GEEs por este fator são devidas à insuficiência de informações concretas referentes aos estoques de carbono presentes nas florestas (HOUGTHON; HALL; GOETZ, 2009) e às taxas regionais de desmatamento, havendo urgente necessidade de se ter um conjuntos de dados que caracterizem melhor a distribuição global da biomassa acima do solo, especialmente nos trópicos (BACCINI et al., 2012).

Um aspecto relevante nos estudos de fixação de carbono em florestas é a determinação e estimação da variável biomassa, a qual precisa ser realizada de forma fidedigna para que haja consistência na quantificação do carbono fixado nos ecossistemas florestais (SANQUETTA, 2002). Mesmo sendo a base para o ajuste de equações de predição, estudos relacionados à parte metodológica da determinação da biomassa são poucos, devido ao custo elevado e excessivo trabalho de campo (SOTOMAYOR, 2013).

Dois métodos diretos de determinação de biomassa são apontados: a técnica gravimétrica e a técnica volumétrica (VISMARA, 2009). Na técnica gravimétrica a biomassa é definida a partir da pesagem dos diversos compartimentos da árvore, e a partir do teor de umidade obtido de amostras destes compartimentos, determina-se a biomassa seca das árvores. Já na técnica volumétrica, as árvores passam por um processo de cubagem rigorosa e, a partir de informações da densidade básica da madeira, tomada de amostra obtidas nos diversos compartimentos desta árvore, converte-se o volume obtido em biomassa seca.

Estas técnicas podem ser utilizadas de forma isolada ou conjunta, sendo normalmente aplicada a gravimetria, às árvores de pequeno porte, ou a compartimentos das árvores de grande porte mas de menor peso e fácil manuseio, como os galhos, ramos e folhas, e a volumetria, especialmente aplicada aos troncos das árvores de grande porte, (HIGUCHI; CARVALHO Jr, 1994). Comparativamente, estudos tem demonstrado ser a técnica 
gravimétrica mais precisa em determinar a biomassa (VISMARA, 2009; SOTOMAYOR, 2013), sendo recomendada para a construção de equações de predição para uso futuros nos inventários de estoques.

A determinação de biomassa de uma floresta pode ser realizada em nível de árvores individuais, onde cada árvore representa uma unidade do conjunto de parcelas, ou em nível de parcela, onde a unidade amostral é definida por uma superfície de área conhecida. (HIGUCHI; CARVALHO JÚNIOR, 1994; SANQUETTA, 2002). No uso de árvores individuais, o processo de amostragem estratificada é aplicado para definir o conjunto amostral a ser utilizado para o ajuste da equação de predição (VISMARA, 2009; 2013; SOTOMAYOR, 2013; FEREZ, 2010).

Neste processo, após a realização de um inventário florestal piloto para se conhecer a distribuição diamétrica da floresta, um determinado número de árvores é derrubado de modo a abranger todas as classes diamétricas existentes na floresta (SILVEIRA et al., 2008).

Com base no conjunto de dados mensurados pelos métodos diretos de determinação de biomassa, técnicas de regressão são aplicadas para o desenvolvimento de equações de predição, correlacionando a biomassa aos dados dimensionais das árvores. Dados dimensionais devem ser de fácil mensuração em campo (ZIANIS; RADROGOU, 2006; HIGUCHI; CARVALHO JR, 1994), tais como o diâmetro do tronco e altura total das árvores (VISMARA, 2009), possibilitando a aplicação das equações de predição aos dados de inventários realizados em maior escala em florestas com mesmas características (PARRESOL, 1999).

Uma série de critérios estatísticos é aplicada para avaliação do ajuste das equações. Neste sentido, Silveira et al. (2008) expõem os comumente aplicados, incluindo: o exame das estimativas dos parâmetros da equação pelo teste $t$; o teste $\mathrm{F}$ completo para o modelo e o teste F parcial para os estimadores dos parâmetros; a análise das medidas de precisão, tal qual o coeficiente de determinação $\left(\mathrm{R}^{2}\right)$ e o coeficiente de determinação ajustados $\left(\mathrm{R}_{\text {ajustado }}^{2}\right.$, o erro padrão da estimativa ou erro padrão residual, expresso em valor absoluto (Syx) ou em porcentagem da média aritmética da variável dependente (Syx\%); a análise gráfica da distribuição dos valores residuais.

Vismara (2009), com base em uma crítica revisão teórica sobre métodos de seleção de modelos, comenta possuir esta abordagem clássica utilizada para inferir sobre a qualidade do ajuste de modelos concorrentes, as quais consideram o teste $\mathrm{F}$ e o coeficiente de determinação como critérios de seleção absolutos na definição do modelo a se adotar, algumas limitações e equívocos em sua interpretação. Neste sentido, o autor propõe a utilização do Critério de 
Informação de Akaike (AIC), o qual se baseia no princípio da máxima entropia e paradigma da verossimilhança, e que se interpretado e usado corretamente sob o ponto de vista da discrepância, torna-se uma ferramenta importante e eficaz neste processo de seleção de equações de predição.

Bataglia e Sands (1998) comentam que as equações de predição devem ser avaliadas não apenas sob o ponto de vista da qualidade do ajuste, mas também quanto à qualidade de sua aplicação, motivo pela qual foram desenvolvidos. Contudo, devido à escassez de amostras destrutivas em grande quantidade para a realização de procedimentos de sua validação, aspectos relacionados à qualidade do desempenho das equações em realizar predições são poucas vezes considerados (VISMARA, 2009).

Neste sentido, Vanclay (1994) afirma que as equações utilizadas para a predição de biomassa e volume, são empíricas e sítio-específicas, pois fornecem uma descrição do comportamento da biomassa sem tentar identificar as causas ou explicar os fenômenos e, para que proporcionem estimativas biologicamente realistas, estas devem ser construídas de modo a incorporarem a máxima amplitude de condições biológicas possíveis.

Por este motivo, Crow e Schlaegel (1988) desaconselha sua utilização para outras localidades se não para a própria floresta da qual se obteve os dados para sua determinação. Em contrapartida, Chave et al. (2005), com o intuito de eliminar a falta de informações sobre estoques de biomassa em florestas tropicais, propõem o uso de equações construídas a partir de uma expressiva quantidade de dados obtidos de estudos realizados em diversas regiões dos trópicos, os quais as qualificam como robustas e aplicáveis para estimar a biomassa das florestas dessa região. Estas são as chamadas equações pan-tropicais, muito utilizadas nas estimativas de biomassa em estudos atuais realizados nos ecossistemas florestais dessa região.

Apesar da aparente validade das equações alométricas construídas com base num amplo conjunto de dados, as árvores diferem quanto as suas relações alométricas de uma região para outra, dependendo de fatores ambientais, tais como solo e clima, e características funcionais das espécies, por exemplo, a densidade da madeira e a arquitetura de copa (VIEILLEDENT et al., 2010).

Neste aspecto, faz-se necessário analisar as equações do ponto de vista de seu desempenho em situações em que a estrutura da floresta seja distinta à da amostra utilizada para o ajuste da equação, de modo a permitir sua adequada avaliação (VISMARA, 2013). Por este motivo, Brown (1997) recomenda que no uso de equações disponíveis na literatura, sempre que possível, deve-se testar a adequação de sua utilização, abatendo algumas árvores e verificando o ajuste dos dados desta floresta à equação utilizada. 
O fato é que na prática, uma vez determinado a equação para uso no estudo da predição de biomassa de uma floresta, as incertezas relativas às estimativas são avaliadas apenas com relação ao processo de amostragem do inventário florestal. No entanto, a principal fonte de propagação de erros de estimação de biomassa em florestas tropicais relaciona-se a seleção das equações, conforme já discutido por alguns autores (CHAVE et al., 2004; SOTOMAYOR, 2010; VISMARA, 2010; 213; VIEIRA et al., 2008).

Com todo o exposto, o presente estudo busca expor o reconhecimento de alguns fatores que geram vieses preditivos e incertezas na estimação de biomassa em florestas nativas, de modo a contribuir na definição de metodologias adequadas para aplicação em estudo desta natureza realizado na Mata Atlântica.

Para isso, equações empíricas desenvolvidas a partir de conjunto de dados de uma amostra estratificada de árvores, as quais consideram a inclusão de diferentes combinações de variáveis preditoras, são avaliadas em termos de qualidade de ajuste e desempenho de predição, de modo a validar sua aplicação para a quantificação da biomassa da floresta em estudo. Adicionalmente, equações de predição de biomassa disponíveis em literatura científica também passaram pelo processo de avaliação de desempenho de predição, com o intuito de verificar os vieses nas estimativas de biomassa. Por fim, verifica-se a variação nas estimativas dos estoques de biomassa devido ao uso das diferentes equações, utilizando os dados dendrométricos de um levantamento realizado na área do estudo.

\subsection{Material e métodos}

\subsection{1 Área de estudo}

A Floresta utilizada para a coleta de dados deste estudo localizava-se no município de Registro, Estado de São Paulo, nas coordenadas aproximadas 212.000,00 E; 7.284.000,00 S, em altitude média de 25 metros acima do nível do mar. Trata-se de uma vegetação nativa secundária presente no aeroporto do município de Registro, a qual foi parcialmente suprimida para o atendimento aos quesitos de segurança de operação da pista de pouso e decolagem de aeronaves. Diante dos entraves e das exigências legais existentes para a obtenção de autorização para a supressão de vegetação junto aos órgãos ambientais, mesmo que em pequena escala e para fins de pesquisa, oportunamente aproveitou-se o licenciamento ambiental deste empreendimento para a realização deste estudo.

Segundo os critérios estabelecidos pelo sistema de classificação fisionômico-ecológico do Instituto Brasileiro de Geografia e Estatística - IBGE, a vegetação na área do estudo é 
classificada como Floresta Ombrófila Densa das Terras Baixas (VELOSO et al. 1991; IBGE, 2102). Esta formação ocorre nos terrenos quaternários situados em geral pouco acima do nível do mar, entre 5 e aproximadamente $50 \mathrm{~m}$ de altitude, nas planícies formadas pelo assoreamento devido à erosão existente nas serras costeiras, e nas enseadas marítimas, havendo no Estado de São Paulo, domínio da espécie Calophyllum brasiliense Cambess. (IBGE, 2102).

Com frequência, a vegetação que ocorre sobre as planícies litorâneas tem sido chamada de vegetação de restinga, ou inclusa dentro do complexo da restinga (RIZZINI 1979; EITEN 1970, 1983; ARAÚJO; HENRIQUES, 1984; PEREIRA 1990; SUGIYAMA, 1998). Porém, por estar inserida na área de domínio da Morraria Costeira e apresentar características peculiares a este domínio, não pode ser considerada como vegetação típica de restinga, uma vez que não ocorre sobre cordões litorâneos nem tampouco sofre influência marinha. Contudo, na área do estudo, em certos trechos onde o solo apresenta-se muito lixiviado e extremamente arenoso, a vegetação assume características de restinga, ora na fisionomia, ora nas espécies indicadoras mais comuns deste ambiente. Assim, pode-se dizer que a vegetação encontra-se numa faixa de transição entre as duas vegetações supracitadas.

\subsubsection{Amostragem}

\subsubsection{Seleção das unidades amostrais}

$\mathrm{Na}$ definição das unidades amostrais para a coleta dos dados, consideraram-se duas condições distintas. Na primeira foram tomados indivíduos arbóreos isolados como sendo a unidade amostral. Estas árvores formaram o conjunto de amostras utilizadas para o ajuste da equação de predição de biomassa. Já na segunda situação, parcelas amostrais destrutivas com área fixa foram instaladas e todas as árvores presentes dentro destas parcelas foram inclusas na amostragem. Esta amostragem foi utilizada para a verificação do desempenho de predição das equações ajustadas. Ressalta-se que o conjunto de amostras das árvores isoladas não sobrepõe às amostras obtidas nas parcelas. Estes dois sistemas de amostras são detalhados a seguir.

\subsection{Amostra destrutiva de árvores isoladas}

Um conjunto de amostras de árvores isoladas foi formado por espécies que apresentaram maior abundância, em termos de número de indivíduos, segundo levantamento 
fitossociológico previamente realizado na área do estudo. Além deste critério, buscou-se também incluir na amostra, espécies com características de densidade básica da madeira distintas, de modo a se ter uma ampla representação desta informação, a qual é utilizada como variável preditora em alguns dos modelos testados. Esta amostragem contou com 10 espécies. De cada uma dessas espécies foram selecionados oito árvores, segundo um processo de amostragem estratificada. Neste sentido, para cada espécie quatro classes de diâmetro foram definidas em função da amplitude diamétrica observada para a espécie. Dentro de cada classe de diâmetro, dois indivíduos foram amostrados. Assim a amostra utilizada para o ajuste do modelo de predição totalizou 80 árvores.

Em termos de representatividade, as 10 espécies selecionadas para comporem esta amostragem, de um total de 133 espécies encontradas no levantamento fitossociológico realizado na área, respondem por $41,5 \%$ da densidade relativa de indivíduos, e por $42,6 \%$ da dominância relativa, expressa pela área seccional das árvores.

A Tabela 3.1 detalha essas informações, apresentando as espécies utilizadas no ajuste das equações de predição de biomassa e a amplitude de variação dos dados de DAP, altura total, densidade básica da madeira e biomassa total dessas árvores.

Tabela 3.1 - Amplitude de variação dos dados das árvores isoladas que compuseram a amostragem referente ao ajuste das equações de predição de biomassa no estudo da Floresta Atlântica de Registro-SP

\begin{tabular}{|c|c|c|c|c|c|c|c|c|c|c|c|c|}
\hline \multirow{2}{*}{ Espécies } & \multicolumn{3}{|c|}{ DAP (cm) } & \multicolumn{3}{|c|}{ Altura (m) } & \multicolumn{3}{|c|}{ DB $\left(\right.$ g.cm $\left.^{-3}\right)$} & \multicolumn{3}{|c|}{ Biomassa (kg) } \\
\hline & $\min$ & med & $\max$ & $\min$ & med & $\max$ & $\min$ & med & $\max$ & $\min$ & med & $\max$ \\
\hline $\begin{array}{l}\text { Alchornea triplinervia } \\
\text { (Spreng.) Müll. Arg. }\end{array}$ & 10,0 & 22,6 & 43,7 & 10,4 & 13,1 & 14,7 & 0,37 & 0,43 & 0,47 & 13,22 & 130,4 & 291,1 \\
\hline $\begin{array}{l}\text { Andira fraxinifolia } \text { Benth. } \\
\text { Calophyllum brasiliense }\end{array}$ & 8,1 & 28,9 & 70,2 & 6,8 & 12,8 & 17,4 & 0,43 & 0,59 & 0,65 & 13,02 & 184,1 & 507,1 \\
\hline $\begin{array}{c}\text { Cambess. } \\
\text { Endlicheria paniculata }\end{array}$ & 7,1 & 24,3 & 54,7 & 10,1 & 13,1 & 17,8 & 0,45 & 0,48 & 0,52 & 8,78 & 199,6 & 505,8 \\
\hline $\begin{array}{l}\text { (Spreng.) JF Macbr. } \\
\text { Gomidesia affinis }\end{array}$ & 5,0 & 9,6 & 27,4 & 5,6 & 8,0 & 12,1 & 0,53 & 0,60 & 0,68 & 3,32 & 19,8 & 96,2 \\
\hline $\begin{array}{l}\text { (Cambess.) D. Legrand } \\
\text { Mvrcia racemosa }\end{array}$ & 5,3 & 7,2 & 11,2 & 5,3 & 8,3 & 9,6 & 0,55 & 0,62 & 0,70 & 3,66 & 17,0 & 58,0 \\
\hline $\begin{array}{l}\text { (O. Berg) Kiaersk. } \\
\text { Jacaranda puberula }\end{array}$ & 7,2 & 12,0 & 17,3 & 6,7 & 9,5 & 11,5 & 0,37 & 0,43 & 0,48 & 7,13 & 27,3 & 55,5 \\
\hline $\begin{array}{c}\text { Cham. } \\
\text { Pera glabrata }\end{array}$ & 5,0 & 7,3 & 15,7 & 5,6 & 6,9 & 9,2 & 0,62 & 0,69 & 0,79 & 4,53 & 16,0 & 40,5 \\
\hline (Schott) Poepp. ex Baill. & 7,9 & 15,7 & 28,6 & 9,7 & 12,4 & 15,2 & 0,56 & 0,61 & 0,67 & 11,28 & 71,6 & 156,9 \\
\hline $\begin{array}{c}\text { Tapirira guianensis Aubl. } \\
\text { Tibouchina pulchra }\end{array}$ & 5,8 & 9,6 & 18,0 & 7,9 & 10,2 & 16,5 & 0,57 & 0,61 & 0,68 & 3,61 & 39,5 & 136,9 \\
\hline (Cham.) Cogn. & 6,4 & 14,7 & 19,5 & 5,9 & 10,0 & 13,8 & 0,41 & 0,47 & 0,62 & 13,64 & 64,4 & 121,4 \\
\hline Totais & $\mathbf{5 , 0}$ & 16,3 & 70,2 & 5,3 & 10,4 & 17,8 & 0,37 & 0,55 & 0,79 & 3,61 & 81,7 & 507,1 \\
\hline
\end{tabular}

min -mínimo(a); med - médio(a); max - máximo(a). 


\subsection{Amostra destrutiva em parcelas}

A floresta presente na área do estudo caracteriza-se por apresentar um mosaico contendo vegetação em diferentes estágios de sucessão, sendo considerados três estágios distintos neste estudo: inicial, médio e avançado. Esta separação foi feita através de observações de campo considerando algumas características estruturais da floresta, dentre as quais: a composição e a diversidade de espécies; a estratificação do perfil vertical da floresta e a altura do dossel; o porte das árvores arbitrado a partir de medidas dendrométricas como diâmetro médio e área seccional das árvores; a densidade de indivíduos por área, e; a abundância e composição florística das espécies de hábitos de vida não arbóreo, tais como bromélias e epífitas.

A classificação da vegetação presente na área foi realizada com base nos critérios legais definidos pela Resolução Conjunta $n^{\circ}$ 01, de 17 de fevereiro1994, da Secretária do Meio Ambiente do Estado de São Paulo - SMA-SP, e, do Instituto Brasileiro do Meio Ambiente e dos Recursos Naturais Renováveis de São Paulo - IBAMA-SP, a qual define vegetação primária e secundária nos estágios pioneiro, inicial, médio e avançado de regeneração de Mata Atlântica.

Três parcelas foram alocadas em cada um desses estágios, de modo a se tem uma boa representação da biomassa das árvores que compõem estes estágios sucessionais, totalizando nove parcelas destrutivas. As parcelas possuíram área fixa de $100,0 \mathrm{~m}^{2}(5,0$ x 20,0 m). No interior das parcelas, todos os indivíduos arbóreos com DAP $\geq 5,0 \mathrm{~cm}$ foram inclusos na amostragem, inclusive indivíduos do gênero Cyathea (samambaiuçu), uma peteridófita com hábito de feto arborescente, de ocorrência conspícua nas florestas da região do estudo. A Tabela 3.2 resume as informações referentes às 31 espécies capturadas na amostragem destas parcelas e, a Tabela 3.3, apresenta a amplitude de variação dos dados de DAP, altura total, densidade básica da madeira e biomassa total destas árvores. 
Tabela 3.2 - Número de indivíduos das espécies arbóreas presentes nas parcelas destrutivas utilizadas para o estudo da biomassa da Floresta Atlântica de Registro-SP

\begin{tabular}{|c|c|c|c|c|c|}
\hline \multirow[b]{2}{*}{ Espécies } & \multicolumn{3}{|c|}{ Estágio sucessional } & \multirow[b]{2}{*}{ Total } & \multirow[b]{2}{*}{$\operatorname{DRa}(\%)$} \\
\hline & inicial & médio & avançado & & \\
\hline Alchornea triplinervia (Spreng.) Müll. Arg. & 3 & 2 & 5 & 10 & 6,8 \\
\hline Amaioua intermedia Mart. & 1 & & & 1 & 0,7 \\
\hline Andira fraxinifolia Benth. & & 6 & 1 & 7 & 4,8 \\
\hline Blepharocalyx salicifolius (Kunth) O. Berg & & 1 & & 1 & 0,7 \\
\hline Calophyllum brasiliense Cambess. & 6 & & 8 & 14 & 9,6 \\
\hline Campomanesia phaea (O. Berg) Landrum & & 2 & & 2 & 1,4 \\
\hline Coussapoa microcarpa (Schott) Rizzini & & 4 & 2 & 6 & 4,1 \\
\hline Cyathea sp & 2 & & & 2 & 1,4 \\
\hline Endlicheria paniculata (Spreng.) JF Macbr. & 13 & 8 & 1 & 22 & 15,1 \\
\hline Eugenia cerasiflora Miq. & 2 & 1 & 2 & 5 & 3,4 \\
\hline Ficus sp & & 1 & & 1 & 0,7 \\
\hline Gomidesia affinis (Cambess.) D. Legrand & 1 & 2 & 1 & 4 & 2,7 \\
\hline Gomidesia fenzliana $\mathrm{O}$. Berg & 1 & & & 1 & 0,7 \\
\hline Guarea macrophylla Vahl & & 3 & & 3 & 2,1 \\
\hline Ilex theezans Mart. ex Reissek & 1 & 3 & 2 & 6 & 4,1 \\
\hline Jacaranda puberula Cham. & & 1 & & 1 & 0,7 \\
\hline Leandra australis (Cham.) Cogn. & & 3 & & 3 & 2,1 \\
\hline Miconia cinerascens Miq. & & & 3 & 3 & 2,1 \\
\hline Miconia sellowiana Naudin & & 1 & & 1 & 0,7 \\
\hline Myrcia pubipetala Miq. & 1 & 2 & & 3 & 2,1 \\
\hline Myrcia racemosa (O. Berg) Kiaersk. & 7 & 6 & 4 & 17 & 11,6 \\
\hline Nectandra oppositifolia Nees \& Mart. & & 1 & & 1 & 0,7 \\
\hline Ocotea brachybotrya (Meisn.) Mez & 1 & & & 1 & 0,7 \\
\hline Ocotea pulchella (Nees \& Mart.) Mez & 2 & & 1 & 3 & 2,1 \\
\hline Pera glabrata (Schott) Poepp. ex Baill. & 5 & 7 & 2 & 14 & 9,6 \\
\hline Posoqueria acutifólia Mart. & & & 1 & 1 & 0,7 \\
\hline Myrsine coriacea (Sw.) R. Br.. ex Roem. \& Schult. & 1 & & & 1 & 0,7 \\
\hline Rollinia sericea (RE Fr.) RE Fr.. & & 1 & & 1 & 0,7 \\
\hline Tapirira guianensis Aubl. & & 2 & 1 & 3 & 2,1 \\
\hline Ternstroemia brasiliensis Cambess. & 1 & & & 1 & 0,7 \\
\hline Tibouchina pulchra (Cham.) Cogn. & 2 & 4 & 1 & 7 & 4,8 \\
\hline Total geral & 50 & 61 & 35 & 146 & 100,0 \\
\hline
\end{tabular}

DRa\% (Densidade relativa de indivíduos com relação ao conjunto amostral). 
Tabela 3.3 - Amplitude de variação dos dados das árvores presentes nas parcelas destrutivas instaladas em áreas com diferentes estágios sucessionais no estudo da Floresta Atlântica de Registro-SP

\begin{tabular}{|c|c|c|c|c|c|c|c|c|c|c|c|c|}
\hline \multirow{2}{*}{$\begin{array}{c}\text { Estágio } \\
\text { sucessional }\end{array}$} & \multicolumn{3}{|c|}{ DAP (cm) } & \multicolumn{3}{|c|}{ Altura total (m) } & \multicolumn{3}{|c|}{$\begin{array}{c}\text { Densidade da } \\
\text { madeira }\left(\text { g.cm }^{-1}\right)\end{array}$} & \multicolumn{3}{|c|}{ Biomassa (kg) } \\
\hline & $\min$ & med & $\max$ & $\min$ & med & $\max$ & $\min$ & med & $\max$ & $\min$ & med & $\max$ \\
\hline Inicial & 5, & 8,6 & 19 & 5,6 & 7,6 & 11,0 & 0,421 & 0,593 & 0,945 & 5,4 & 20,6 & 62,0 \\
\hline Médio & 5,0 & 10,9 & 36,4 & 4,8 & 8,8 & 16,0 & 0,341 & 0,599 & 0,857 & 3,3 & 34,6 & 212,7 \\
\hline & 5,1 & 19,6 & 81,0 & 6,1 & 13,4 & 23,6 & 0,381 & 0,555 & 0,722 & 4,4 & 298,3 & $4.200,1$ \\
\hline & 5,0 & 12,2 & 81 & 4,8 & 9,5 & 23,6 & 0,341 & 0,587 & 0,945 & 3,3 & 93,0 & $4.200,1$ \\
\hline
\end{tabular}

min -mínimo(a); med - médio(a); max - máximo(a).

De todas as espécies inclusas na amostragem das árvores das parcelas, apenas uma, a Blepharocalyx salicifolius, não esteve presente entre as espécies do levantamento fitossociológico realizado previamente na área. Com relação às espécies que compõem a amostra de árvores isoladas, todas se incluem na amostra de árvores da parcela.

\subsubsection{Medidas dendrométricas}

A altura total das árvores foi medida com o uso de um clinômetro digital Vertex IV, da marca Haglöf. Tal medida foi anotada em metros com precisão em centímetros. O diâmetro com casca dos troncos das árvores, medidos à altura do Peito (DAP: 1,30 m de altura), foi tomado com uma suta dendrométrica, sendo a anotação da medida em centímetros e com precisão em milímetros. Árvores bifurcadas abaixo da altura do DAP tiveram todos os troncos medidos e, posteriormente, extraiu-se o diâmetro equivalente resultante da soma das áreas seccionais dos troncos dessas árvores, para uso do dap como variável preditora na equação de predição. O valor do dap obtido por este método é o mesmo que o valor resultante do DAP quadrático (MACDICKEN et al., 1991).

\subsubsection{Resistência à penetração da madeira}

Dentre as variáveis preditoras testadas no ajuste das equações de predição de biomassa deste estudo, tem-se a resistência da madeira à penetração de um pino Para obtenção deste índice utilizou-se um penetrômetro da marca Pilodyn ${ }^{\circledR}$, sendo a medida tomada na porção mais externa do lenho do tronco da árvore, na altura do peito. Este aparelho também foi utilizado em estudos relacionados à seleção de equações de predição de biomassa por outros autores (VISMARA, 2009; SOTOMAYOR, 2013). A resistência à penetração da madeira, 
teoricamente, possui relação inversa à densidade da madeira, já que quanto mais densa for esta, maior é sua resistência à penetração do pino. Esta é uma variável tomada diretamente na mensuração dos indivíduos em campo nos processo de inventário cuja realização possui certa facilidade operacional. Assim, este índice foi considerado um forte candidato para ser utilizado como variável preditora da equação de predição, objetivando incluir alguma informação relacionada à densidade da madeira como preditora no modelo, sem necessitar de métodos destrutivos para sua obtenção.

Em campo, a medida de resistência à penetração do lenho foi tomada das árvores à altura do DAP, sendo sua anotação realizada em milímetros.

\subsubsection{Determinação da biomassa}

Considerou-se neste estudo a biomassa da parte aérea das árvores. Esta é composta pelos seguintes compartimentos: tronco (porção do caule até primeira bifurcação) e copa, a qual e composta pelos galhos grossos (porção do lenhosa das copas com diâmetro maior que $5,0 \mathrm{~cm}$ ), galhos finos (porção lenhosa da copa das árvores com diâmetro menor que 5,0 cm) e folhas (ramos e folhas). Estes três últimos compartimentos formam a biomassa da copa das árvores.

Após a derrubada das árvores, estas foram inicialmente desfolhadas. As folhas foram ensacadas e pesadas. Este material foi misturado e homogeneizado para a obtenção de uma amostra de aproximadamente $100 \mathrm{~g}$, utilizada posteriormente para determinação da massa seca deste compartimento em laboratório.

Posteriormente a árvore foi desgalhada para separação dos galhos finos. Estes foram pesados em campo. Uma amostra de aproximadamente 300 gramas desse material foi separada e pesada.

Os galhos grossos foram seccionados e pesados. Dois discos com casca de aproximadamente $5,0 \mathrm{~cm}$ de espessura foram obtidos em diferentes posições da copa das árvores para posterior determinação da massa seca. $\mathrm{O}$ tronco das árvores foram seccionados e pesados. Para a determinação da massa seca, discos com aproximadamente $5,0 \mathrm{~cm}$ de espessura foram tomados em três níveis de medida da altura do tronco: 0\% (base do tronco da árvore); $50 \%$ (meio) e 100\% (topo).

Para a pesagem do material relativo à massa verde foi utilizado um dinamômetro. Este aparelho possui capacidade de carga máxima de $200 \mathrm{~kg}$, com precisão em decigramas. A pesagem das amostras foi realizada em célula de carga, com capacidade de $3 \mathrm{~kg}$, e precisão 
em miligramas. Todas as anotações relativas à massa verde dos compartimentos foram realizadas em quilogramas, com precisão em decigramas, e das amostras em gramas, com precisão em miligramas.

Em laboratório, as massas secas das amostras do compartimento folhas e galhos finos foram obtidos após secagem em estufa de circulação forçada de ar, à temperatura de $75^{ \pm} 2^{\circ} \mathrm{C}$, até que a amostra apresentasse valores constantes entre duas pesagens consecutivas, em intervalo superior a 24 horas. Já para os compartimentos galhos grossos e tronco, o processo de secagem ocorreu em estufa de circulação de ar forçada, a temperatura média de $103^{ \pm} 2^{\circ} \mathrm{C}$.

O teor de umidade da amostra foi obtido pela fórmula:

$$
U c_{i}(\%)=\left(\frac{m_{v}-m_{s}}{m_{v}}\right) \cdot 100
$$

onde: $U$ é o teor de umidade da amostra, em porcentagem (\%); $c_{i}$ é o índice que indica o compartimento da amostra; $i$ é o índice referente à árvore; $m_{v}$ é o o peso da massa verde obtido da amostra em campo $(\mathrm{kg})$, e $m_{s}$ é o peso da massa seca $(\mathrm{kg})$.

Para a obtenção da biomassa seca dos diferentes compartimentos de cada árvore, foi utilizada a seguinte expressão:

$$
B c_{i}=m_{v}\left(1-\frac{U c_{i}}{100}\right)
$$

onde: $B$ é a biomassa seca $(\mathrm{kg}) ; \quad c$ é o índice que indica o compartimento da amostra; $i$ é o índice referente à árvore; $m_{v}$ é a massa verde obtido da amostra em campo $(\mathrm{kg}) ; U$ é o teor de umidade da amostra (\%).

A biomassa seca total de cada árvore amostrada foi obtida através do somatório da biomassa seca de todos os compartimentos da árvore, ou seja, tronco, galhos, grossos e finos, e folhas. 


\subsubsection{Densidade básica da madeira}

A importância de se ter informação a respeito da densidade básica da madeira ocorre devido ao fato de que na prática, comumente é utilizado este índice como uma das variáveis das equações de predição de biomassa. Os procedimentos para a determinação da densidade básica da madeira das árvores amostradas foram realizados conforme apresentado pelas normas NBR 11941 (ABNT, 2003). Para isso, utilizou-se o método de imersão, com auxílio de balança hidrostática, para determinação do volume e dos pesos, seco e úmido, da amostra.

As amostras dos discos coletados do tronco, em três níveis de altura (base; meio, e; topo), ainda em campo, foram identificadas e ensacadas, visando reduzir perdas de umidade. Estes discos foram posteriormente imersos em água para que estas amostras obtivessem o máximo teor de umidade. Depois de saturada, tomou-se o peso da amostra imerso em água na balança hidrostática. Feito este procedimento, a amostra foi seca em estufa de circulação forçada de ar, a temperatura de $105^{+} 2^{\circ} \mathrm{C}$. Quando atingiu massa constante, determinada pelos valores obtidos entre duas pesagens com intervalo superior a $24 \mathrm{~h}$, obteve-se o peso da amostra seca.

A densidade básica de cada amostra foi determinada pela fórmula:

$$
D B_{c i}=\frac{P A S}{(P A M-P A I)}
$$

onde: $D B$ é a densidade da amostra $\left(\mathrm{g} . \mathrm{cm}^{-3}\right) ; c$ é a identificação do nível de altura do tronco da árvore onde a amostra foi tomada; $i$ é o índice que identifica a árvore; PAS é o peso da amostra seca (g); PAM é o peso da amostra em seu máximo teor de umidade; $P A I$ é peso da amostra imersa em água na balança hidrostática, e; o volume da amostra $\left(\mathrm{cm}^{-3}\right)$ é dado pela diferença entre $P A M$ e $P A I(V c i=P A M-P A I)$.

A densidade básica da madeira de cada árvore $(i)$ foi obtida pela média ponderada de todas as três amostras de discos tomadas do tronco desta árvore. Tal ponderação foi realiza considerando o diâmetro do disco das amostras.

Devido à dificuldade de obter informações diretas sobre a densidade das árvores nos inventários florestais, é pratica comum nos estudos de quantificação de biomassa, a utilização de dados disponíveis na literatura para aplicação aos modelos que incluem esta informação como uma das variáveis preditoras. Esta situação poder ser uma das fontes de erros associados às estimativas de biomassa não explicitas nos estudos de biomassa florestal. 
Normalmente a densidade básica disponível em literatura é expressa com 12 a $15 \%$ de teor de umidade. Se aplicada diretamente estes valores aos preditores relacionados à densidade básica da equação, superestimativas deverão ser geradas. Assim ajustou-se um modelo de regressão linear com os dados de densidade obtido no estudo, contrapondo-os aos dados disponíveis em literatura, para conversão desses valores em densidade da madeira correspondente a massa seca total, através da seguinte expressão:

$$
y=\beta_{0}+\beta_{1} \cdot x+\varepsilon
$$

onde: $y$ é a densidade da madeira completamente seca $\left(\mathrm{g} \mathrm{cm}^{-3}\right) ; x$ é a densidade da madeira provinda de dados de literatura $\left(\mathrm{g} . \mathrm{cm}^{-3}\right)$; a e b são os estimadores dos coeficientes da regressão, e; $\varepsilon$ é o erro aleatório do modelo.

As informações de densidade básica da madeira foram extraídas do trabalho de Chave et al. (2006). Neste estudo, esses dados secundários de densidade básica de madeira foram corrigidos através da conversão acima proposta e aplicados para quantificar a biomassa da floresta. Porém, a fim de validar sua aplicação, previamente avaliou-se a magnitude dos erros gerados pelo uso desta informação, utilizando-a para predição da biomassa do conjunto total de amostras do estudo.

\subsubsection{Equações de predição de biomassa}

Resumidamente, equações de predição de biomassa são funções matemáticas utilizadas para estimar valores de uma variável resposta, dado observações tomadas de um determinado sistema. Para a determinação das equações de predição, foram utilizados os dados das 80 árvores isoladas abatidas.

Seguindo o princípio da parcimônia, testou-se a importância de inclusão das variáveis preditoras altura total $(h t)$ e densidade básica $(d b)$ no ajuste da equação, verificando se a inclusão dessas variáveis explicaria melhor o comportamento da variável resposta, no caso, a biomassa. Esse conhecimento torna-se relevante se considerado que a medida altura é de difícil mensuração em campo e, geralmente, relacionada a fontes de incertezas no processo de medição.

As incertezas estão associadas também às estimativas de densidade básica, visto que se reconhece a variação deste índice, entre espécies, dentro da mesma espécie e mesmo nas amostras de madeira tomadas em diferentes porções do lenho das árvores. Estas variações 
estão relacionadas a fatores diversos tais como idade do indivíduo, características genéticas, aspectos climáticos regionais e condição do micro-habitat onde o indivíduo se estabeleceu na floresta.

Assim, a altura total $(h t)$ e a densidade básica $(d b)$, apesar de fortes candidatas à inclusão nas equações, visto que aparentemente possuem uma boa relação com a biomassa, caso excluídas do modelo, tem-se ganhos em termos de praticidade nas mensurações de campo, minimização das fontes de incertezas e simplificação das equações.

Com todo o exposto, na avaliação do ajuste das equações de predição de biomassa, as seguintes variáveis preditoras foram consideradas: dap (diâmetro à altura do peito); $h t$ (altura total da árvore); $d b$ (densidade básica da madeira, considerando o valor da média ponderada de todas as amostras do compartimento tronco) e pilodyn (medida de resistência da madeira à penetração, tomada à altura do peito).

Como o ajuste do modelo é mais conveniente quando utiliza-se modelos lineares (VISMARA, 2013), aplicou-se a transformação logarítmica à variável resposta, de modo a tornar o modelos testados, linearizados. Este artifício é muito utilizado como alternativa para contornar a heterocedasticidade da variância. Sendo todos os modelos testados na escala logarítmica, torna-se possível a avaliação direta quanto à qualidade de ajustes destes modelos, por critérios tais como o coeficiente de determinação e erro padrão das estimativas, sem a necessidade de transformação para a escala original.

Para a elaboração das equações, tomou-se como base no modelo volumétrico de Schumacher-Hall, amplamente utilizada no setor florestal para predição de volume e biomassa, e que aqui configura-se por ser não linear e assumir as variáveis preditoras de forma independente na função da média.

Sob esta função de Schumacher-Hall fez-se modificações, incluindo informações relativas à densidade da madeira, seja de forma direta, com a utilização da densidade básica da madeira das árvores $(d b)$, seja de forma indireta, pela aplicação do valor do índice de resistência da madeira à penetração (pylodin), obtida pelo penetrômetro Pilodyn.

Outra forma de modificação utilizada foi a exclusão da altura $(h t)$ como variável preditora, mantendo apenas alguma dessas informações relacionadas à densidade da madeira. E, por fim, uma última abordagem foi o uso do DAP (dap) de forma isolada.

Ao todo seis modelos foram testados, conforme apresentado a seguir: 
Modelo E-0: $\quad \ln (B)=\beta_{0}+\beta_{1} \ln ($ dap $)+\beta_{2} \ln (h t)+\varepsilon$

Modelo E-1: $\quad \ln (B)=\beta_{0}+\beta_{1} \ln ($ dap $)+\beta_{2} \ln (h t)+\beta_{3} \frac{1}{\text { pylodin }} \varepsilon$

Modelo E-2: $\quad \ln (B)=\beta_{0}+\beta_{1} \ln ($ dap $)+\beta_{2} \ln (h t)+\beta_{3} \ln (d b)+\varepsilon$

Modelo E-3: $\quad \ln (B)=\beta_{0}+\beta_{1} \ln ($ dap $)+\beta_{2} \frac{1}{\text { pylodin }}+\varepsilon$

Modelo E-4: $\quad \ln (B)=\beta_{0}+\beta_{1} \ln (d a p)+\beta_{2} \ln (d b)+\varepsilon$

Modelo E-5: $\quad \ln (B)=\beta_{0}+\beta_{1} \ln ($ dap $)+\varepsilon$

onde: $B$ é a biomassa da árvore $(\mathrm{kg})$; dap é o diâmetro a altura do peito $(\mathrm{cm})$; ht é a altura total da árvore $(\mathrm{m})$; $d b$ é a densidade da madeira com base na massa seca $\left(\mathrm{g} . \mathrm{cm}^{-3}\right)$; pilodyn é a medida de penetração $(\mathrm{mm}) ; \varepsilon$ é o erro aleatório do modelo, e; E denota ser o modelo desenvolvido com dados provenientes da área do estudo.

\subsubsection{Predição da biomassa}

Os modelos ajustados foram utilizados para a predição da biomassa das árvores, inicialmente para o conjunto amostral das árvores presentes nas parcelas e, depois, aos dados do inventário da floresta em estudo. Neste último caso, utilizou-se apenas o modelo de melhor desempenho quanto à qualidade de ajuste e predição.

O uso da transformação logarítmica implica na obtenção de estimativas de biomassa enviesadas (PARRESOL, 1999). Assim, aplicou-se um fator de correção as biomassas preditas, conforme a seguir:

$$
\hat{B}=\exp \left(\widehat{\ln (B)} \frac{S x y_{m}{ }^{2}}{2}\right)
$$

onde: $\widehat{B}$ é a biomassa das árvores predita por determinado modelo na escala original; $\overline{\ln (B)}$ é a biomassa das árvores predita por determinado modelo na escala logarrítmica; $m$ indica o modelo testado, e; Sxy é o erro padrão das estimativas obtido para o modelo testado.

Teoricamente as estimativas realizadas sem este fator de correção subestimam os valores de biomassa real (CHAVE et al., 2005). Seus valores sempre serão superior a 1 sendo maior quanto menor for a qualidade de ajuste do modelo. 


\subsubsection{Avaliação dos modelos de predição}

\subsubsection{Qualidade de ajuste e aplicação dos modelos}

Para se testar os parâmetros do modelo de regressão, aplicou-se o teste $t$ aos parâmetros no intuito de verificar se estes são iguais a zero, para a qual assume-se a hipótese nula, ou diferente de zero, sendo neste caso assumida a hipótese alternativa.

Relativo ao atendimento as pressuposições do modelo de regressão linear, a normalidade dos resíduos foi verificada com o auxílio do gráfico quantil-quantil, o qual confronta os quantis da distribuição normal padronizada contra os quantis da distribuição dos resíduos do modelo; assim como a homocedasticidade da variância, através do gráfico de dispersão da raiz quadrada do valor absoluto do resíduo padronizado versus valor ajustado. Conforme Vismara (2009), este exame gráfico visa analisar o desempenho do modelo na predição do próprio conjunto de dados, avaliando a magnitude do erro na predição de árvores de diferentes tamanhos.

A primeira avaliação relacionada aos modelos de predição de biomassa testados foi realizada em termos de qualidade de seu ajuste em relação ao conjunto de dados utilizados para seu desenvolvimento.

Para inferir comparativamente quanto aos modelos de melhor ajuste, os critérios de avaliação incluíram: os valores do coeficiente de determinação ajustado $\left(\mathrm{R}_{\text {aj }}{ }_{\mathrm{aj}}\right)$, os erros padrão residual das estimativas (Syx), e os valores do Critério de Informação de Akaike - AIC (AKAIKE, 1974).

Posteriormente, testou-se a aplicação dos modelos ajustados em termos de desempenho de aplicação para predizer a biomassa das árvores da floresta em estudo. Para isso as árvores presentes nas nove parcelas instaladas na área, cuja biomassa foi determinada através do método gravimétrico, tiveram a biomassa predita pelo uso dos seis diferentes modelos desenvolvidos. O comportamento das estimativas de biomassa pelos modelos foi avaliada pelo viés em relação à média real obtida para o conjunto de árvores presentes nas parcelas dos diferentes estágios sucessionais. Este viés é expresso pela média absoluta do erro de predição, conforme a seguir:

$$
\text { Viés }=\frac{\sum_{i=1}^{n}\left(B_{i}-\widehat{B_{l}}\right)}{n}
$$


onde: $B$ é a biomassa seca mensurada pelo método gravimétrico; $\hat{B}$ é a biomassa seca obtida pelo modelo; $n$ é o número de árvores presentes na amostra, e o índice $i$ é o identificador da amostra.

$\mathrm{O}$ viés denota o erro associado à predição da biomassa de uma árvore pelo modelo. Os erros podem ocorrer tanto para mais, superestimando o valor real da biomassa, ou para menos, subestimando a biomassa das árvores. Se distribuídos normalmente, estes tenderão à zero, já que não possuem tendências positivas ou negativas de expressão das predições de biomassa pelo modelo. Assim quanto mais próximo da nulidade o valor do viés, melhor pode ser considerado o desempenho do modelo.

Visando facilitar a comparação dos vieses gerados pelo uso dos diferentes modelos, estes foram também apresentados em escala relativa (\%), dividindo o valor do viés, pela média aritmética de biomassa das árvores que compõem o conjunto de amostras do estrato em observação e, posteriormente, multiplicando este valor resultante por 100. A precisão das estimativas foi avaliada pela amplitude do intervalo de confiança, no nível de $95 \%$ de probabilidade.

Adicionalmente fez-se uso também de um modelo desenvolvido por VISMARA (2013), o qual utiliza o conjunto completo das amostras das árvores amostradas, tanto das isoladas como as das parcelas destrutivas, para verificar a influência da intensidade amostral no desempenho de aplicação das equações.

\subsubsection{Incertezas associadas ao uso de diferentes equações de predição}

Nesta etapa, procurou-se expor os fatores geradores das incertezas associadas às estimativas de biomassa devido ao uso de diferentes equações de predição, aplicando-as aos dados de certo inventário florestal composto de 105 parcelas de $100 \mathrm{~m}^{2}$, totalizando assim, uma intensidade amostral de 1,05 hectares. Para isso, as biomassas destas parcelas foram estimadas utilizando-se o modelo mais adequado obtido neste estudo, em termos de qualidade do seu ajuste e do desempenho de predição, juntamente com outros oito modelos disponíveis na literatura científica. Estes modelos foram selecionados considerando a premissa de que, ou são modelos desenvolvidos para a Floresta Atlântica da região do estudo, ou são modelos pantropicais que teoricamente adequam-se à situação estudada; ou variam quanto as variáveis preditoras inclusas no modelo. Desse modo, foi possível avaliar a influência sobre o desempenho dos modelos aqui ajustados, em função da intensidade de amostras utilizadas na 
modelagem. Informações sobre as equações de literatura utilizadas neste estudo encontram-se na Tabela 3.4.

Tabela 3.4 - Equações de predição de biomassa disponíveis em literatura aplicadas aos dados do estudo para comparação das estimativas

\begin{tabular}{|c|c|c|c|c|c|c|}
\hline Referências & Região & Tipo de Floresta & $\mathbf{R}^{2}$ & Sxy & $\begin{array}{c}\text { No de } \\
\text { amostras }\end{array}$ & $\begin{array}{c}\text { Amplitude } \\
\text { do dap } \\
\text { (cm) }\end{array}$ \\
\hline \multicolumn{7}{|c|}{ Equação PT-1: $\operatorname{Exp}[-2,134+2,540 \ln ($ dap $)]$} \\
\hline Brown (1997) & Pan-tropical & Tropical úmida & 0,97 & $\ldots$ & 170 & $5,0-148,0$ \\
\hline \multicolumn{7}{|c|}{ Equação PT-2: $\operatorname{Exp}\left[-3,3012+0,0439 \ln \left(\right.\right.$ dap $\left.\left.^{2} h t\right)\right]$} \\
\hline Brown et al. (1989) & Pan-tropical & Tropical & $\ldots$ & 0,459 & $\ldots$ & $\ldots$ \\
\hline \multicolumn{7}{|c|}{ Equação PT-3: $\quad \operatorname{Exp}[-2,00+2,42 \ln ($ dap $)]$} \\
\hline Chave; Dubois $(2001$ & Pan-tropical & Tropical & 0,97 & $\ldots$ & 378 & $5,0-125,0$ \\
\hline \multicolumn{7}{|c|}{ Equação PT-4: $\operatorname{Exp}\left[-2,997+\ln \left(d b d a p^{2} h t\right)\right]$} \\
\hline Chave et al. (2005) & Pan-tropical & Tropical úmida & 0,99 & 0,31 & 1.350 & $5,0-156,0$ \\
\hline \multicolumn{7}{|c|}{ Equação ET: $\operatorname{Exp}[-2,71008+1,64740 \ln ($ dap $)+0,94106 \ln (h t)]$} \\
\hline Vismara (2013) & $\begin{array}{l}\text { Floresta } \\
\text { Atlântica }\end{array}$ & Área do estudo & 0,86 & 0,4926 & 219 & $4,8-81,0$ \\
\hline
\end{tabular}

Equação MA-1: $21,297-6,953($ dap $)+0,740(\text { dap })^{2}$

Floresta

\begin{tabular}{lllllll} 
Tiepolo et al. (2002) & Atlântica & Ombrófila Densa & 0,91 & $\ldots$ & $\ldots$ & $4,0-116,0$ \\
\hline
\end{tabular}

Equação MA-2: $\operatorname{Exp}\left[-3,676+0,951 \ln \left(\right.\right.$ dap $\left.\left.{ }^{2} h t\right)\right]$

Floresta Ombrófila Densa

\begin{tabular}{lllllll} 
Burger; Delitti (2008) & Atlântica & (Secundária) & 0,94 & 0,56 & 82 & $1,6-47,8$ \\
\hline
\end{tabular}

Equação MA-3: $\operatorname{Exp}[-1,352+2,009 \ln ($ dap $)]$

Floresta Ombrófila

\begin{tabular}{|c|c|c|c|c|c|c|}
\hline Burger; Delitti (2010): & Atlântica & (Baixa de Restinga) & 0,96 & 0,34 & 102 & $2,1-67,8$ \\
\hline
\end{tabular}

Equação MA-4: $\operatorname{Exp}[-2,3082+1,9870 \ln (d a p)+0,7963 \ln (h t)+0,9297 \ln (d b)]$

Floresta Estacional

\begin{tabular}{lllllll} 
Sotomayor (2013) & Atlântica & Semidecídua & $\ldots$ & 0,2639 & 66 & $5,0-34,9$ \\
\hline \hline PT
\end{tabular}

PT - Equações pan-tropicais; ET - Equação desenvolvida com todas as amostras do estudo; MA equações desenvolvidas na região da Mata Atlântica.

\subsection{Resultados}

\subsubsection{Ajuste dos modelos testados}

As pressuposições para uso do modelo de regressão linear foram plenamente atendidas, tornando-os adequados para aplicação neste estudo. A Tabela 3.5 apresenta as 
estatísticas relacionadas ao ajuste dos modelos, apresentando os resultados do teste $t$ relacionados às estimativas dos parâmetros dos modelos de predição de biomassa testados, assim como informações a respeito da qualidade de ajuste dos modelos, apresentando o valor do coeficiente de determinação ajustado, o erro padrão das estimativas, em porcentagem (Sxy\%), além do valor do AIC.

Tabela 3.5 - Resultados do teste $\mathrm{t}$ relacionados às estimativas dos parâmetros dos modelos e estatísticas relacionadas ao ajuste das equações de predição de biomassa

\begin{tabular}{|c|c|c|c|c|c|c|c|c|}
\hline Equação & Preditores & Coeficientes & Estimativas & Erro & Valor-p & Sxy & $R_{a j}^{2}$ & AIC \\
\hline \multirow{3}{*}{ E-0 } & Intercepto & $\widehat{\beta_{0}}$ & $-2,6348$ & 0,4511 & $2,26 \mathrm{E}-07 * * *$ & \multirow{3}{*}{0,3816} & \multirow{3}{*}{0,916} & \multirow{3}{*}{62,31} \\
\hline & $\log ($ dap) & $\widehat{\beta_{1}}$ & 1,5611 & 0,1472 & $2,23 \mathrm{E}-15 * * *$ & & & \\
\hline & $\log (\mathrm{ht})$ & $\widehat{\beta_{2}}$ & 0,9719 & 0,3139 & $0,00298 * *$ & & & \\
\hline \multirow{4}{*}{ E-1 } & Intercepto & $\widehat{\beta_{0}}$ & $-2,4786$ & 0,5136 & $1,02 \mathrm{E}-05 * * *$ & \multirow{4}{*}{0,3834} & \multirow{4}{*}{0,915} & \multirow{4}{*}{63,87} \\
\hline & $\log ($ dap) & $\widehat{\beta_{1}}$ & 1,5179 & 0,1623 & $3,00 \mathrm{E}-13 * * *$ & & & \\
\hline & $\log (h t)$ & $\widehat{\beta_{2}}$ & 1,0041 & 0,3193 & $0,00261 * *$ & & & \\
\hline & 1/pilodyn & $\widehat{\beta_{3}}$ & $-1,5932$ & 2,4626 & 0,52018 Nos & & & \\
\hline \multirow{4}{*}{ E-2 } & Intercepto & $\widehat{\beta_{0}}$ & $-2,4053$ & 0,4538 & $1,80 \mathrm{E}-06 * * *$ & \multirow{4}{*}{0,3718} & \multirow{4}{*}{0,920} & \multirow{4}{*}{60,00} \\
\hline & $\log ($ dap $)$ & $\widehat{\beta_{1}}$ & 1,6261 & 0,1470 & $5,09 \mathrm{E}-16 * * *$ & & & \\
\hline & $\log (h t)$ & $\widehat{\beta_{2}}$ & 0,9380 & 0,3063 & $0,00331 * *$ & & & \\
\hline & $\log (d b)$ & $\widehat{\beta_{3}}$ & 0,5148 & 0,2519 & $0,04547 *$ & & & \\
\hline \multirow{3}{*}{ E-3 } & Intercepto & $\widehat{\beta_{0}}$ & $-1,3299$ & 0,3869 & $0,00107 * *$ & \multirow{3}{*}{0,4108} & \multirow{3}{*}{0,903} & \multirow{3}{*}{71,63} \\
\hline & $\log (\mathrm{dap})$ & $\widehat{\beta_{1}}$ & 1,9451 & 0,0952 & $2,00 \mathrm{E}-16 * * *$ & & & \\
\hline & 1/pilodyn & $\widehat{\beta_{2}}$ & $-0,3861$ & 2,6064 & $0,88273 \mathrm{~ns}$ & & & \\
\hline \multirow{3}{*}{ E-4 } & intercepto & $\widehat{\beta_{0}}$ & $-1,1771$ & 0,2264 & $2,54 \mathrm{E}-06 * * *$ & \multirow{3}{*}{0,3969} & \multirow{3}{*}{0,909} & \multirow{3}{*}{67,29} \\
\hline & $\log ($ dap) & $\widehat{\beta_{1}}$ & 2,0080 & 0,0830 & $2,00 \mathrm{E}-16 * * *$ & & & \\
\hline & $\log (d b)$ & $\widehat{\beta_{2}}$ & 0,5566 & 0,2685 & $0,0425 *$ & & & \\
\hline \multirow{2}{*}{ E-5 } & intercepto & $\widehat{\beta_{0}}$ & $-1,3778$ & 0,2101 & 1,33E-08 *** & \multirow{2}{*}{0,4075} & \multirow{2}{*}{0,904} & \multirow{2}{*}{69,65} \\
\hline & $\log (\mathrm{dap})$ & $\widehat{\beta_{1}}$ & 1,9546 & 0,0807 & $2,00 \mathrm{E}-16 * * *$ & & & \\
\hline
\end{tabular}

$\mathrm{IC}_{(95 \%)}$ é o intervalo de confiança para a estimativa do parâmetro, ao nível de $95 \%$ de probabilidade. Sxy é o erro padrão da estimativa. $R_{a j}^{2}$ é o coeficiente de determinação ajustado. AIC é o valor obtido para o Critério de Informação de Akaike. Significância do teste $t$ : $* * *<0,001 ; * *<0,01 ; *<0,05$; ns - não significativo

O valor- $p$ do teste $t$ para os parâmetros da regressão linear contendo as variáveis dap e $h t$ como preditoras nos modelos testados foram extremamente baixos e inferiores a 0,01 . Nos casos em que a variável $d b$ estava presente no modelo, o valor-p foi inferior a 0,05. Com isso, se aceita a hipótese alternativa de que as estimativas desses parâmetros são diferentes de zero, sendo os mesmos adequados para uso nas equações de predição. Tal fato, não ocorre quando aplicado o teste $t$ aos coeficientes que incluem o índice de resistência à penetração da madeira (pilodyn), já que o valor-p apresentou-se muito superior a probabilidade considerada para a rejeição da hipótese nula. Neste caso, o poder explicativo da variável resposta em análise, no 
caso, a biomassa, em função desta variável é baixo, sendo assim pouco plausível manter esta informação como variável preditora na equação.

Tal fato pode ser explicado pela inconsistente correlação apresentada pelos valores medidos deste índice com a densidade da madeira das árvores que compuseram a amostra [coeficiente de correlação $(r)=-0,56]$. Teoricamente, esperava-se que a densidade da madeira possuísse correlação inversa com o valor medido pelo penetrômetro, já que quanto mais densa a madeira maior é sua resistência à penetração, sendo assim, menor seria a distância percorrida pelo pino do aparelho, gerando baixos valores medidos deste índice. Porém, este padrão não foi observado para todas as árvores. De fato, isto é verdadeiro. No entanto, muitas espécies arbóreas tropicais apresentam variação da densidade da madeira ao longo do raio da secção transversal do tronco, a qual se reduz no sentido medula-casca, principalmente pelo fato de já conterem cerne. Deste modo, a densidade no centro do lenho é comumente maior que a densidade na porção mais externa, próximo à casca. Com isto, sendo a medida de penetração tomada à altura do DAP e na parte externa do lenho, esta irá representar apenas as características de densidade da madeira desta porção do lenho, não sendo capaz de reproduzir toda expressão da variação existente no lenho do tronco da árvore.

Apenas para exemplificar, se tomada todas as 22 amostras abatidas neste estudo de Calophyllum brasiliense, uma espécie de ampla ocorrência na floresta estudada e que possui distinção de cerne e alburno no lenho, pode-se observar que os valores medidos com o penetrômetro (pilodyn) possuíram correlação positiva com o dap das árvores $(\mathrm{r}=0,902)$, ou seja, quanto maior o diâmetro, maior os valores obtidos na medição deste índice em campo, menor a resistência à penetração na madeira e supostamente sua densidade. No entanto, a densidade básica da madeira da espécie, obtida pelo método direto de determinação, apresentou-se relativamente constante com valor médio de $0,48^{ \pm} 0,04 \mathrm{~g} . \mathrm{cm}^{-1}$. Pelo o exposto, nota-se ser este índice de resistência da madeira à penetração inadequado para explicar a densidade das árvores de algumas das espécies desta floresta, que apresentam esta variação de densidade ao longo da secção transversal do tronco. A aplicação do valor direto da densidade básica da madeira é um preditor mais adequado, já que incorpora em sua determinação toda a porção da secção transversal do tronco, incluindo a porção do cerne e alburno do lenho.

O coeficiente de determinação ajustado $\left(R_{a j}^{2}\right)$ expressa a relação do modelo ajustado em relação ao modelo mais simples construído para os dados empíricos do conjunto de observações da amostra, que é a média amostral. Este quantifica a proporção da biomassa que é explicada pelas variáveis preditoras utilizadas no modelo, sendo considerado melhor o ajuste do modelo quanto mais próximo a 1,0 é o valor deste índice. 
Em projetos voltados ao mercado de carbono, considera-se adequado o uso de equações de predição que apresentem o valor do coeficiente de determinação superior a 0,85 (United Nations Framework Convention on Climate Change - UNFCCC, 2012). Neste sentido, nota-se que para todos os modelos testados, sendo o valor do coeficiente de determinação superior a 0,90, estes são considerados validos para aplicação nas estimativas de estoques de biomassa e carbono de projetos desenvolvidos no âmbito do Mecanismo de Desenvolvimento Limpo - MDL.

O maior valor deste índice foi verificado para a Equação $E-2\left(R_{a j}^{2}=0,920\right)$, o qual inclui os vetores dap, $h t$ e $d b$ como variáveis preditoras. Esta também foi a equação que apresentou o menor erro padrão residual das estimativas (Sxy $=0,3718)$, demonstrando melhor ajuste do modelo aos dados utilizados na amostragem para sua calibração.

Segundo os parâmetros em análise, a retirada da variável preditora $d b$ faz com que o modelo reduza sua qualidade de ajuste, mas ainda assim, a equação considerando apenas dap e $h t$, mantém-se como bom ajuste, conforme verificado para a Equação E-0 $\left(\mathrm{R}_{\mathrm{aj}}^{2}=0,916\right.$; Sxy $=$ 0,3816). O índice de resistência da madeira à penetração, não se apresentou como uma boa variável explicativa no ajuste, mas quando associado ao dap e $h t$, a manutenção desta informação na equação determinou melhoras na qualidade do ajuste quando comparada às equações que não considera nenhuma informação relativa a densidade da madeira. Por fim, o uso do modelo simplificado, representado pela Equação E-5, o qual inclui apenas o dap como variável preditora foi o qual apresentou ajuste menos adequado entre os modelos testados. Este comparado ao modelo representado pela Equação E-2, possui erro padrão da estimativa $9,6 \%$ superior em termos relativos.

Os valores desses critérios estatísticos utilizados para verificação da qualidade do ajuste das equações aproximam-se a outros estudos realizados em florestas nativas da região da Mata Atlântica (Tabela 3.4).

O AIC possibilita uma comparação direta entre os modelos testados, classificando vários modelos concorrentes quanto ao seu ajuste, independentemente de sua relação funcional considerada para a descrição da média, sendo o melhor modelo ajustado o qual apresenta o menor o valor de AIC. Modelos concorrentes com valores de AIC inferior a dois possuem condições suficientes para suportar a hipótese de que estes são iguais, sendo a diferença de quatro a sete, indicativa de que este suporte de igualdade é menor, e por fim, diferenças maiores que 10 seguramente qualificam os modelos em análise como diferentes (BURNHAM; ANDERSON, 2010). 
Segundo este critério, em ordem decrescente, tem-se a seguinte classificação quanto à qualidade de ajuste dos modelos aos dados da amostra: E-2, E-0, E-1, E-4, E-5 e E-3. Pela definição conceitual deste índice, os modelos das Equações E-2 e E-0 podem ser considerados similares em termos de qualidade ou capacidade de explicação da biomassa da amostra, já que apresentam valores com diferença absoluta em torno de 2. Há um distanciamento pouco significativo entre os modelos das equações E-0 e E-1, porém este último expressa-se similar ao Modelo E-2. Os outros três modelos (E-3, E-4 e E-5), os quais não possuem nenhuma informação relativa a altura das árvores, apresentam um distanciamento mais expressivo com relação aos já citados.

\subsubsection{Desempenho das equações ajustadas}

Outra abordagem utilizada para verificar a qualidade dos modelos foi através de seu desempenho em predizer a biomassa da floresta em estudo. Este desempenho foi avaliado em função dos vieses preditivos gerados pelo uso das equações quando utilizado para quantificar a biomassa das 146 árvores presentes nas parcelas. Com isso, tornou-se possível reconhecer as discrepâncias entre o valor real da biomassa determinada pelo método direto em comparação ao valor obtido pelo método indireto, quando aplicada as equações a um conjunto de dados não utilizados em sua construção. Os valores são expressos em termos do viés médio absoluto de predição, sendo para este apresentado o intervalo de confiança a 95\% de probabilidade. $\mathrm{O}$ viés é também apresentado em termos relativos, em percentagem, tomando como base a biomassa média das árvores observada para o estrato em análise.

A primeira abordagem relativa a esta análise foi realizada considerando as diferentes classes de DAP das árvores presentes nas parcelas (Tabela 3.6).

Como a variável preditora resistência à penetração apresentou baixo poder explicativo da biomassa, sua função no modelo torna-se praticamente irrelevante, de modo que sua exclusão pouco afeta as estimativas da biomassa, motivo pelo qual as Equações E-1 e E-3 expressam-se de forma similar às Equações E-0 e E-5, respectivamente, que são as formas simplificadas desses modelos com a exclusão da variável pilodyn.

Nota-se que os valores de viés apresentado pelas estimativas de biomassa foram negativos em todos as classes de DAP e para todos as equações, com uma única exceção para A Equação E-4 na classe de 5,0 a 10,0 cm, o que implica em considerar que as equações ajustados apresentam tendências em subestimar a biomassa real das árvores. Observa-se que o viés na predição aumenta proporcionalmente em relação às classes de DAP, fato esperado em 
decorrência da menor amplitude dos valores absolutos do viés nas classes de menor diâmetro. Porém, o viés relativo $(\%)$ permanece praticamente constante entre as classes de DAP até 50 cm, em especial, para as Equações E-0, E-1 e E-2, os quais apresentaram os melhores ajustes segundo os critérios de verificação adotados. Neste sentido, a Equação E-0 apresentou viés relativo de $-3,5 \%$ a -6,9\%, já a Equação E-1 apresentou variação de $-3,7 \%$ a -6,7\%, e por fim, esta variação para a Equação 2 foi de $-2,8 \%$ a $-8,0 \%$.

Tabela 3.6 - Informação referente aos vieses das estimativas de biomassa $(\mathrm{kg})$ das árvores representantes de diferentes classes de DAP em função da Equação de predição utilizada

\begin{tabular}{|c|c|c|c|c|c|c|c|}
\hline \multirow{2}{*}{$\begin{array}{l}\text { Classes de } \\
\text { DAP }(\mathbf{c m})\end{array}$} & \multirow[b]{2}{*}{ Parâmetro } & \multicolumn{6}{|c|}{ Equações } \\
\hline & & E-0 & E-1 & E-2 & E-3 & E-4 & E-5 \\
\hline \multirow{3}{*}{$\begin{array}{c}5,0-10,0 \\
(87)\end{array}$} & Viés (kg) & $-0,8$ & $-0,9$ & $-0,6$ & $-0,2$ & 0,0 & $-0,2$ \\
\hline & $\mathrm{IC}_{95 \%}(\mathrm{~kg})$ & {$[-2,7 ; 0,7]$} & {$[-2,4 ; 0,6]$} & {$[-2,0 ; 0,9]$} & {$[-1,6 ; 1,1]$} & {$[-1,3 ; 1,4]$} & {$[-1,6 ; 1,1]$} \\
\hline & Viés (\%) & $-5,9$ & $-6,7$ & $-4,1$ & $-1,8$ & 0,4 & $-1,7$ \\
\hline \multirow{3}{*}{$\begin{array}{c}10,1-20,0 \\
\quad(43)\end{array}$} & Viés (kg) & $-2,2$ & $-2,2$ & $-1,7$ & $-3,0$ & $-2,3$ & $-3,0$ \\
\hline & $\mathrm{IC}_{95 \%}(\mathrm{~kg})$ & {$[-9,8 ; 5,4]$} & {$[-9,8 ; 5,4]$} & {$[-9,2 ; 5,8]$} & {$[-13,2 ; 7,3]$} & {$[-12,5 ; 7,9]$} & {$[-13,2 ; 7,3]$} \\
\hline & Viés (\%) & $-4,3$ & $-4,2$ & $-3,4$ & $-5,8$ & $-4,4$ & $-5,8$ \\
\hline \multirow{3}{*}{$\begin{array}{c}20,1-30,0 \\
\text { (7) }\end{array}$} & Viés (kg) & $-6,5$ & $-6,4$ & $-8,0$ & $-8,2$ & $-9,4$ & $-8,3$ \\
\hline & $\mathrm{IC}_{95 \%}(\mathrm{~kg})$ & {$[-53,1 ; 40,1]$} & {$[-53,5 ; 40,6]$} & {$[-50,0 ; 34,0]$} & {$[-65,6 ; 49,2]$} & {$[-65,1 ; 46,2]$} & {$[-65,7 ; 49,2]$} \\
\hline & Viés (\%) & $-4,7$ & $-4,6$ & $-5,8$ & $-5,9$ & $-6,8$ & $-5,9$ \\
\hline \multirow{3}{*}{$\begin{array}{c}30,1-50,0 \\
(5)\end{array}$} & Viés (kg) & $-10,9$ & $-10,1$ & $-7,8$ & $-33,6$ & $-26,0$ & $-33,6$ \\
\hline & $\mathrm{IC}_{95 \%}(\mathrm{~kg})$ & {$[-145,3 ; 123,5]$} & {$[-142,6 ; 122,3]$} & {$[-155,8 ; 140,2]$} & {$[-230,1 ; 162,8]$} & {$[-247,8 ; 195,9]$} & {$[-230,9163,7]$} \\
\hline & Viés (\%) & $-3,9$ & $-3,7$ & $-2,8$ & $-12,2$ & $-9,4$ & $-12,2$ \\
\hline \multirow{3}{*}{$\begin{array}{c}>50,0 \\
(4)\end{array}$} & Viés (kg) & $-968,8$ & $-951,6$ & $-904,5$ & $-1090,3$ & $-1028,8$ & $-1093,9$ \\
\hline & $\mathrm{IC}_{95 \%}(\mathrm{~kg})$ & {$[-2.738 ; 800]$} & {$[-2.696 ; 793]$} & [-2.668;859] & {$[-2.866 ; 685]$} & {$[-2.801 ; 743]$} & {$[-2.875 ; 687]$} \\
\hline & Viés (\%) & $-49,3$ & $-48,5$ & $-46,1$ & $-55,5$ & $-52,4$ & $-55,7$ \\
\hline \multirow{3}{*}{$\begin{array}{l}\text { Todas } \\
\text { Situação A* } \\
\quad(146)\end{array}$} & Viés (kg) & $-28,3$ & $-27,9$ & $-26,3$ & $-32,4$ & $-30,2$ & $-32,5$ \\
\hline & $\mathrm{IC}_{95 \%}(\mathrm{~kg})$ & {$[-65,4 ; 8,7]$} & {$[-64,4 ; 8,6]$} & {$[-62,1 ; 9,6]$} & {$[-72,1 ; 7,2]$} & {$[-68,7 ; 8,3]$} & {$[-72,3 ; 7,2]$} \\
\hline & Viés (\%) & $-30,5$ & $-30,0$ & $-28,2$ & $-34,9$ & $-32,4$ & $-35,0$ \\
\hline \multirow{3}{*}{$\begin{array}{c}\text { Todas } \\
\text { Situação B* } \\
\quad(142)\end{array}$} & Viés (kg) & $-1,8$ & $-1,9$ & $-1,5$ & $-2,6$ & $-2,0$ & $-2,6$ \\
\hline & $\mathrm{IC}_{95 \%}(\mathrm{~kg})$ & {$[9,0 ;-0,6]$} & {$[-9,1 ;-0,7]$} & {$[-8,3 ; 0,4]$} & {$[-12,9 ; 1,1]$} & {$[-11,6 ; 1,0]$} & {$[-12,9 ;-1,1]$} \\
\hline & Viés (\%) & $-4,6$ & $-4,7$ & $-3,8$ & $-6,5$ & $-5,1$ & $-6,5$ \\
\hline
\end{tabular}

* Situação A - todas as árvores medidas nas parcelas; Situação B - exclusão das árvores com DAP > 50 $\mathrm{cm}$. Entre parênteses - número de árvores amostradas em cada classe de DAP

Para as outras equações (E-3, E-4 e E-5) o viés relativo é um pouco mais acentuado na classe de DAP de 30,0 a 50,0 cm, chegando a -12,2\%. Porém, nas classes inferiores de DAP, estas equações comportam-se de forma similar às demais equações testadas. Na classe de diâmetro das árvores com DAP > $50 \mathrm{~cm}$, o viés apresentou-se alto com viés relativo expressando-se entre $-46,1 \%$ a $-55,7 \%$, sendo mais baixo para a Equação E-2, e mais alto para 
a Equação E-5. Isto demonstra menor capacidade de predição das equações ajustadas em quantificar a biomassa das árvores de grande porte, fato que pode estar relacionado à diferente relação funcional das variáveis de predição com relação à biomassa destas árvores devido a sua arquitetura diferenciada, bem como à pequena quantidade desses indivíduos dentro da amostra de árvores utilizadas no ajuste das equações.

Porém, esta segunda condição é inerente da floresta na área em estudo, já que no próprio inventário florestal realizado na área, em um conjunto de 1.933 indivíduos amostrados, apenas 0,72\% (14 árvores) apresentaram DAP > $50 \mathrm{~cm}$. Deste modo, considerase ter a amostragem representado de forma equitativa todas as classes de diâmetro, tanto para o conjunto de árvores isoladas, como para o conjunto de árvores nas parcelas. Isto pode ser verificado pelo gráfico presente na Figura 3.1, o qual apresenta a distribuição das classes diamétricas das árvores presentes no conjunto de amostras de árvores isoladas, parcelas e inventário florestal da área.

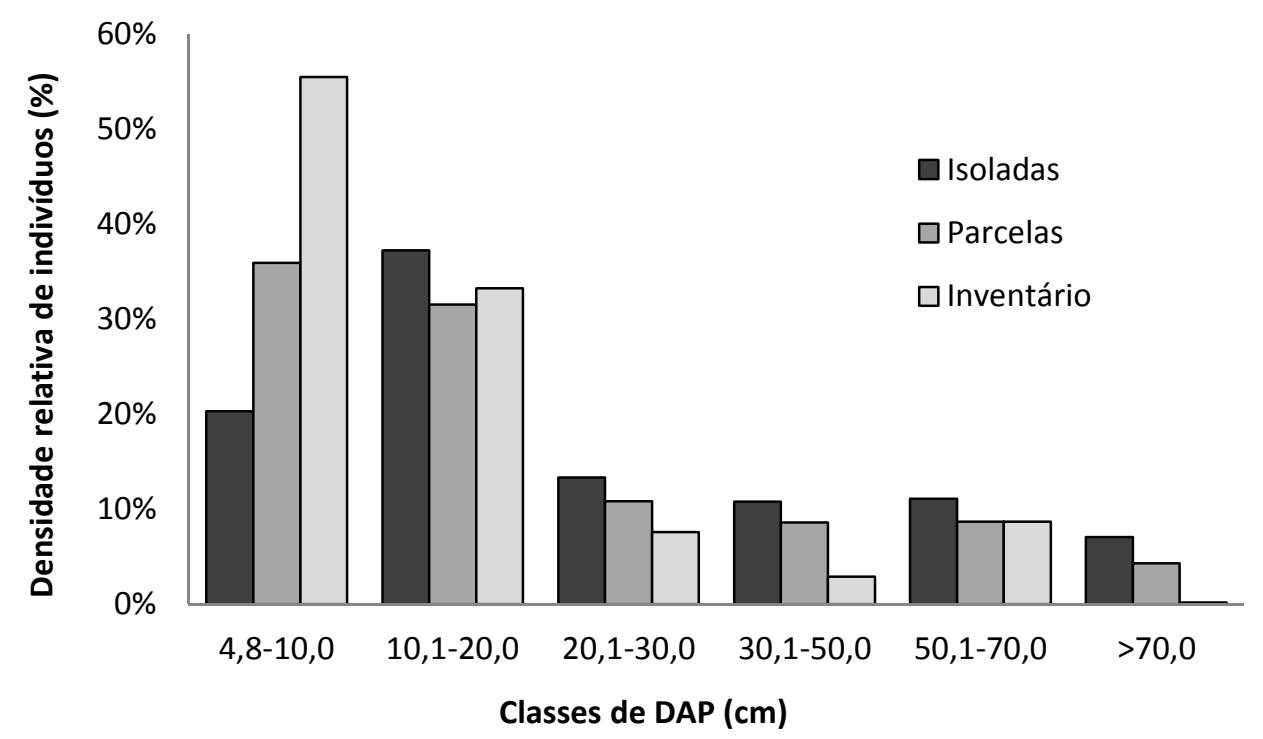

Figura 3.1 - Distribuição diamétrica das árvores presentes no diferentes conjuntos de amostras utilizados no estudo

O viés relativo de predição, considerando todas as árvores presentes nas parcelas, variou de $-39,3 \%$ a $-53,8 \%$. No entanto, se excluídos os indivíduos de maior porte (DAP > 50 $\mathrm{cm}$ ) do conjunto amostral das parcelas utilizadas para verificação do desempenho de predição das equações, os quais apresentam grandes discrepâncias entre a biomassa estimada e a real, os valores do viés relativo passam a ser inferiores a $-6,5 \%$. Neste sentido, o melhor desempenho de predição foi apresentado pela Equação 2 (Viés\% = -3,8), seguida das 
Equações E-0 (Viés\% = -4,6\%) e E-1 (Viés\% = -4,7). A Figura 3.2 apresenta um gráfico de dispersão dos resíduos apontando os indivíduos de grande porte geradores dos maiores valores do viés de predição, exclusos para a obtenção dos valores de viés relativo acima exposto.

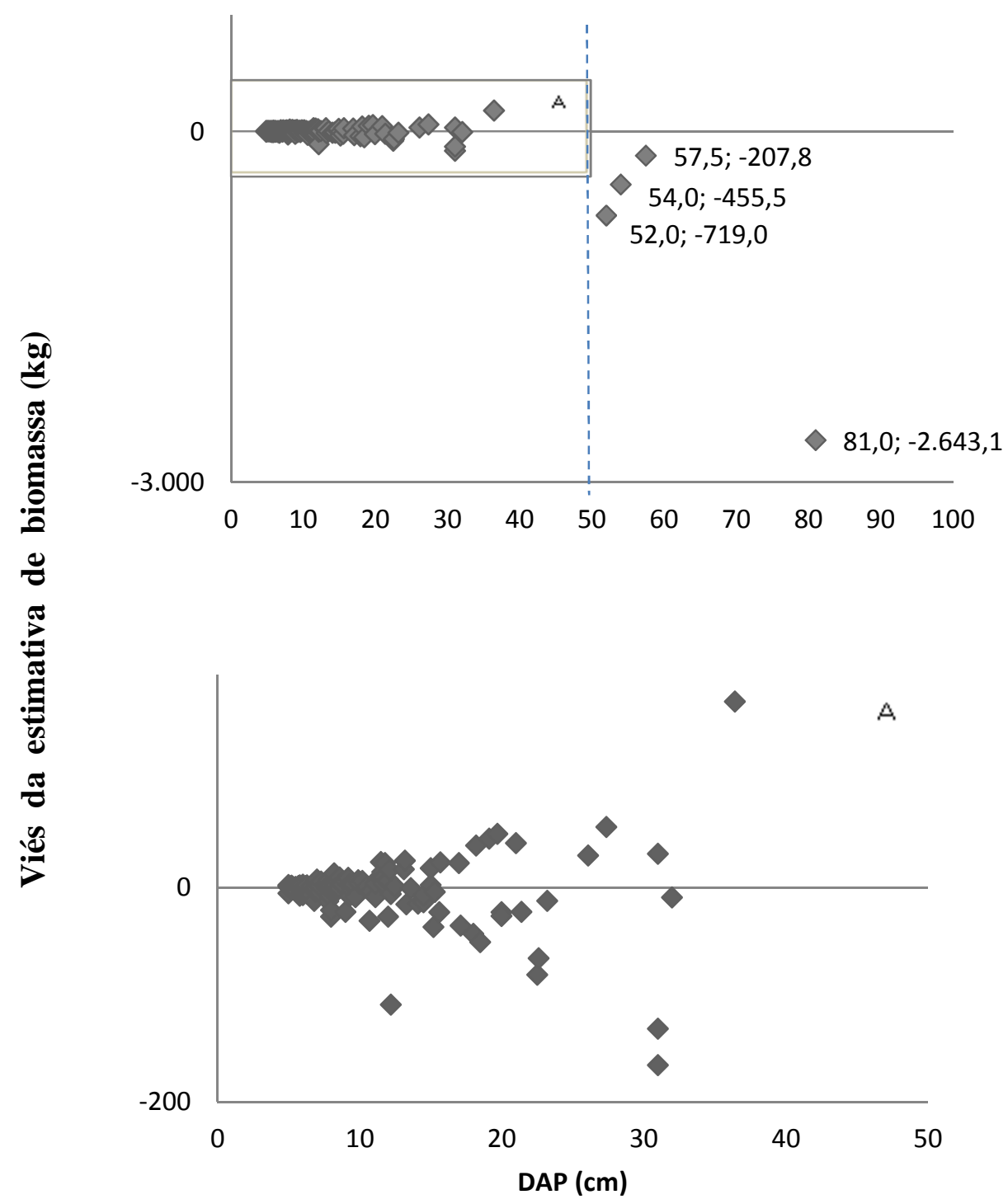

Figura 3.2 - Dispersão dos valores residuais médios da estimativa de biomassa das árvores presentes nas parcelas gerados pela aplicação das equações ajustadas. O índice A no gráfico superior representa a área ampliada e apresentada no gráfico inferior

A observação da figura 3.2 pode sugerir um falso comportamento heterocedástico da variância. Cabe ressaltar, no entanto, que os resíduos neste gráfico estão na escala original. A observação correta do comportamento dos resíduos deve ser feita a partir da observação dos gráficos presentes nos ANEXOS A a F. 
Outra análise relativa ao comportamento do viés foi realizada considerando o conjunto de árvores presentes nas parcelas classificadas em diferentes estágios sucessionais (Tabela 3.7). Esta abordagem é pertinente visto que em muitos estudos de biomassa, as florestas são estratificadas considerando classes de estágios sucessionais como critério para definição de estratos. A estratificação da amostragem é um procedimento comumente utilizado em inventários florestais e possui o intuito de minimizar a variabilidade dos dados dentro de um mesmo estrato, reduzindo a variância, de modo a aumentar a precisão das estimativas da média a partir de uma intensidade amostral normalmente mais baixa. Atualmente, este procedimento de estratificação, é aportado por ferramentas de análises de sensoriamento remoto e sistema de informação geográfico, possibilitando a definição de classes, através da classificação visual das imagens ou por índices de vegetação. A partir deste procedimento, extrapolações das estimativas para área total são realizadas para a quantificação de biomassa em escala ampla.

Tabela 3.7 - Vieses das estimativas de biomassa do conjunto de árvores presentes nas parcelas dos diferentes estágios sucessionais em função das Equações de predição utilizadas

\begin{tabular}{|c|c|c|c|c|c|c|c|}
\hline \multirow{2}{*}{$\begin{array}{c}\text { Estágio } \\
\text { Sucessional } \\
\end{array}$} & \multirow[b]{2}{*}{ Parâmetro } & \multicolumn{6}{|c|}{ Equações ajustadas } \\
\hline & & E-0 & E-1 & E-2 & E-3 & E-4 & E-5 \\
\hline \multirow{3}{*}{$\begin{array}{c}\text { Inicial } \\
\text { (50 árvores) }\end{array}$} & Viés (kg) & $-2,7$ & $-2,9$ & $-2,4$ & 0,2 & 0,5 & 0,2 \\
\hline & $\mathrm{IC}_{95 \%}(\mathrm{~kg})$ & {$[-6,4 ; 1,1]$} & {$[-6,6 ; 0,9]$} & {$[-6,1 ; 1,3]$} & {$[-4,1 ; 4,5]$} & {$[-3,8 ; 4,9]$} & {$[-4,1 ; 4,6]$} \\
\hline & Viés (\%) & $-12,9$ & $-14,0$ & $-11,7$ & 1,0 & 2,6 & 1,2 \\
\hline \multirow{3}{*}{$\begin{array}{c}\text { Médio } \\
\text { (61 árvores) }\end{array}$} & Viés (kg) & 1,0 & 0,7 & 2,0 & 3,6 & 5,0 & 3,7 \\
\hline & $\mathrm{IC}_{95 \%}(\mathrm{~kg})$ & {$[-5,8 ; 7,8]$} & {$[-6,0 ;-7,3]$} & {$[-5,4 ; 9,4]$} & {$[-5,9 ; 13,1]$} & {$[-5,8 ; 15,8]$} & {$[-5,9 ; 13,2]$} \\
\hline & Viés (\%) & 2,8 & 1,9 & 5,8 & 10,4 & 14,4 & 10,5 \\
\hline \multirow{3}{*}{$\begin{array}{c}\text { Avançado } \\
\text { (35 árvores) } \\
\text { Situação A* }\end{array}$} & Viés (kg) & $-116,1$ & $-113,5$ & $-109,6$ & $-141,9$ & $-135,3$ & $-142,4$ \\
\hline & $\mathrm{IC}_{95 \%}(\mathrm{~kg})$ & {$[-272,4 ; 40,1]$} & $-267,3 ; 40,4]$ & {$[-260,7 ; 41,5]$} & {$[-307,2 ; 23,4]$} & {$[-295,5 ; 24,9]$} & {$[-308,2 ; 23,4]$} \\
\hline & Viés (\%) & $-38,9$ & $-38,0$ & $-36,7$ & $-47,5$ & $-45,3$ & $-47,7$ \\
\hline \multirow{3}{*}{$\begin{array}{l}\text { Avançado } \\
\text { (31 árvores) } \\
\text { Situação B* }\end{array}$} & Viés (kg) & $-6,11$ & $-5,30$ & $-7,06$ & $-19,54$ & $-20,02$ & $-19,63$ \\
\hline & $\mathrm{IC}_{95 \%}(\mathrm{~kg})$ & {$[-19,6 ; 7,4]$} & {$[-19,0 ; 8,4]$} & {$[-20,1 ; 6,0]$} & {$[-37,7 ;-1,4]$} & {$[-37,8 ;-2,2]$} & {$[-37,8-1,5]$} \\
\hline & Viés (\%) & $-7,33$ & $-6,36$ & $-8,46$ & $-23,43$ & $-24,01$ & $-23,55$ \\
\hline
\end{tabular}

As parcelas dos diferentes estágios sucessionais da floresta possuem estrutura florestal distinta com relação à distribuição diamétrica, possuindo as parcelas instaladas nas áreas em estágio inicial uma maior, e exclusiva, representação de indivíduos de pequeno porte; e as parcela nos estágios mais avançados, árvores representantes de todas as classes diamétricas, incluindo os indivíduos de grande porte, com diâmetro superior a $50 \mathrm{~cm}$. Consequentemente, as parcelas em estágios iniciais acabam incorporando os viesse das árvores de menor porte, 
que são menores, e as em estágio mais avançados, incorporam os vieses de subestimação da biomassa verificada para as árvores grandes. Esta situação pode ser verificada pelos resultados referentes aos vieses apresentado na Tabela 3.7. Observando as médias de viés absoluto das árvores das parcelas em estágio inicial e médio, verifica-se que estas são mais baixas e próximas a nulidade, se comparado às parcelas em estágio avançado.

Novamente às árvores grandes fazem com que o viés de predição da biomassa torne-se amplo neste estágio. A exclusão das árvores de grande porte, representada por quatro árvores de DAP > $50 \mathrm{~cm}$, reduz o viés relativo das equações de melhor desempenho (E-0, E-1 e E-2), de cerca de $-38 \%$ para aproximadamente $-7 \%$.

Nos estágios iniciais, outro ponto a ser observados é a variação dos vieses existentes entre as equações que consideram a altura total $(h t)$ como variável do modelo na estimação das árvores nas classes de DAP $<10 \mathrm{~cm}$. Estes são sempre negativos nas áreas com maior número de árvores de porte pequeno. Este fato está relacionado à diferença da arquitetura (forma) das árvores neste estágio com relação às árvores utilizadas na amostra para o processo de modelagem das equações de predição. Estas últimas foram coletadas em ambientes de florestas em estágio médio a avançado. Nestes ambientes as árvores de pequeno porte apresentam formas mais retilíneas com proporção média da biomassa entre tronco e copa de aproximadamente 2:1 (tronco: 65,4\%; copa: 34,6\%). Já nas parcelas do estágio inicial esta relação apresentou relação inversa $(45,1 \% ; 54,9 \%)$, ou seja, menor biomassa no tronco e maior na copa, visto que as copas tendem a serem mais densas e esparsas, sendo esta uma característica intrínseca destes ambientes de florestas secundárias em estágio inicial de regeneração. Neste sentido, a inclusão da informação de altura total às equações ajustadas muito provavelmente não consegue assimilar esta pequena nuance expressa pelas árvores de pequeno porte presentes neste estágio, gerando uma pequena subestimação de sua biomassa.

\subsubsection{Desempenho das equações de predição disponíveis em literatura}

A Tabela 3.8 apresenta os valores do viés médio na estimação da biomassa seca das árvores, bem como o viés relativo à média observada, em termos percentuais, considerando diferentes classes de DAP das árvores e os estágios sucessionais das parcelas destrutivas. De modo a facilitar a visualização destas informações, a Figura 3.3 apresenta os gráficos do viés relativo (\%) dessas equações em função da classe de DAP e do estágio sucessional das parcelas destrutivas. 
Tabela 3.8 - Desempenho das equações de predição presentes na literatura científica, expressos pelos vieses de predição da biomassa das árvores amostradas nas parcelas destrutivas (Viés médio, em kg, e Viés relativo, em percentual)

\begin{tabular}{|c|c|c|c|c|c|c|c|c|c|c|c|}
\hline \multirow[b]{2}{*}{ Estrato } & \multirow[b]{2}{*}{ Viés } & \multirow{2}{*}{$\begin{array}{l}\text { No de } \\
\text { árvores }\end{array}$} & \multicolumn{9}{|c|}{ Equações da literatura utilizadas } \\
\hline & & & PT-1 & PT-2 & PT-3 & PT-4 & ET & MA-1 & MA-2 & MA-3 & MA-4 \\
\hline \multicolumn{12}{|c|}{ Classe de DAP $(\mathrm{cm})$} \\
\hline \multirow{2}{*}{$5,0-10,0$} & \multirow{2}{*}{87} & $\mathrm{~kg}$ & 4,9 & $-2,4$ & 3,3 & $-0,83$ & $-1,2$ & $-2,6$ & $-5,5$ & 0,5 & 3,1 \\
\hline & & $\%$ & 36,8 & $-17,9$ & 25,1 & $-6,3$ & $-9,4$ & $-19,5$ & $-41,0$ & 4,0 & 23,2 \\
\hline \multirow{2}{*}{$10,1-20,0$} & \multirow{2}{*}{43} & $\mathrm{~kg}$ & 48,4 & 1,9 & 33,2 & 10,3 & $-1,7$ & 22,1 & $-12,6$ & 1,9 & 23,8 \\
\hline & & $\%$ & 94,1 & 3,7 & 64,7 & 20,1 & $-3,2$ & 43,0 & $-24,6$ & 3,6 & 46,3 \\
\hline \multirow{2}{*}{$20,1-30,0$} & \multirow{2}{*}{7} & $\mathrm{~kg}$ & 213,6 & 26,2 & 145,4 & 48,9 & $-0,5$ & 129,8 & $-18,0$ & 8,7 & 82,4 \\
\hline & & $\%$ & 153,6 & 18,8 & 104,5 & 35,2 & $-0,4$ & 93,4 & $-13,0$ & 6,2 & 59,3 \\
\hline \multirow{2}{*}{$30,1-50,0$} & \multirow{2}{*}{5} & $\mathrm{~kg}$ & 507,7 & 87,5 & 334,7 & 163,3 & 6,8 & 294,7 & $-8,4$ & 2,8 & 219,8 \\
\hline & & $\%$ & 183,6 & 31,6 & 121,0 & 59,0 & 2,4 & 106,5 & $-3,0$ & 1,0 & 79,5 \\
\hline \multirow{2}{*}{$>50,0$} & \multirow{2}{*}{4} & $\mathrm{~kg}$ & 2231,5 & $-267,1$ & 1062,9 & 343,1 & $-847,9$ & 497,4 & $-698,7$ & $-924,0$ & 447,7 \\
\hline & & $\%$ & 113,6 & $-13,6$ & 54,1 & 17,5 & $-43,2$ & 25,3 & $-35,6$ & $-47,1$ & 22,8 \\
\hline \multicolumn{12}{|c|}{ Estágio sucessional } \\
\hline \multirow{2}{*}{ Inicial } & \multirow{2}{*}{50} & $\mathrm{~kg}$ & 15,4 & $-3,1$ & 10,9 & $-0,9$ & $-2,9$ & 3,7 & $-8,0$ & 1,9 & 5,2 \\
\hline & & $\%$ & 74,8 & $-15,2$ & 52,9 & $-4,4$ & $-13,9$ & 18,1 & $-38,8$ & 9,2 & 25,1 \\
\hline \multirow{2}{*}{ Médio } & \multirow{2}{*}{61} & $\mathrm{~kg}$ & 53,4 & 5,6 & 38,1 & 13,9 & 1,7 & 28,8 & $-5,3$ & 7,8 & 24,7 \\
\hline & & $\%$ & 154,4 & 16,1 & 110,0 & 40,1 & 5,0 & 83,1 & $-15,4$ & 22,5 & 71,4 \\
\hline \multirow{2}{*}{$\begin{array}{l}\text { Avançado } \\
\text { (situação A) }\end{array}$} & \multirow[t]{2}{*}{35} & $\mathrm{~kg}$ & 326,8 & $-21,6$ & 165,6 & 60,1 & $-100,1$ & 90,2 & $-93,1$ & $-116,1$ & 85,5 \\
\hline & & $\%$ & 109,6 & $-7,3$ & 55,5 & 20,1 & $-33,6$ & 30,2 & $-31,2$ & $-38,9$ & 28,7 \\
\hline \multirow{2}{*}{$\begin{array}{l}\text { Avançado } \\
\text { (situação B) }\end{array}$} & \multirow{2}{*}{31} & $\mathrm{~kg}$ & 81,1 & 10,0 & 49,8 & 23,6 & $-3,7$ & 37,7 & $-14,9$ & $-11,9$ & 38,8 \\
\hline & & $\%$ & 97,2 & 3,4 & 16,7 & 7,9 & $-1,2$ & 12,6 & $-5,0$ & $-4,0$ & 13,0 \\
\hline \multicolumn{12}{|c|}{ Totais } \\
\hline \multirow{2}{*}{$\begin{array}{c}\text { Todas árvores } \\
\text { (situação A) }\end{array}$} & \multirow[t]{2}{*}{146} & $\mathrm{~kg}$ & 105,9 & $-3,9$ & 59,3 & 19,9 & $-24,3$ & 34,9 & $-27,3$ & $-23,9$ & 32,6 \\
\hline & & $\%$ & 113,9 & $-4,2$ & 63,8 & 21,4 & $-26,1$ & 37,5 & $-29,3$ & $-25,7$ & 35,0 \\
\hline \multirow{2}{*}{$\begin{array}{l}\text { Todas árvores } \\
\text { (situação B) }\end{array}$} & \multirow{2}{*}{142} & $\mathrm{~kg}$ & 46,1 & 3,5 & 31,1 & 10,8 & $-1,1$ & 21,9 & $-8,4$ & 1,4 & 20,9 \\
\hline & & $\%$ & 114,3 & 3,7 & 33,4 & 11,6 & $-1,1$ & 23,5 & $-9,0$ & 1,5 & 22,5 \\
\hline
\end{tabular}

* Situação A - todas as árvores medidas nas parcelas; Situação b - Exclusão das árvores com DAP > $50 \mathrm{~cm}$

As equações pan-tropicais, PT-1 e PT-3, as quais consideram apenas a informação de dap como variável preditora, apresentaram os maiores vieses de predição, superestimando a biomassa em todas as situações, sendo estas maiores nas classes de diâmetro entre 20,0 a 50,0 $\mathrm{cm}$. A mesma observação de superestimativas no intervalo destas classes de DAP é verificada também para as equações pan-tropicais PT-2 e PT-4, os quais consideram a altura total das 
árvores $(h t)$ como uma informação adicional, expresso pelo diâmetro ao quadrado pela altura $\left(\operatorname{dap}^{2} \mathrm{~h}\right)$.
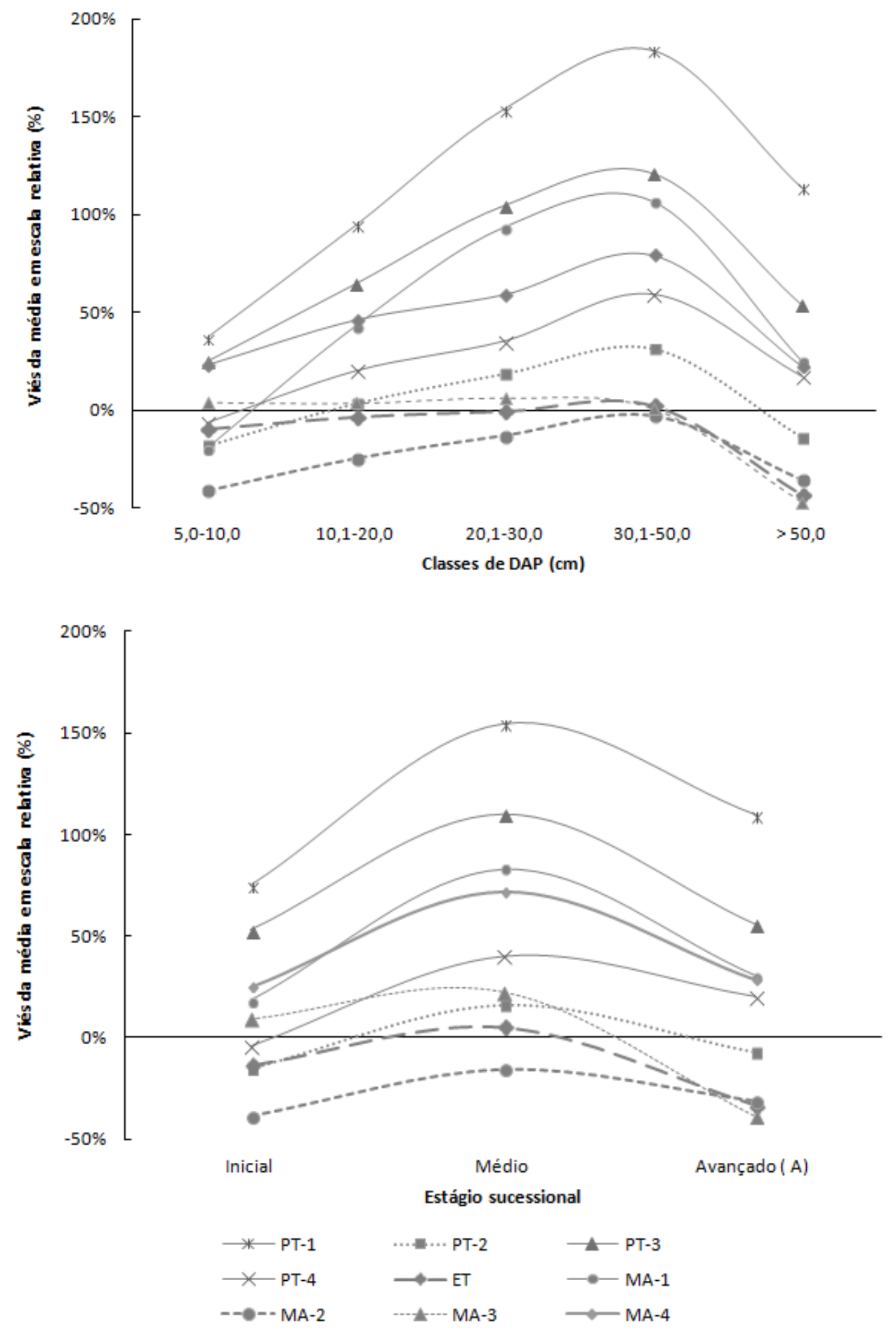

Figura 3.3 - Viés relativo da média de biomassa das árvores apresentado pelas equações de predição disponíveis na literatura, considerando como estratos as classes de DAP e estágios sucessionais da floresta. Observação: As linhas continuas apresentadas nos gráficos são mera ilustrações da tendência das estimativas nos diferentes estágios e classes de DAP e não são modelos matemáticos ajustados aos dados 
Porém os vieses são muito menores comparativamente aos apresentados pelas equações anteriores, sendo que a Equação PT-2 aproxima-se ao desempenho das equações desenvolvidas na região do estudo. Considerando o conjunto total de amostras, esta equação é o qual apresenta o menor viés de predição da biomassa, em especial, pelo fato de apresentar maior capacidade de predição das árvores de grande porte, visto que para as demais equações avaliadas estas árvores apresentam influências notáveis nos vieses de predição da biomassa. Apesar do baixo viés na estimativa da biomassa predita, quando considerado o conjunto total de amostras, nota-se que este viés não é constante para todas as classes de diâmetro, ora subestimando a biomassa, nas classes de menor diâmetro, ora superestimando a biomassa, nas classes de diâmetro intermediário. Considerando que muitos dos estudos adotam os estágios sucessionais como critério de estratificação da amostragem, esta situação pode gerar sérios problemas nas estimativas individuais dos estratos.

Superestimativas da biomassa das árvores amostradas nas parcelas destrutivas em todas as classes de diâmetro também foram verificadas na aplicação da Equação MA-4, modelada a partir de dados obtidos na região da Mata Atlântica. No entanto, a formação florestal para obtenção dos dados de sua amostra foi a floresta estacional semidecidual, a qual apresenta composição e estrutura bastante diferente da floresta em estudo.

A Equação MA-1 também apresentou ampla discrepância com relação ao valor nas estimativas da biomassa das árvores neste estudo, subestimando o componente das árvores de menor porte e superestimando as árvores das classes intermediárias de diâmetro, especialmente de 20 a $50 \mathrm{~cm}$. Modelos com funções probabilísticas polinomiais como o expresso pela equação MA-1, apesar de normalmente apresentarem bons ajustes aos dados originais, com altos valores do coeficiente de determinação $\left(\mathrm{R}^{2}\right)$, mascaram limitações relacionadas ao seu desempenho de aplicação.

A Equação MA-3, desenvolvida a partir de dados coletados em uma floresta de restinga em mesma região ecológica da área do estudo, apresentando assim, expressiva similaridade florística e estrutural com a floresta em questão, apresentou tendência à subestimação das árvores de menor porte, reduzindo esta situação, para as classes de diâmetros intermediárias, sendo praticamente nulos os vieses na classe de diâmetro entre 30,0 a 50,0 cm. Esta equação incorpora apenas o dap como variável preditora.

Já a Equação MA-2, modelada com dados de uma floresta secundária da região da Mata Atlântica, incorporando informação de dap e $h t$, apresentou elevado desempenho na predição da biomassa das árvores, com valores de viesse da estimativa baixos e similares aos observados pelas equações de melhor desempenho ajustadas neste estudo. 
Por fim, a Equação ET, a qual considera o conjunto completo de amostras de árvores utilizado neste estudo (árvores isoladas e parcelas), também assemelha-se as equações de melhor desempenho ajustadas no estudo, com baixo viés relativo nas classes de DAP entre 10,0 a 50,0 cm, aumentando na classe de DAP > $50 \mathrm{~cm}$, para a qual apresenta viés de predição negativo. No entanto, se avaliado seu desempenho quando excluídas as quatro árvores da amostra com DAP > $50 \mathrm{~cm}$, esta equação apresenta alto desempenho, com valor médio de viés de $1,1 \%$ negativo.

Das equações de literatura utilizadas, com a exclusão das árvores de grande porte, as duas de melhor desempenho são: MA-3, com viés relativo igual a 1,5\%, e; PT-2, com 3,7\%. A melhor qualidade de desempenho destas com relação à demais equações de literatura avaliadas, pode ser verificada pela análise gráfica dos vieses relativos (Figura 3.3). Por esta, nota-se que estas duas equações possuem certa linearidade dos vieses de predição sempre próxima a nulidade. Exclusas as árvores de DAP $>50 \mathrm{~cm}$, especialmente a Equação MA-3, passa a apresentar média de viés ainda melhor, com valores constantes próximos a nulidade (Figura 3.4), comportamento este similar aos modelos desenvolvidos para o presente estudo.

Um aspecto a se considerar com relação à Equação ET é o fato de que os parâmetros clássicos utilizados como critérios de seleção dessas equações $\left(\mathrm{R}^{2}=0,85 ; \operatorname{Sxy} \%=0,49\right)$, expressam ajustes inferiores ao verificados para equações ajustadas apenas com as 80 árvores que compõem a amostra de árvores isoladas. No entanto, avaliando seu desempenho, verificase uma pequena superioridade com relação à equação de melhor desempenho ajustado com amostras isoladas, a Equação E-2. 


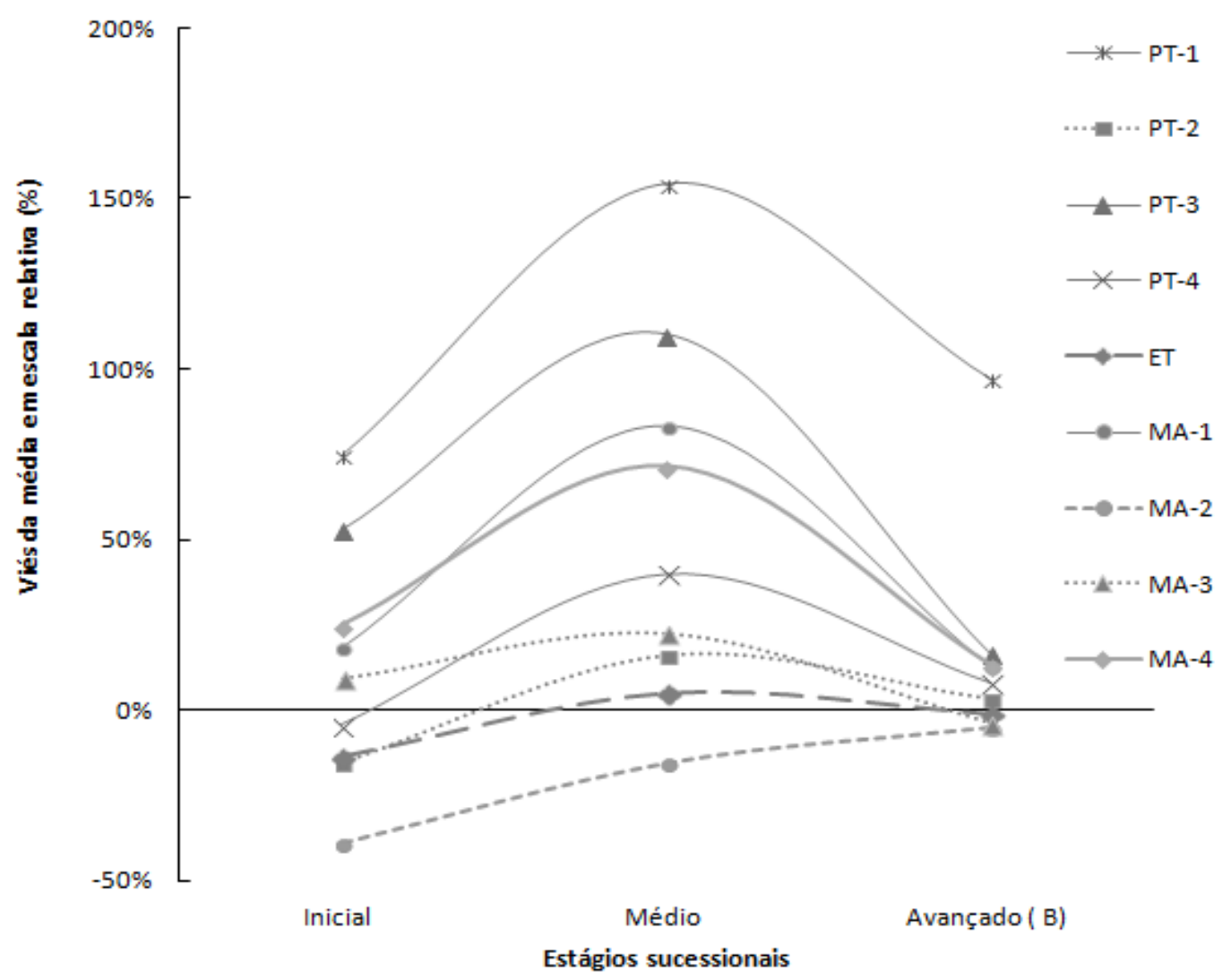

Figura 4. Viés relativo da média de biomassa das árvores que compõem o conjunto de amostra das parcelas em distintos estágios sucessionais, expresso pelo uso das diferentes equações de predição da literatura, considerando a exclusão das quatro árvores de grande porte que apresentam DAP $>50 \mathrm{~cm}$ (Situação B). Observação: as linhas continuas apresentadas no gráfico são mera ilustrações da tendência das estimativas nos diferentes estágios sucessionais e não são modelos matemáticos ajustados aos dados

\subsubsection{Influência da fonte de informação de densidade da madeira na predição da biomassa}

Como visto, a Equação E-2, a qual incorpora a informação de densidade básica da madeira $(d b)$, juntamente ao diâmetro $(d a p)$ e altura da árvore $(h t)$ foi o que apresentou melhor desempenho em predizer a biomassa das árvores entre as equações ajustadas neste estudo. Porém, a inexistência de medidas direta de densidade básica da madeira das árvores nos processos de inventário, obriga a utilização de dados secundários provindos da literatura científica. Estes valores comumente são expressos com teor de umidade de 12 a $15 \%$, de modo que se aplicados diretamente aos modelos deverão gerar superestimativas. Assim, aplicou-se uma equação de regressão para correção dos dados densidade da madeira provindos da literatura. Neste sentido, a eq. (3.4) ficou com a seguinte expressão: 


$$
d b_{\text {corrigida }}=0,0345+0,8330 d b_{\text {literatura }} \quad\left(\mathrm{R}^{2}=0,98 ; \mathrm{N}=226\right)
$$

Procedimento similar ao aqui utilizado para a correção da densidade básica determinada sob outra base de teor de umidade são apontados por Reyes et al. (1992) e Chave et al. (2006).

A média da densidade básica da madeira da literatura para os dados do conjunto da amostra foi de $0,672 \mathrm{~g} . \mathrm{cm}^{-3}$, ao passo que a densidade corrigida pela aplicação da equação de regressão acima apresentou média de $0,594 \mathrm{~g} . \mathrm{cm}^{-3}$, valor este muito próximo à média da densidade básica real determinada para as árvores da amostra que foi de $0,574 \mathrm{~g} \cdot \mathrm{cm}^{-3}$.

Vê-se que a média de densidade básica verificada para o conjunto de árvores deste estudo foi muito próximas às apresentadas para a floresta tropical por alguns autores. Neste sentido Chave et al. (2006), considerando uma ampla compilação de informações de dados de densidade básica de madeiras tropicais das Américas Central e do Sul obteve média de 0,64 g.cm ${ }^{-3}$. Reyes et al. (1992) aponta para valores médios de $0,60 \mathrm{~g} . \mathrm{cm}^{-3}$ para as madeiras tropicais das Américas. Já Sotomayor (2013) com base em um conjunto de dados de 66 árvores de 11 espécies da floresta estacional semidecídua, encontrou valores médio de densidade da madeira de 0,52 g.cm $\mathrm{cm}^{-3}$, com variação de 0,65 a $0,75 \mathrm{~g} . \mathrm{cm}^{-3}$, inferiores às encontradas neste estudo.

Aplicando valores dos dados de densidade básica da literatura na Equação 2, sem a correção proposta, o viés médio na predição da biomassa das árvores do estudo é de 5,79\%, ou seja, há superestimativas na biomassa conforme já discutido. Quando realizada a correção, esse viés passa a ser de apenas $-0,31 \%$, assim, seria plenamente recomendado este procedimento visando aumentar a acurácia nas estimativas de biomassa da floresta. Outra possibilidade é o uso de um valor médio da densidade obtida para as árvores amostradas, no caso, 0,574 g.cm ${ }^{-3}$ ( $\mathrm{IC}_{95 \%}$ : 0,560; 0,588). Pelo uso desse valor fixo na equação, tem-se um viés de 3,69\% com relação à estimativa obtida pela Equação E-2. No caso de se utilizar um valor médio de densidade básica de árvores da floresta tropical, por exemplo, o valor de 0,64 g.cm ${ }^{-3}$ obtido por Chave et al. (2006), o viés nas estimativas dessa equação passa a ser de $9,67 \%$, ou seja, há uma superestimativa da biomassa das árvores, sendo esta maior quanto maior o estágio sucessional, com valores de 6,54\%,7,19\% e 10,94\%, respectivamente, para os estágios inicial, médio e avançado da sucessão. 


\subsubsection{Estimativas de biomassa da floresta pelo uso das diferentes equações de predição}

A Equação E-2, de melhor ajuste e desempenho na predição, foi aplicada para quantificar o estoque de biomassa da área do estudo. A Tabela 3.9 apresenta os resultados deste inventário.

Tabela 3.9 - Informações referente às estimativas do estoque de biomassa (t.ha $\left.{ }^{-1}\right)$ da floresta estudada pela aplicação da equação empírica de predição de biomassa seca de melhor ajuste e desempenho desenvolvida no estudo (Equação E-2)

\begin{tabular}{|c|c|c|c|c|}
\hline \multirow[b]{2}{*}{ Descrição dos parâmetros } & \multicolumn{3}{|c|}{ Estágios Sucessionais } & \multirow[b]{2}{*}{ Totais } \\
\hline & Inicial & Médio & Avançado & \\
\hline Número de parcelas (n) & 24 & 65 & 16 & 105 \\
\hline Média (t.ha $\left.{ }^{-1}\right)$ & 39,43 & 69,54 & 114,84 & 69,56 \\
\hline Desvio Padrão (t.ha $\left.{ }^{-1}\right)$ & 17,71 & 34,04 & 57,52 & 42,24 \\
\hline $\mathrm{IC}_{90 \%}\left(\right.$ t.ha $\left.^{-1}\right)$ & {$[33,24 ; 45,63]$} & {$[62,49 ; 76,59]$} & {$[89,63 ; 140,05]$} & {$[62,72 ; 76,40]$} \\
\hline Incerteza (\%) & $15,71 \%$ & $10,13 \%$ & $21,95 \%$ & $9,84 \%$ \\
\hline Mínimo (t.ha $\left.{ }^{-1}\right)$ & 12,70 & 14,82 & 44,19 & 12,70 \\
\hline Máximo (t.ha $\left.{ }^{-1}\right)$ & 69,44 & 160,24 & 259,54 & 259,54 \\
\hline Mediana (t.ha $\left.{ }^{-1}\right)$ & 36,01 & 56,95 & 95,00 & 56,56 \\
\hline
\end{tabular}

Aplicando os dados do inventário à Equação E-2 para estimação da biomassa da floresta, tem-se uma média de 69,56 t.ha ${ }^{-1}$. Considerando que a Equação PT-2 apresentou o menor viés de predição para os indivíduos com DAP > $50 \mathrm{~cm}$, comparativamente, à Equação E-2, apenas para se ter conhecimento de uma estimativa mais aproximada da real biomassa da floresta, fez-se uma combinação entre estes modelos, utilizando este segundo para a estimação apenas destas árvores de maior diâmetro. Com esta abordagem, a média de biomassa da floresta passou para 75,9 t.ha ${ }^{-1}$ [IC $90 \%$ : 66,4;85,4], tendo a média do estágio avançado apresentado o valor de 119,1 t.ha ${ }^{-1}$, e o estágio médio de 77,2 t.ha ${ }^{-1}$.

As árvores de grande porte, com DAP > 50,0 cm, apesar de representarem apenas $0,72 \%$ dos indivíduos amostrados, contribuem com 14,53\% da biomassa total das árvores amostradas dessa floresta, ao passo que as árvores inclusas na classe de DAP $<10,0 \mathrm{~cm}$, as quais representam 55,51\% da densidade relativa de indivíduos amostrados, contribuem com apenas $13,26 \%$ da biomassa. A maior concentração de biomassa da floresta encontra-se nas árvores da Classe de DAP entre 10,0 e 20,0 cm. Esta classe com densidade relativa de indivíduos de $33,26 \%$ comporta $28,72 \%$ da biomassa da floresta. A Tabela 3.10 resume estas informações. 
Tabela 3.10 - Distribuição relativa do número de indivíduos (\%) e biomassa expressa pelas árvores presentes nas diferentes classes de diâmetro do inventário florestal

\begin{tabular}{ccc}
\hline $\begin{array}{c}\text { Classes de DAP } \\
(\mathbf{c m})\end{array}$ & $\begin{array}{c}\text { Densidade relativa } \\
(\mathbf{\%})\end{array}$ & $\begin{array}{c}\text { Biomassa relativa } \\
(\mathbf{\%})\end{array}$ \\
\hline $4,8-10,0$ & $55,51 \%$ & $13,26 \%$ \\
$10,1-20,0$ & $33,26 \%$ & $28,72 \%$ \\
$20,1-30,0$ & $7,60 \%$ & $22,22 \%$ \\
$30,1-40,0$ & $2,07 \%$ & $12,87 \%$ \\
$40,1-50,0$ & $0,83 \%$ & $8,40 \%$ \\
$50,1-60,0$ & $0,41 \%$ & $5,75 \%$ \\
$60,1-70,0$ & $0,10 \%$ & $2,24 \%$ \\
$>70,0$ & $0,21 \%$ & $6,55 \%$ \\
\hline
\end{tabular}

Como esperado, nota-se um a tendência de gradiente ascendente de estoques de biomassa das parcelas nos estágios iniciais para os estágios finais de sucessão. Maiores incertezas nas estimativas da média de biomassa para as áreas em estágio inicial e avançado desta floresta são decorrentes da menor intensidade amostral destes dois estratos. No entanto, a proporcionalidade distinta de parcelas nestes estágios explicita a representatividade destes estágios na floresta estudada, visto que o sistema amostral utilizado no inventário foi a amostragem simples aleatória.

A amplitude dos valores de biomassa apresentada pelas parcelas presentes nos diferentes estágios sucessionais segue um gradiente direcional, sendo maiores nos estágios mais avançados. Porém, é importante observar a existência de parcelas no estágio inicial com valores de biomassa maiores do que algumas parcelas no estágio avançado. Isto ocorre por ser a dimensão das parcelas pequenas $\left(100 \mathrm{~m}^{2}\right)$, de modo que algumas das presentes em áreas de floresta em estágio avançado, não captam em sua amostra, árvores de grande porte. Tem-se com isso, uma maior variabilidade entre parcelas, com necessidade assim de maior número dessas unidades amostrais para se atingir a precisão da estimativa requerida para o estrato. Contudo, a incerteza da estimativa de biomassa para a floresta como um todo foi de $9,84 \%$, adequada aos critérios definidos para projetos vinculados ao mercado de carbono, a qual exige valores inferiores a 10\%, a 90\% de confiabilidade (UNFCCC, 2010).

A Tabela 3.11 apresenta a quantificação de biomassa resultante dos diferentes modelos de predição da literatura utilizados no estudo, bem como o viés da estimativa com relação ao Modelo 2, considerado como o mais adequado para a aplicação à floresta em questão. Já a Figura 3.5 ilustra o viés relativo da estimativa da média de biomassa das árvores presentes nas parcelas de diferentes estágios sucessionais e totais do inventário florestal. 
Tabela 3.11 - Estimativa de biomassa média da floresta $\left(\mathrm{t} \mathrm{ha}^{-1}\right)$ pela aplicação dos diferentes modelos de predição aos dados do inventário florestal da área do estudo

\begin{tabular}{cccc}
\hline Modelos & $\begin{array}{c}\text { Biomassa } \\
\left(\text { t.ha }^{-1}\right)\end{array}$ & $\begin{array}{c}\mathbf{I C}_{\mathbf{9}_{\mathbf{0}} \%} \\
\left(\mathrm{t.ha}^{-1}\right)\end{array}$ & Viés $(\%)^{*}$ \\
\hline ET & 69,39 & {$[62,26 ; 76,52]$} & $-0,3 \%$ \\
MA-2 & 61,35 & {$[52,07 ; 70,63]$} & $-11,8 \%$ \\
PT-2 & 83,77 & {$[73,33 ; 94,22]$} & $20,4 \%$ \\
MA-3 & 102,64 & {$[93,36 ; 111,92]$} & $47,6 \%$ \\
PT-4 & 106,09 & {$[91,97 ; 120,21]$} & $52,5 \%$ \\
MA-4 & 130,17 & {$[114,31 ; 146,04]$} & $87,1 \%$ \\
MA-1 & 173,73 & {$[152,11 ; 195,36]$} & $149,8 \%$ \\
PT-3 & 201,30 & {$[175,27 ; 227,34]$} & $189,4 \%$ \\
PT-1 & 254,23 & {$[218,2 ; 290,27]$} & $265,5 \%$ \\
\hline
\end{tabular}

* Viés relativo à média de biomassa apresentada pelo modelo empírico (Modelo E-2); $\mathrm{IC}_{90 \%}$ : intervalo de confiança da média; nível de $90 \%$ de probabilidade

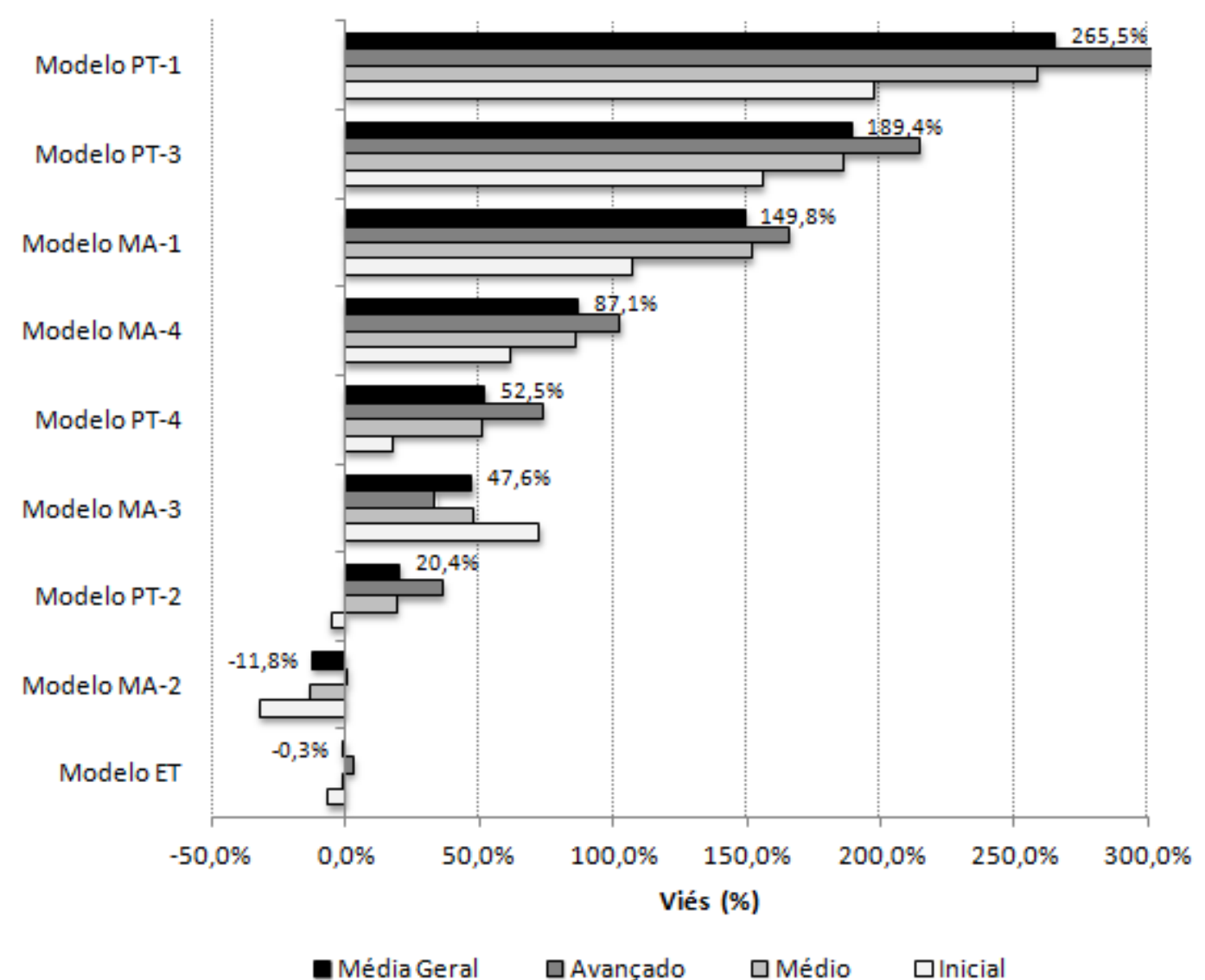

Figura 3.5 - Viés relativo (\%) das estimativas da média de biomassa das árvores presentes nas parcelas nos diferentes estágios sucessionais e totais do inventário florestal em relação à estimativa obtida pela Equação E-2 
A manutenção da Equação ET nesta análise serve para demonstrar que a Equação E-2, apesar de conter uma amostragem menor de árvores, apresentou desempenho de predição muito similar.

Das equações da literatura, ajustadas com dados de outras florestas que não a do presente estudo, o modelo expresso pela Equação MA-2, desenvolvido por Burger e Delitti (2008) foi o qual mais se aproximou aos modelos desenvolvidos com dados da própria floresta. Este apresentou viés negativo de $-11,8 \%$, mantendo assim a tendência em subestimar a biomassa, sendo o viés maior e negativo, quanto mais inicial é o estágio sucessional da floresta, conforme já verificado na análise de sua aplicação aos dados das árvores das parcelas destrutivas. Porém, como as árvores de menor porte, influenciam pouco na biomassa total, este modelo foi mais preciso que o outro desenvolvido pelos mesmos autores (BURGER; DELITTI, 2010), o expresso pela Equação MA-3, a qual superestima levemente a biomassa das árvores em todas as classes de diâmetro até $50 \mathrm{~cm}$. Como a maior parte das árvores do inventário encontram-se dentro deste intervalo de classe de DAP, esta situação faz com que a estimativa de biomassa total da floresta apresente viés positivo de $20,4 \%$.

A Equação PT-2 (BROWN et al.,1989) subestima a biomassa das parcelas no estágio inicial e superestima a biomassa nos estágios mais avançados. Esta situação gera um viés na média da estimativa de biomassa da floresta com relação ao modelo E-2, de 47,6\%. Contudo, entre os modelos da literatura, os expressos pela Equação PT-2 e o Equação MA-2 (BURGER; DELITTI, 2008), apresentam média inclusa dentro do intervalo de confiança da média de biomassa verificada para o modelo da Equação E-2. Já os demais modelos apresentam vieses positivos e expressivos, chegando a apresentar viés relativo de até $265,5 \%$, como é o caso do pan-tropical PT-1 (BROWN, 1997).

Altos valores de viés são verificados até mesmo para modelos desenvolvidos para Floresta Atlântica em região próxima a área de estudo, como é o caso do modelo expresso pela Equação MA-1 (TIEPOLO et al., 2002), o qual apresenta viés positivo de 149,8\%. A Figura 3.6 possibilita visualizar os vieses apresentados pelos diferentes modelos de predição da literatura para os três estágios sucessionais considerados, em termo de valores absoluto de estimativas de biomassa, com relação aos modelos empíricos ajustados para a floresta em estudo, ou seja, as Equações E-2 e a Equação ET. 


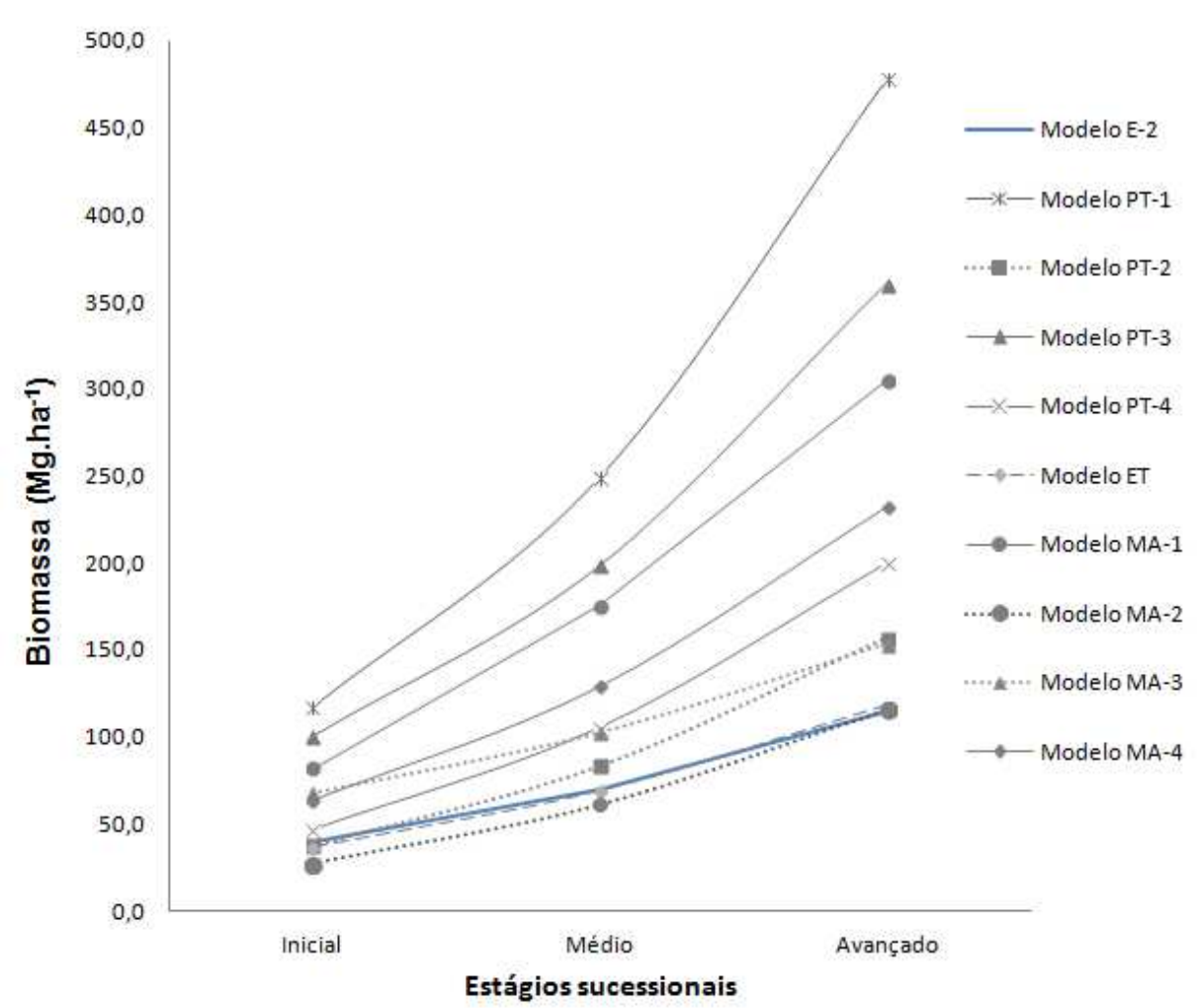

Figura 3.6 - Valores absolutos da estimativa de biomassa $\left(\mathrm{t} \mathrm{ha}^{-1}\right)$ dos diferentes estágios sucessionais da floresta obtidos pela aplicação dos modelos testados aos dados do inventário florestal. Obs: As linhas continuas apresentadas nos gráficos são mera ilustrações da tendência das estimativas nos diferentes estágios sucessionais e não são modelos matemáticos ajustados aos dados

\subsection{Discussão}

Com relação às equações de predição de biomassa desenvolvidas, ficou evidente a partir deste estudo, que a concatenação das variáveis diâmetro (dap), altura total $(h t)$ e densidade básica $(d b)$ como preditoras, melhora a qualidade destas equações, tanto em termos de ajuste dos modelos aos dados como em termos de desempenho de predição. A equação desenvolvida neste estudo considerando este conjunto de variáveis é representada pela Equação E-2. A equação que inclui apenas as informações de diâmetro (dap) e altura total $(h t)$, sem a inclusão da variável $d b$, foi a segunda melhor em termos de ajuste, apresentandose como uma alternativa de aplicação no caso de não se ter informações sobre a densidade básica da madeira das espécies. Por fim, a equação utilizando apenas o dap apresentou-se como a menos adequada para utilização, sendo distinta das duas primeiras supracitadas, segundo avaliação realizada através do AIC.

O índice de resistência à penetração da madeira pelo penetrômetro Pilodyn, inicialmente considerado como uma alternativa para a inclusão ao modelo, de alguma 
informação relacionada à densidade da madeira ao modelo, por ser uma medida direta tomada de cada uma das árvores no inventário e com alto rendimento operacional, demonstrou baixa capacidade de explicação da biomassa, não sendo viável seu uso como variável preditora no modelo no ajuste da equação de predição de biomassa. Fato este atribuído a inconsistência entre o valor deste índice com a densidade básica da madeira, principalmente para as espécies que apresentam distinção de alburno e cerne no lenho.

Relativo ao uso da densidade básica da madeira como variável preditora dos modelos, confirmado seu desempenho em melhorar as estimativas de biomassa, esta sempre que possível deve estar presente nas equações desenvolvidas para a predição de biomassa das árvores. Como a densidade básica da madeira é uma variável de difícil obtenção no inventário, é comum se valer de valores médios por espécie obtidos na área do estudo, ou mesmo dados disponíveis em literatura científica, para aplicação as equações que requerem esta variável. Os resultados do estudo demonstraram que para a utilização desses dados secundários é necessário se aplicar um fator de correção a fim de evitar superestimativas da biomassa. Isto porque os valores de densidade básica disponíveis em literatura comumente são determinados com base no teor de umidade de 12 a 15\%. Neste sentido, a aplicação da equação de regressão, ajustada neste estudo para a correção da densidade da madeira, fez com que os valores provindos da literatura se aproximassem aos valores reais determinado deste índice para as árvores do estudo. Consequentemente, as estimativas de biomassa quando utilizado este fator de correção, tornaram-se muito similares aos valores das estimativas obtidas pela aplicação da densidade básica determinada no estudo, com diferença entre as estimativas inferior a $1 \%$.

Outro fator gerador de viés nas estimativas de biomassa é a utilização dos modelos de predição sem prévia correção dos vieses, quando utilizado a técnica de logaritmização dos modelos como forma de minimizar a heterocedasticidade da variância. Este procedimento, sempre que utilizado, implica em subestimativas da variável resposta, conforme exposto por Parresol (1999). Neste estudo, a aplicação do fator de correção aos modelos que sofreram a transformação logarítmica, tornou as estimativas preditas mais próximas aos valores reais da biomassa determinada para as árvores, sendo assim, recomendada sua aplicação.

$\mathrm{Na}$ avaliação do desempenho de predição, pode-se verificar que a equação de melhor ajuste aqui desenvolvida, ou seja, as Equações E-2 e E-0, apresentaram também adequada expressão de qualidade para a aplicação, demonstrando baixas discrepâncias nas predições, quando aplicados ao conjunto de dados das árvores das parcelas destrutivas. Estas 
apresentaram vieses constantes e próximos à nulidade nas classes de DAP até $50 \mathrm{~cm}$, e com um viés pouco maior e negativo, para as estimativas das árvores com DAP $>50 \mathrm{~cm}$.

Uma observação relevante a ser considerada é a natureza empírica das equações de predição de biomassa, conforme já relatado por outros autores e, mais uma vez, confirmado pelo presente estudo. Esta condição remete ao entendimento de que a qualidade do ajuste da equação, por quaisquer que sejam os critérios de seleção adotados em sua avaliação, é sempre uma análise feita com relação ao próprio conjunto de dados utilizados em sua modelagem.

O problema de se considerar apenas os critérios de qualidade de ajuste dos modelos, desconsiderando a avaliação de seu desempenho de aplicação, é que este procedimento pode gerar uma falsa impressão de generalidade de determinado modelo, quando este é obtido a partir de amostra composta por indivíduos provenientes de uma vasta gama de espécies, tamanhos e procedências geográficas (VISMARA, 2013).

Assim, a avaliação de modelos sempre que possível deve ser realizada também em função de seu desempenho de predição, aplicando a equação ajustada pelo modelo para estimar a biomassa de outro conjunto de árvores que não as utilizadas na amostra de sua modelagem. Esta condição é ainda mais relevante se utilizado para o estudo da biomassa, equações disponíveis em literatura, desenvolvidos a partir de dados de outras florestas.

Neste sentido, cabe expor que a floresta tropical, tal como a Mata Atlântica, apresenta grande diversidade de ambientes, dentro da própria comunidade em estudo (diversidade beta) e, principalmente, entre regiões dentro de um mesmo bioma (diversidade gama), com distinta composição florística e estrutural entre as florestas, devido às características edafo climáticas, a dinâmica sucessional, ou mesmo pelo seu estado de conservação.

No entanto, quando esta avaliação de desempenho de aplicação dos modelos for impossibilitada por questões de logística operacional ou mesmo entraves legais para o abate de árvores na área do estudo, é importante que no conjunto amostral, todas as características dendrométricas que apresentam relação direta com a biomassa, entre estas, diâmetro, altura e densidade, estejam adequadamente representadas em sua máxima amplitude, de modo a garantir maior precisão às estimativas na extrapolação de seu uso aos dados do inventário florestal da área.

Avaliando as Equações E-2 e E-0, pode-se notar que estas apresentaram desempenhos similares à Equação ET, o qual utilizou um conjunto mais amplo de amostras de árvores da área. Esta condição possibilita afirmar que a amostragem deste estudo, mesmo com um número de amostras mais restrito de 80 árvores, foi suficientemente adequada para 
desenvolver uma equação empírica e com bom desempenho de predição da biomassa para a floresta estudada.

$\mathrm{Na}$ avaliação do desempenho das equações disponíveis em literatura, foi possível observar que as equações pan-tropicais que consideram apenas a variável dap, Equações PT-1 e PT-3, apresentaram vieses expressivos com relação à biomassa média real da floresta estudada. Esta condição repete também, mas em menor proporção, para as equações pantropicais que consideram conjuntamente as variáveis dap e $h t$, expressas pelas Equações PT-2 e PT-4.

Vieses expressivos na predição da biomassa foram verificados mesmo para as equações desenvolvidas a partir de dados da Mata Atlântica de regiões próximas ao estudo, porém, com diferenças estruturais das florestas, tais como as Equações MA-1 e MA-4. Até mesmo para a Equação MA-3, cuja floresta utilizada para a coleta de dados para seu ajuste, apresenta forte similaridade com a floresta do presente estudo, foi observado moderado viés nas estimativas de predição. Apenas a Equação MA-2, desenvolvido a partir de dados de outra floresta da mesma região fitogeográfica, expressou desempenho na predição da biomassa similar aos modelos empíricos aqui desenvolvidos.

Uma vez definida a equação a ser utilizada para quantificar a biomassa de uma floresta e, considerando que o processo de coleta de dados de campo do inventário foi bem conduzido, os únicos parâmetros relacionados às incertezas dessas estimativas estão vinculados aos erros amostrais do inventário. Em projetos desenvolvidos no âmbito do mercado de carbono, maior ênfase tem sido dada a estes procedimentos de análise das incertezas nas quantificações de biomassa, sendo pouco abordada a questão da qualidade das equações em termos de desempenho de predição da biomassa.

Neste sentido, os resultados deste estudo demonstraram que, dependendo da equação adotada, as estimativas de biomassa da floresta podem conter extremos, com superestimação em mais de $265 \%$ com relação ao valor obtido pela equação empírica de melhor ajuste e desempenho. Por estes, é possível concluir que no uso de equações desenvolvidas a partir dos dados de uma determinada floresta e, extrapolada sua aplicação para os dados de outra floresta, tal procedimento pode gerar erros amplos nas estimativas de biomassa. Neste sentido, deve-se ressaltar que estes erros nunca serão reconhecidos se procedimentos de validação da qualidade do desempenho dessas equações não forem previamente avaliados no intuito de verificar sua adequação para uso na floresta em estudo.

Deste modo, é fortemente recomendado que os estudos relacionados à estimativa de biomassa apresentem alguma avaliação do desempenho de predição das equações utilizadas, 
de modo a minimizar as fontes de incertezas sobre as estimativas, ou, ao menos, reconhecer a amplitude de erros associados. Esta condição é ainda mais relevante para os estudos de biomassa que envolvem transações financeiras, tal como as atividades de projetos relacionados à comercialização de créditos de carbono, visto que para além do conhecimento dos reais estoques existentes deste elemento, estas incertezas implicam em valores monetários distintos a serem negociados.

Por fim, cabe ressaltar que o intuito desde estudo não foi inferir sobre a aplicabilidade dos poucos modelos de literatura aqui utilizados, da vasta gama atualmente disponíveis, visto que certamente estes devem ser modelos adequados para a aplicação específica às florestas para as quais foram desenvolvidos. Simplesmente, estes foram utilizados como forma de possibilitar atingir o objetivo deste estudo, que foi o de expor alguns fatores a serem considerados nos estudos relacionados à quantificação de biomassa e carbono em florestas nativas na Mata Atlântica, de modo a minimizar as incertezas dessas estimativas.

\subsection{Conclusão}

Diante do exposto, conclui-se que a aplicação dos modelos retirados da literatura deve ser feita de maneira bastante cuidadosa, já que pode gerar erros de predição bastante expressivos e impactantes na estimativa final da biomassa no processo de inventário.

Sempre que possível deve-se considerar a construção de modelos preditivos próprios, construídos partir de uma amostra obtida no local do estudo.

A análise conduzida neste estudo demostrou que modelos ajustados com o uso conjunto do DAP, altura e densidade básica da madeira como variáveis independentes apresentam expressiva qualidade de ajuste e desempenho de predição, devendo sempre que possível ser utilizado. Na ausência de informação relativa à densidade da madeira das espécies, tem-se como alternativa o uso da equação que considera apenas as variáveis preditoras DAP e altura.

A seleção do melhor modelo deve ser realizada não apenas em função da qualidade do seu ajuste à amostra utilizada para sua modelagem, mas também com relação ao seu poder preditivo. A avaliação do poder preditivo do modelo deve ser feito a partir da aplicação do modelo a outro conjunto de árvores, que não o utilizado para o seu ajuste. Na ausência de amostras para validação, procedimentos de validação cruzada devem ser aplicados. 


\section{Referências}

AKAIKE, H. A new look at statistical model identification. IEEE Transactions on Automatic Control, Tokyo, v. 19, n. 6, p.717-723, Dec. 1974.

ARAÚJO, D.S.D.; HENRIQUES R.P.D. Análise florística das restingas do Estado de Rio de Janeiro. In: LACERDA, L.D; ARAÚJO, D.S.D.; CERQUEIRA, R.TURQ, B. (Coord.) Restingas: Origem, Estrutura, Processos. Niterói: Universidade Federal Fluminense. 1984. p.159-193.

ASSOCIAÇÃO BRASILEIRA DE NORMAS TÉCNICAS. NBR 11941: Madeira determinação da densidade básica. Rio de Janeiro, 2003. 6p.

BACCINI, A; GOETZ, S. J.; WALKER, W. S.; LAPORTE, N. T. ; SUN, M. ; SULLA MENASHE, D.; HACKLER, J.; BECK, P. S. A.; DUBAYAH, R.; FRIEDL, M. A.; SAMANTA, S.; HOUGHTON, R.A. HOUGHTON, R. A. Estimated carbon dioxide emissions from tropical deforestation improved by carbon-density maps. NATURE CLIMATE CHANGE, New York, v. 2, n. 3, p 182-185, Mar. 2012.

BATAGLIA, M.; SANDS, P.J. Process-based forest productivity models and their application in forest management. Forest Ecology and Management, Wisconsin, v. 102, n. 1, p. 13-32, Mar. 1998.

BROWN, S.; GILLESPIE, A.J.R.; LUGO, A. E. Biomass estimation methods for tropical forest with applications to inventory data. Forest Science, Bethesda, v. 35, n. 4, p.881-902, Dec. 1989.

BROWN, S. Estimating biomass and biomass change of tropical forests: a primer. Rome: FAO, 1997. 55p. (FAO. Forestry Paper, 134).

BURGER, D.M.; DELITTI, W.B.C. Allometric models for estimating the phytomass of a secondary Atlantic Forest area of southeastern Brazil. Biota Neotropica, Campinas, v. 8, n. 4, p.131-136, Oct./Dec. 2008.

Modelos preditores da fitomassa aérea da Floresta Baixa de Restinga. Revista

Brasileira de Botânica, São Paulo, v. 33, n.1, p. 143-153, 2010.

BURNHAM, K.P.; ANDERSON, D.R. Model selection and multimodel inference: a practical-theoretic approach. $2^{\text {nd }}$ ed. New York: Springer-Verlag, 2010. 488p.

CHAVE, J.; RIÉRA, B.; DUBOIS, M. Estimation of biomass in a neotropical Forest of French Guiana: spatial and temporal variability. Jornal of Tropical Ecology, Winchelsea, v. 17, p. 79-96, Jan. 2001.

CHAVE, J.; CONDIT, R.; AGUILAR, S.; HERNANDEZ, A.; LAO, S.; PEREZ, R. Error propagation and scaling for tropical forest biomass estimates. Philosophical Transactions of the Royal Society Biological Sciences, London, v. 359, n. 1443, p. 409-420, Mar 2004. 
CHAVE, J.; ANDALO, C.; BROWN, S.; CAIRNS, M.; CHAMBERS, J.C.; EAMUS, D.; FÖLSTER, H.; FROMARD, F.; HIGUCHI, N.; KIRA, T.;LESCURE, J.; NELSON, B.W.; OGAWA, H.; PUIG, H.; RIÉRA, B.; YAMAKURA, T. Tree allometry and improved estimation of carbon stocks and balance in tropical forests. Oecologia, Heidelberg, v. 145, n. 1, p. 87-99, Jun. 2005.

CHAVE, J.; MULLER-LANDAU, H.C.; BAKER, T.R.; EASDALE, T.A.; TER STEEGE, H.; WEBB, C.O. Regional and phylogenetic variation of wood density across 2,456 neotropical tree species. Ecological Applications, Washington, DC, n. 16, p. 2356-2367, 2006.

CROW, T. R.; SCHLAEGEL, B. E. A guide to using regression equations for estimating tree biomass. Northern Journal of Applied Forestry, Bethesda, v. 5, n. 1, p. 15-22, Mar. 1988.

EITEN, G. Classificação da vegetação do Brasil. Brasília: CNPq/Coordenação editorial. 1983. 305p. v.7, p.1-22, 1970.

A vegetação do Estado de São Paulo. Boletim do Instituto de Botânica. São Paulo,

FEREZ, A.P.C. Efeito de práticas silviculturais sobre as taxas iniciais de sequestro de carbono em plantios de restauração da Mata Atlântica. 2010. 108 p. Dissertação (Mestrado em Recursos Florestais) - Escola Superior de Agricultura "Luiz de Queiroz", Universidade de São Paulo, Piracicaba, 2010.

HIGUCHI, N.; CARVALHO JR., J.A. de. Fitomassa e conteúdo de carbono de espécies

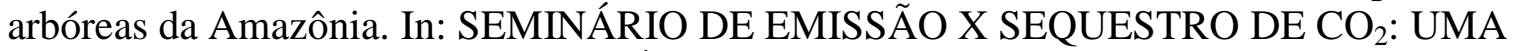
NOVA OPORTUNIDADE DE NEGÓCIOS PARA O BRASIL. 1994, Rio de Janeiro. Anais... Rio de Janeiro: Companhia Vale do Rio Doce, 1994. p. 125-153.

HOUGTHON; R.A.; HALL, F.; GOETZ, S.J. Importance of biomass in the global carbon cycle. Journal of Geophysical Research, Washington, v.144, n. G00E03, 13 p, Set. 2009.

INSTITUTO BRASILEIRO DE GEOGRAFIA E ESTATISTICA. Manual técnico da vegetação brasileira: sistema fitogeográfico: inventário das formações florestais e campestres: técnicas e manejo de coleções botânicas: procedimentos para mapeamentos. Série: Manuais Técnicos em Geociências, n. 1, Rio de Janeiro, IBGE, 2012. 272p.

MACDICKEN, K.G.; WOLF, G.V.; BRISCOE, C.B. Standard research methods for multipurpose tree and shrubs. Arlington: Winrock International Institute for Agricultural Development/ICRAF, 1991. 92p.

MOUTINHO, P; SCHWARTZMAN, S. (Org.). Tropical deforestation and climate change. Belém: Instituto de Pesquisa Ambiental da Amazônia - IPAM; Washington DC - USA: Environmental Defense, 2005. 131p.

PARRESOL, B.R. Assessing tree and stand biomass: a review with examples and critical comparisons. Forest Science, Washington, v. 45, n.4, p. 573-593, Nov. 1999.

PEREIRA, O.J. Caracterização fitofisionômica da restinga de Setiba, Guarapari, Espírito Santo. 1990. In: SIMPÓSIO SOBRE ECOSSISTEMAS DA COSTA SUL E SUDESTE BRASILEIRA, 2., 1990, Guarapari. Anais... ACIESP, v. 71, n. 3, p. 207-219. 
REYES, G.; BROWN, S.; CHAPMAN, J.; LUGO, A.E. Wood densities of tropical tree species. New Orleans: U.S. Departament of Agriculture, Forest Service, Southern Forest, 1992. Experiment Station. 15 p. (General Techical Report SD-88).

RIZZINI, C.T. Tratado de fitogeografia do Brasil: aspectos sociológicos e florísticos. v. 2. São Paulo: HUCITEC e EDUSP, 1979. 374 p.

SANQUETTA, C.R. Métodos de determinação de biomassa florestal. In: SANQUETA, C.R.; WATZLAWICK, L.F.; BALBINOT, R.; ZILIOTTO, M.A.B; GOMES, F.S. (Ed.) As

Florestas e o Carbono. Curitiba: Imprensa Universitária da UFPR, 2002. cap.6, p. 119-140.

SILVEIRA, P.; KOEHLER, H.S.; SANQUETTA, C.R.; ARCE, J.E. O Estado da Arte na Estimativa de Biomassa e Carbono em Formações Florestais. Revista Floresta, Curitiba, v. 38, n. 1, p. 185-206, 2008.

SOTOMAYOR, J.F.M.; VISMARA, E.S.; COUTO, H.T.Z.; BATISTA, J.L.F. Prediction models and estimation bias of Forest aboveground biomass: the case of Atlantic Forest. In: INTERNATIONAL BIOMETRIC CONFERENCE, 25. 2010, Florianópolis. Anais... Florianópolis: IBS, 2010. p 117-118.

SOTOMAYOR, J.F.M. Determinação de biomassa aérea em florestas nativas num ambiente agrícola do Estado de São Paulo. 2013. 129 p. Tese (Doutorado em Recursos Florestais) - Escola Superior de Agricultura "Luiz de Queiroz", Universidade de São Paulo, Piracicaba, 2013.

SUGIYAMA, M. Estudo de florestas da restinga da Ilha do Cardoso, Cananéia, São Paulo Brasil. Boletim do Instituto de Botânica, São Paulo, v.11, p.119-159, 1998.

TIEPOLO, G.; CALMON, M.; FERETTI, A.R. Measuring and Monitoring Carbon Stocks at the Guaraqueçaba Climate Action Project, Paraná, Brazil. In:International Symposium on Forest Carbon Sequestration and Monitoring. Extension Series, Taiwan Forestry Research Institute, Taipei, n. 153, p. 98-115, 2002.

UNITED NATIONS FRAMEWORK CONVENTION ON CLIMATE CHANGE UNFCCC. Aforestation/reforestation Methodological tool: Calculation of the number of sample plots for measurements within A/R CDM project activities. Report. CDM-EB 58, Annex 15 Version 02.1.0, Nov. 2010, 7 p.

VAN DER WERF, G.R.; MORTON, D.C.; DEFRIES, R.S.; OLIVIER, J.G.J.;

KASIBHATLA, P.S.; JACKSON, R.B.; COLLATZ, G.J.; RANDERSO, J.T. $\mathrm{CO}_{2}$ emissions from forest loss. Nature Geoscience, London, n. 2, p. 738-739. 2009.

VANCLAY, J. K. Modelling forest growth and yield: applications to mixed tropical Forests. Wallingford: CAB International, 1994. 212 p.

VELOSO, H.P.; RANGEL FILHO, A.L.R.; LIMA, J.C.A. Classificação da Vegetação Brasileira, adaptada a um Sistema Universal. Rio de Janeiro: Fundação IBGE, 1991. 123 p. 
VIEILLEDENT, G.; VAUDRY, R. ; ANDRIAMANOHISOA, S. F. D.; RAKOTONARIVO, O. S.; RANDRIANASOLO, H.Z.; RAZAFINDRABE, H. N.; BIDAUD

RAKOTOARIVONY, C.; J. EBELING; M. RASAMOELINA. A universal approach to estimate biomass and carbon stock in tropical forests using generic allometric models.

Ecological Applications, Washington, n. 22, p. 572-583, 2012.

VIEIRA, S.A., ALVES, L.F.; AIDAR, M.; ARAÚJO, L. S.; BAKER, T.; BATISTA, J. L. F.; CAMPOS, M.C,; CAMARGO, P.B.;CHAVE, J.; DELLITI, W.B.C; HIGUCHI, N.; HONORIO, E.; JOLY, C.A.; KELLER, M.; MARTINELLI, L.A.; MATTOS, E.A.; METZKER, T.; PHILLIPS, O.; SANTOS, F.A.M.; SHIMABUKURU, M.T.; SILVEIRA, M.; TRUMBORE, S.E. Estimation of biomass and carbon stocks: the case of the Atlantic Forest. Biota Neotropica, Campinas, v. 8, n. 2, p. 21-29, Jun.2008.

VISMARA, E.S. Mensuração da biomassa e seleção de modelos para a construção de equação de biomassa. 2009. 102 p. Dissertação (Mestrado em Recursos Florestais) - Escola Superior de Agricultura “Luiz de Queiroz”, Universidade de São Paulo, Piracicaba, 2009.

Avaliação da construção e aplicação de modelos florestais de efeitos fixos e efeitos mistos sob o ponto de vista preditivo. 2013. 106 p. Tese (Doutorado em Recursos Florestais) - Escola Superior de Agricultura "Luiz de Queiroz", Universidade de São Paulo, Piracicaba, 2013.

VISMARA, E.S.; BATISTA, J.L.F.; NICOLETTI, M.F.; CASTRO, T.N.; COUTO, H.T.Z. Análise da aplicação de equações de biomassa e carbono para espécies nativas da Mata Atlântica na região de Linhares, ES. In: JORNADAS TÉCNICAS FORESTALES Y AMBIENTALES, 14., 2010, Missiones. Anais...Missiones: Facutad de Ciencias Forestales, 2010. p. 92-112.

ZIANIS, D.; RADROGOU, K. Comparison between empirical and theorical biomass allometric models and statistical implications in stem volume predictions. Forestry, Oxford, v. 79, p. 477-487, 2006. 


\section{CONCLUSÕES GERAIS}

Os resultados obtidos neste trabalho possibilitam as seguintes conclusões:

- O modelo de predição de biomassa ajustado para quantificar os estoques de carbono das florestas nativas restauradas aqui estudadas atendeu a todas as pressuposições do modelo e demostrou qualidade de ajuste satisfatória para sua aplicação. A equação de biomassa gerada pelo ajuste deste modelo é expressa abaixo:

$$
\begin{gathered}
\ln (B)=7,54527+0,97825 \ln (c 30)+0,53264 \ln (h t)+1,06742 \ln (d b) \\
\left(\mathrm{R}^{2}{ }_{\text {ajustado: }} 0,9316 ; \mathrm{S}_{\mathrm{xy}}: 0,3854\right)
\end{gathered}
$$

onde: $B$ é a biomassa seca total da árvore, incluindo a aérea e subterrânea (Kg); c30 é a área da secção transversal do tronco, a 0,30 m de altura do solo $(\mathrm{cm})$; $h t$ é a altura total da árvore (m), e; $d b$ é a densidade básica da madeira $\left(\mathrm{g} \cdot \mathrm{cm}^{-3}\right)$.

- Dentre os processos de amostragem utilizados para quantificar a biomassa florestal do projeto de reflorestamento estudado, notou-se que o sistema de amostragem estratificada, considerando a idade de plantio como critério de estratificação, foi o qual apresentou melhor desempenho, em termos de precisão, intensidade amostral requerida e conservadorismo das estimativas. Desempenho similar tiveram os sistemas de amostragem que consideraram a utilização do NDVI, seja como critério para estratificação da população amostral, seja como variável auxiliar na definição do estimador de regressão no processo de amostragem dupla. Para todos esses sistemas, o erro amostral foi em torno dos $10 \%$ e a intensidade de amostras requeridas $\left(\mathrm{n}^{*}\right)$ foi inferior as 111 parcelas instaladas em campo.

- O índice de vegetação NDVI apresentou adequada correlação com a biomassa florestal, sendo recomendada sua aplicação como ferramenta auxiliar nos estudos de biomassa de florestas nativas restauradas, especialmente quando estas apresentarem expressiva variabilidade, em termos de estrutura e composição florística, influenciada pela idade diferenciada, pela aplicação de técnicas distintas de restauração florestal, por fatores inerentes à qualidade de sítio, ou mesmo por distintas formas de intervenção de implantação e manejo silvicultural.

- Em ordem, os modelos de predição de biomassa de melhor desempenho, em termos qualidade de ajuste e capacidade preditiva, para o estudo da Floresta Ombrófila Densa de Terras Baixas do município de Registro-SP, foram os quais consideram conjuntamente as seguintes variáveis preditoras: i) diâmetro do tronco (dap), altura total $(h t)$ e densidade da 
madeira $(d b)$, e; ii) diâmetro do tronco (dap) e altura total $(h t)$. As equações de biomassa resultantes destes modelos são apresentadas a seguir:

Equação E-0:

$$
\begin{gathered}
\ln (B)=-2,6348+1,5611 \ln (\text { dap })+0,9719 \ln (h t) \\
\left(\mathrm{R}_{\text {ajustado: }}^{2} 0,916 ; \mathrm{S}_{\mathrm{xy}}: 0,3834\right)
\end{gathered}
$$

Equação E-2: $\quad \ln (B)=-2,4053+1,6261 \ln ($ dap $)+0,9380 \ln (h t)+0,5148 \ln (d b)$

$$
\left(\mathrm{R}_{\text {ajustado: }}^{2} 0,920 ; \mathrm{S}_{\mathrm{xy}}: 0,3718\right)
$$

onde: onde: $B$ é a biomassa seca da árvore $(\mathrm{kg})$; dap é o diâmetro à altura do peito $(\mathrm{cm}) ; h t$ é a altura total da árvore (m), e: $d b$ é a densidade básica da madeira $\left(\mathrm{g} . \mathrm{cm}^{-3}\right)$.

- A aplicação da transformação logarítmica implica na obtenção de estimativas de biomassa enviesadas, necessitando da aplicação de um fator de correção às biomassas preditas, expresso abaixo:

$$
\hat{B}=\exp \left(\widehat{\ln (B)} \frac{S x y_{m}{ }^{2}}{2}\right)
$$

onde: $\widehat{B}$ é a biomassa das árvores predita por determinado modelo na escala original; $\overline{\ln (B)}$ é a biomassa das árvores predita por determinado modelo na escala logarrítmica; $m$ indica o modelo testado, e; Sxy é o erro padrão das estimativas obtido para o modelo testado.

- Pode-se verificar que o modelo considerando apenas o DAP como variável preditora desenvolvido neste estudo foi o que apresentou a pior qualidade, tanto em termos de ajuste como em termos de capacidade preditiva. Esta condição foi corroborada pela avaliação dos modelos de literatura avaliados com esta mesma relação funcional, já que os mesmos apresentara vieses expressivos nas predições de biomassa das árvores, superestimando os valores estimados.

- O estudo demostrou que modelos de predição de biomassa são empíricos e sítio-específico, e na quantificação da biomassa de determinada floresta, os valores estimados podem ser bastante discrepante dependendo da equação de predição utilizada. Neste sentido, recomendase que sejam priorizadas as equações desenvolvidas a partir de dados da própria floresta. $\mathrm{Na}$ ausência ou impossibilidade de modelagem de uma equação empírica, deve-se priorizar equações desenvolvidas a partir de dados de florestas com características similares as áreas em estudo e, sempre que possível, estas equações devem ser previamente avaliadas quanto ao 
seu desempenho de predição. Esta avaliação pode ser realizada aplicando as equações concorrentes para determinação da biomassa de um conjunto de árvores da população, selecionadas de modo a incorporar a máxima heterogeneidade dos preditores utilizados no modelo. Ainda que esta amostra seja representada por um número limitado de árvores, este procedimento possibilitará reconhecer a amplitude dos vieses de predição para árvores de diferentes dimensões, permitindo inferir sobre a adequação de uso da equação.

Relativo às hipóteses testadas neste trabalho, tem-se as seguintes considerações:

I. Em florestas nativas restauradas da Mata Atlântica, o índice de vegetação NDVI apresenta adequada correlação com a biomassa florestal, possibilitando seu uso como ferramenta auxiliar no inventário de estoques de biomassa em projetos florestais voltados ao mercado de carbono: corroborada pelo estudo de caso.

II. A aplicação da amostragem dupla, utilizando o índice de vegetação NDVI como variável auxiliar na definição de um estimador de regressão, relacionando-o à biomassa florestal, é um processo de amostragem confiável para quantificar estoques de biomassa e carbono em florestas nativas com precisão, requerendo reduzida intensidade amostral: corroborada pelo estudo de caso.

III. A utilização da altura total e da densidade básica da madeira como variáveis preditoras dos modelos de biomassa aumentam a qualidade de ajuste dos mesmos, se comparado à utilização de modelos ajustados apenas com a variável preditora diâmetro do tronco: corroborada integralmente.

IV. O estudo do desempenho de aplicação das equações de biomassa através da avaliação do viés de predição é um bom parâmetro para se reconhecer a grandeza das incertezas associadas ao uso de determinada equação na quantificação da biomassa das árvores de uma floresta: corroborada integralmente.

V. Modelos de predição de biomassa são empíricos e sítio-específico: corroborada integralmente.

VI. O índice de resistência do lenho à penetração, de fácil mensuração em campo através do aparelho Pilodyn, apresenta adequada correlação com a densidade básica da madeira e, deste modo, é útil para aplicação como uma das variáveis independentes do modelo de predição de biomassa de árvores da floresta tropical: rejeitada, pois o índice apresenta limitações em explicar a densidade básica da madeira das espécies que apresentam distinção de cerne e alburno no lenho. 
VII. As informações de densidade básica da madeira extraídas em literatura específica são adequadas para aplicação nas equações de predição de biomassa: corroborada parcialmente, já que necessita da aplicação de fator de correção. 
ANEXOS 
ANEXO A - Gráfico dos quantis dos resíduos padronizados do modelo de predição de biomassa da parte aérea das árvores, com relação aos quantis teóricos da distribuição normal padronizada, e; gráfico de dispersão dos resíduos percentuais com relação aos valores ajustados do Modelo 0
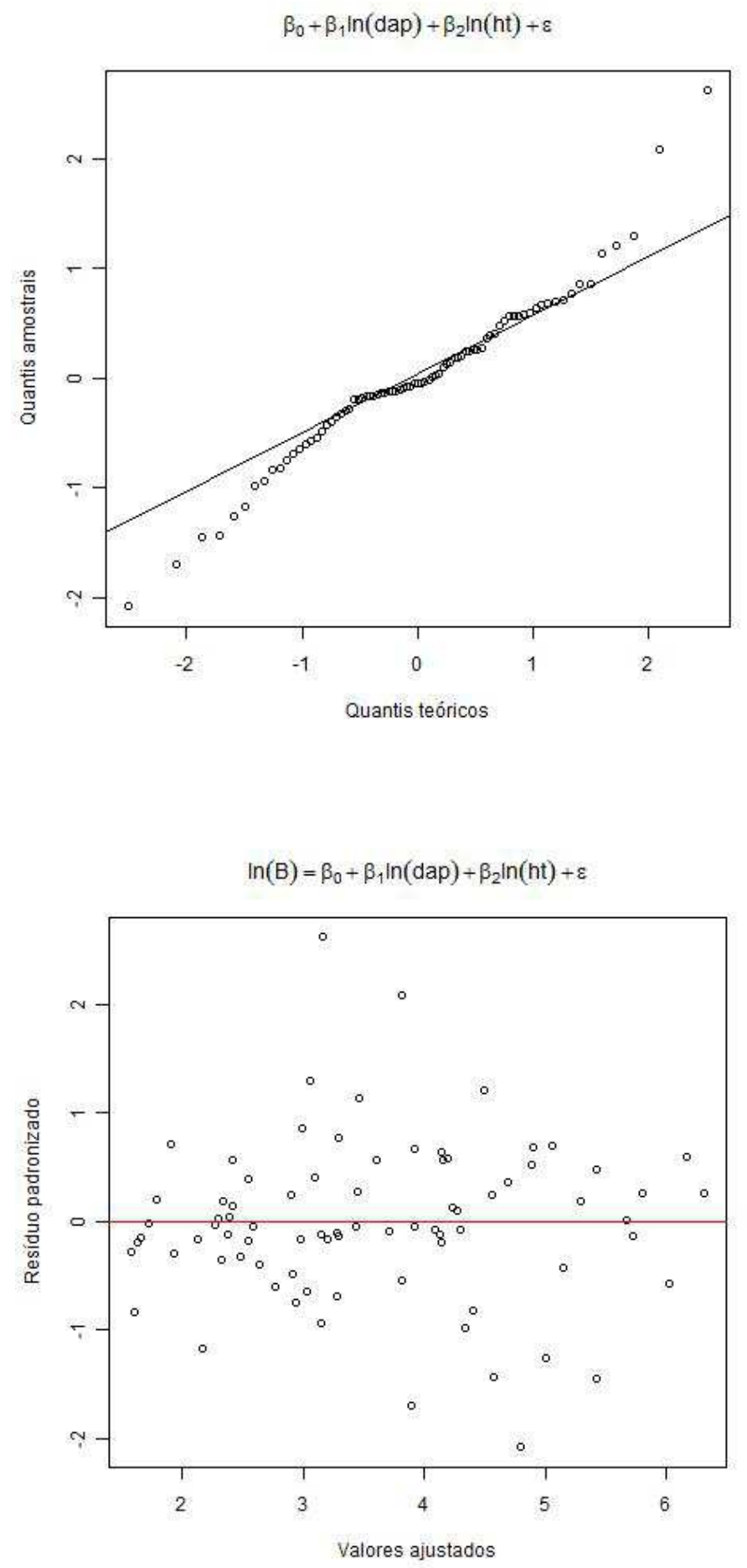
ANEXO B - Gráfico dos quantis dos resíduos padronizados do modelo de predição de biomassa da parte aérea das árvores, com relação aos quantis teóricos da distribuição normal padronizada, e; gráfico de dispersão dos resíduos percentuais com relação aos valores ajustados do Modelo 1
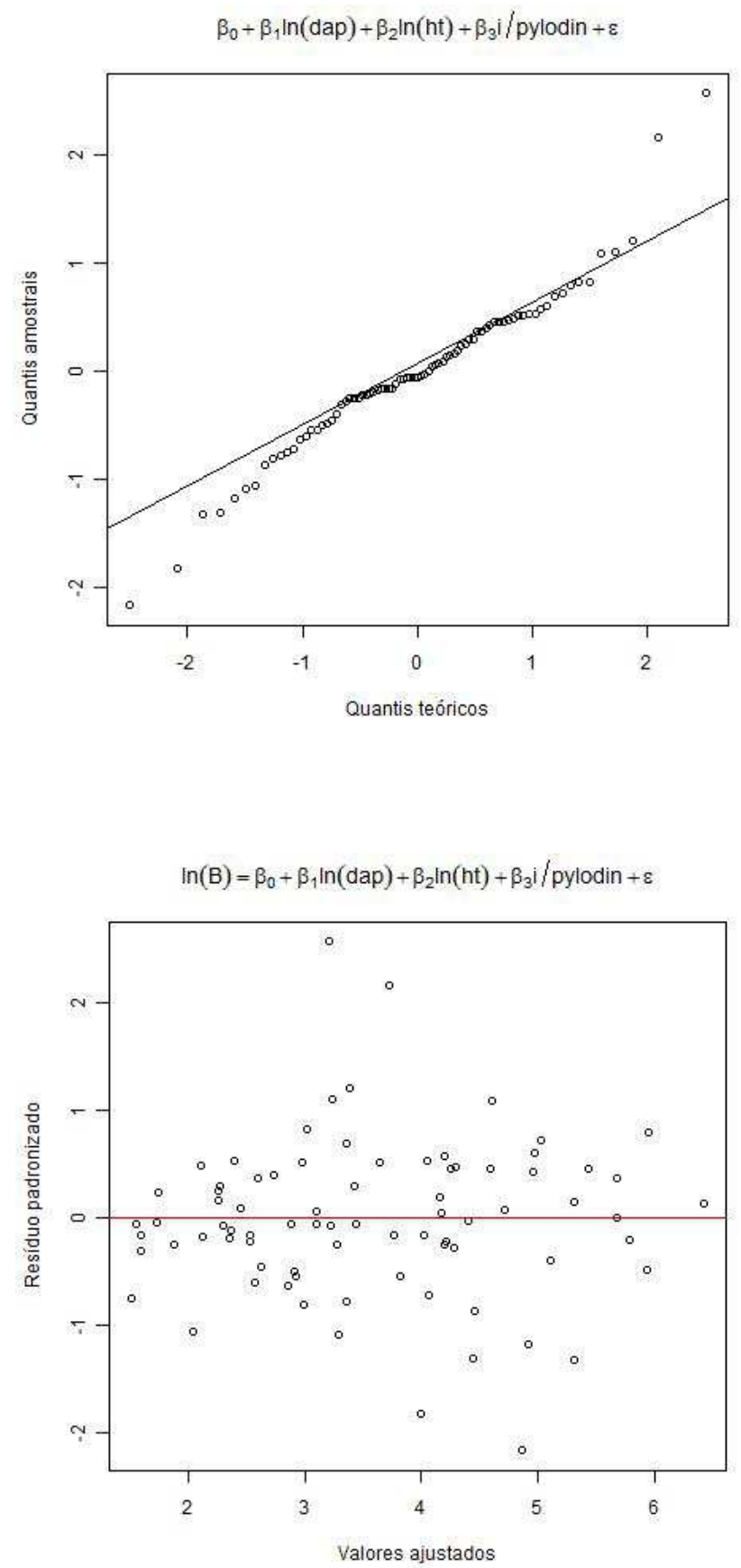
ANEXO C - Gráfico dos quantis dos resíduos padronizados do modelo de predição de biomassa da parte aérea das árvores, com relação aos quantis teóricos da distribuição normal padronizada, e; gráfico de dispersão dos resíduos percentuais com relação aos valores ajustados do Modelo 2
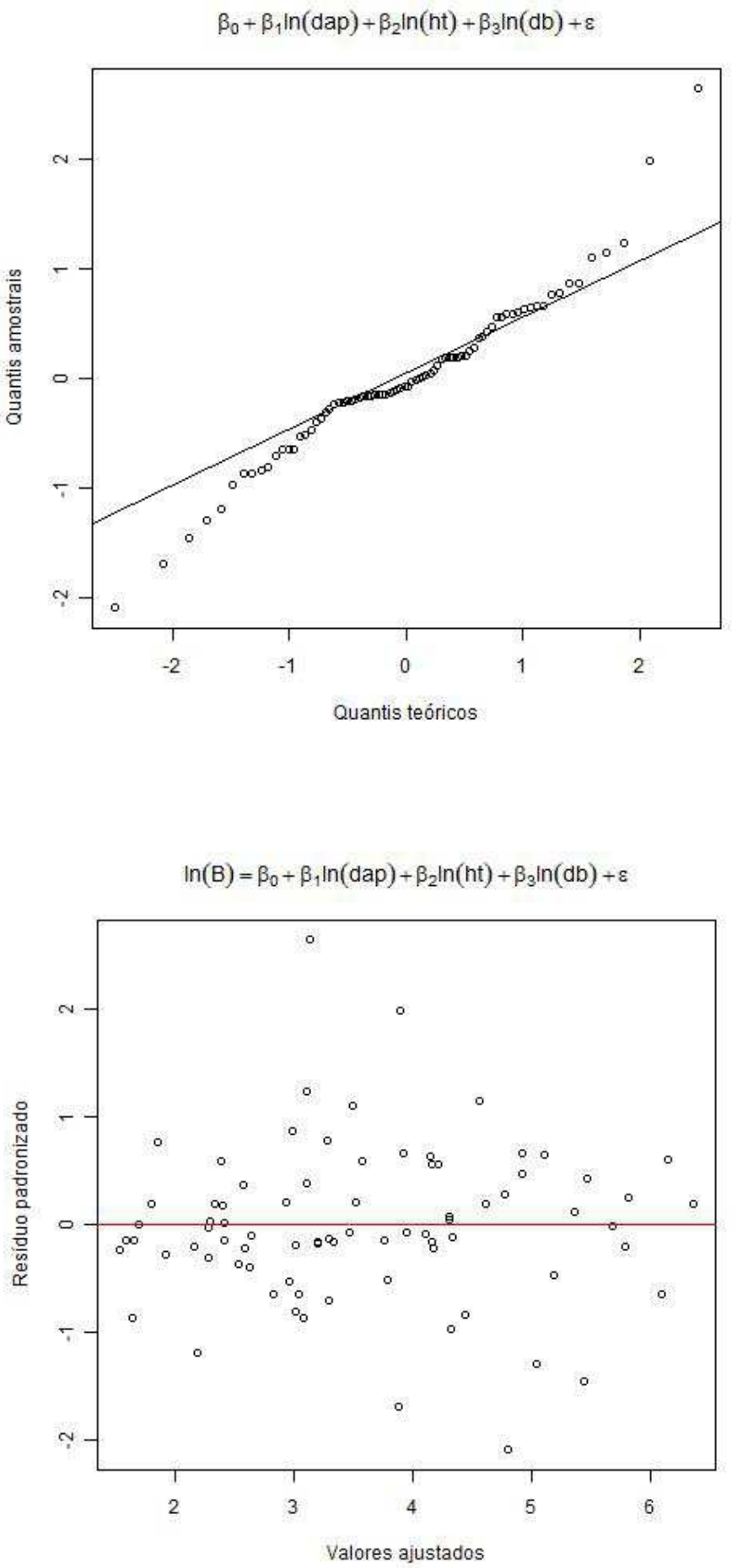
ANEXO D - Gráfico dos quantis dos resíduos padronizados do modelo de predição de biomassa da parte aérea das árvores, com relação aos quantis teóricos da distribuição normal padronizada, e; gráfico de dispersão dos resíduos percentuais com relação aos valores ajustados do Modelo 3
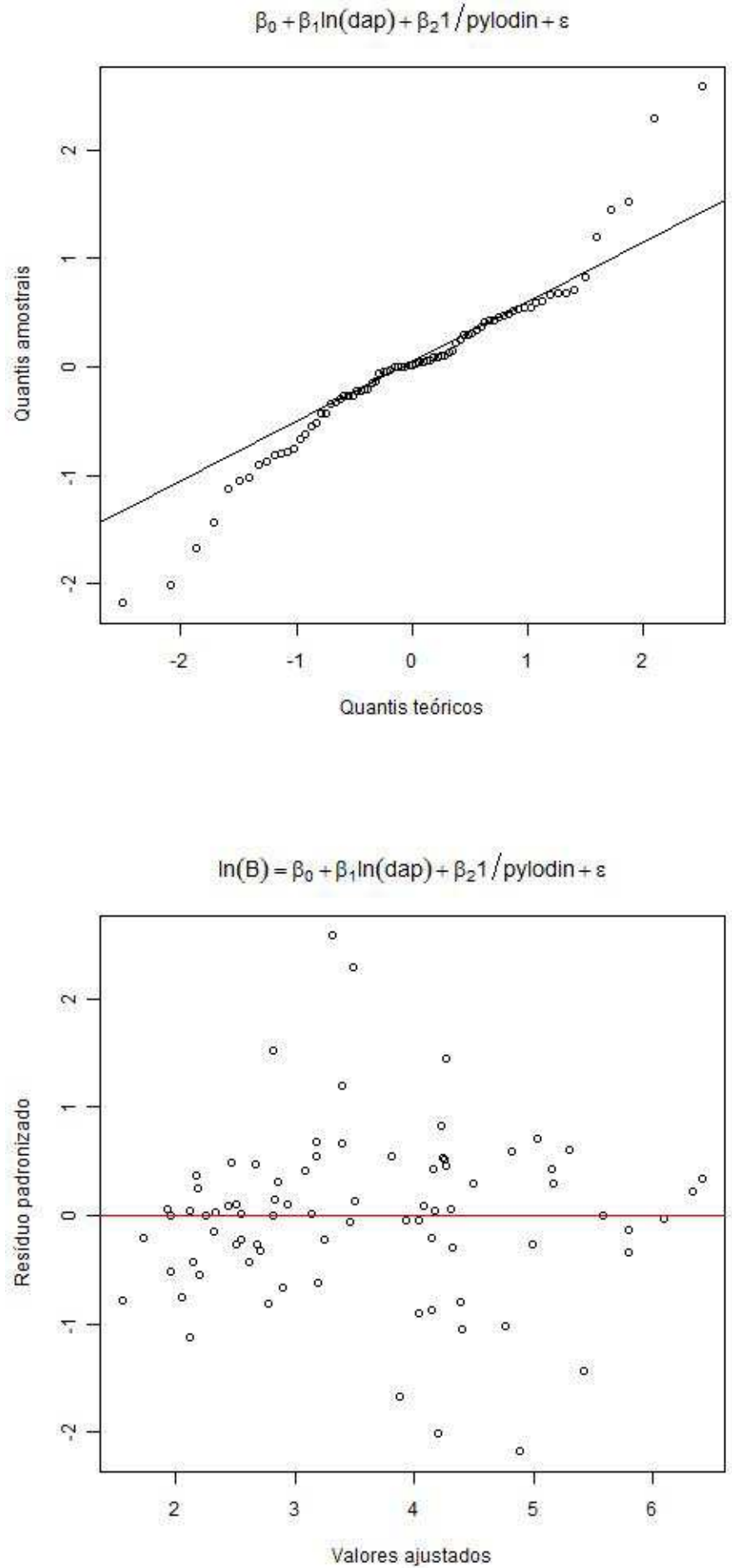
ANEXO E - Gráfico dos quantis dos resíduos padronizados do modelo de predição de biomassa da parte aérea das árvores, com relação aos quantis teóricos da distribuição normal padronizada, e; gráfico de dispersão dos resíduos percentuais com relação aos valores ajustados do Modelo 4
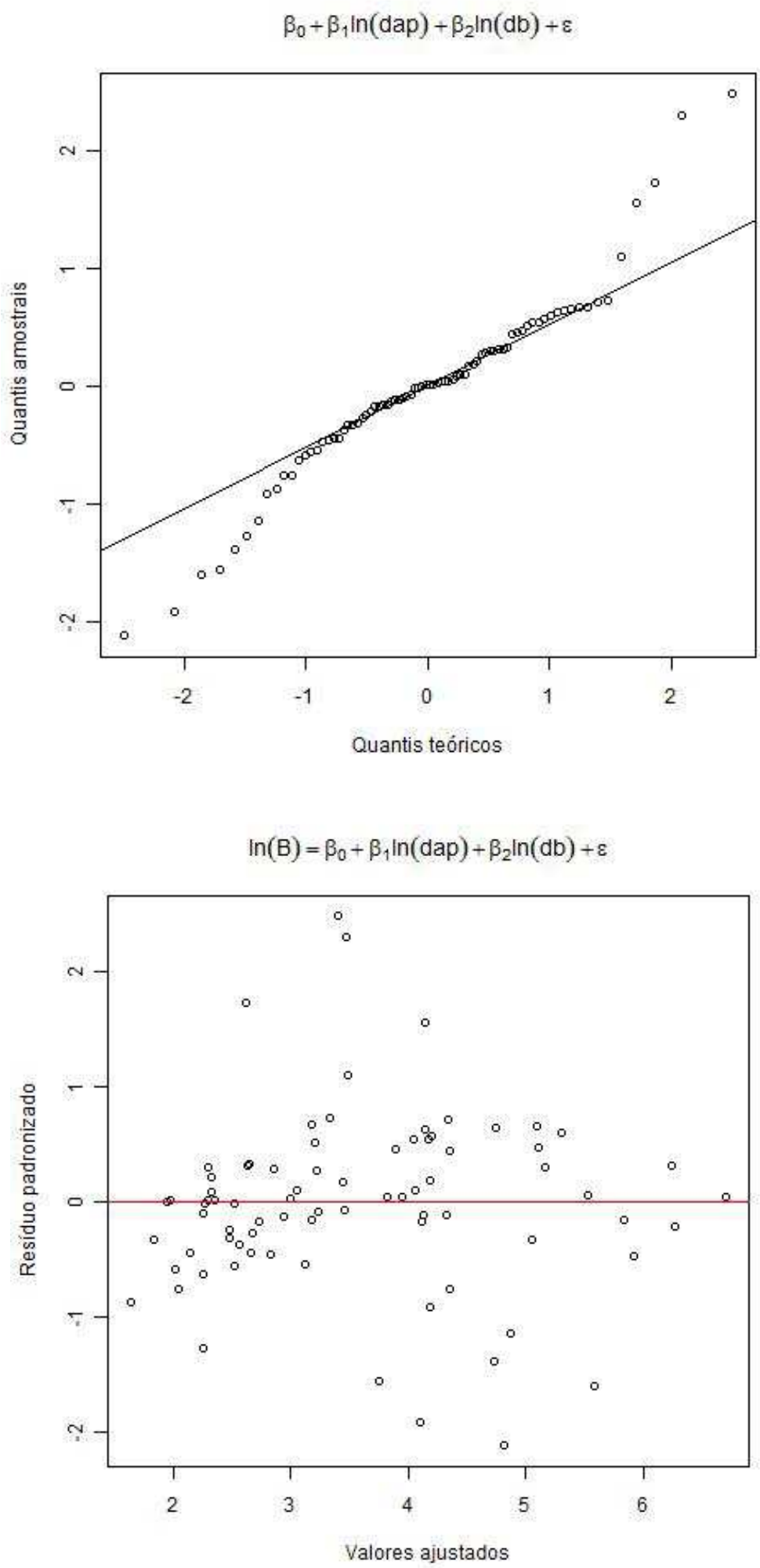
ANEXO F - Gráfico dos quantis dos resíduos padronizados do modelo de predição de biomassa da parte aérea das árvores, com relação aos quantis teóricos da distribuição normal padronizada, e; gráfico de dispersão dos resíduos percentuais com relação aos valores ajustados do Modelo 5
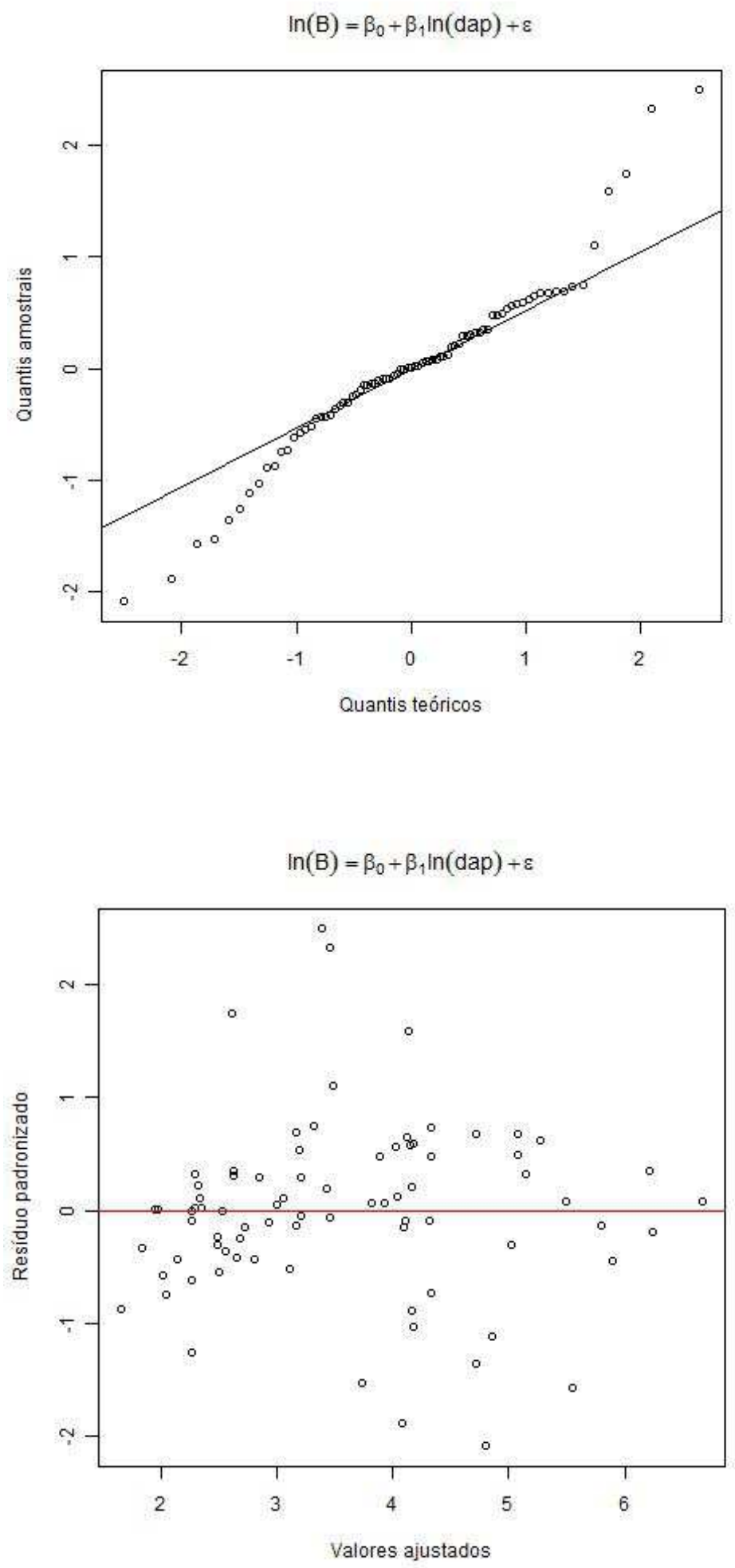